Aus der Abteilung Gastroenteropathologie

(Prof. Dr. med. L. Füzesi)

im Zentrum Pathologie und Rechtsmedizin

der Medizinischen Fakultät der Universität Göttingen

\title{
Chromosomale Veränderungen von Hirnmetastasen klarzelliger Nierenzellkarzinome
}

\author{
INAUGURAL - DISSERTATION \\ zur Erlangung des Doktorgrades \\ der Medizinischen Fakultät \\ der Georg-August-Universität zu Göttingen
}

vorgelegt von

Martin David Nischwitz

aus

Marburg

Göttingen 2009 
Dekan: Prof. Dr. med. C. Frömmel

I. Berichterstatter: Prof. Dr. med. L. Füzesi

II. Berichterstatter/in: Priv.Doz. Dr. rer. nat. P. Burfeind III. Berichterstatter/in: Prof. Dr. med. M. Oppermann Tag der mündlichen Prüfung: 29. Juni 2010 


\section{Inhaltsverzeichnis}

$\begin{array}{lr}\text { Abkürzungsverzeichnis } & 1\end{array}$

1 Einleitung 4

1.1 Nierenzellkarzinome . . . . . . . . . . . . . . . . . . . . . 4

1.2 Hirnmetastasen . . . . . . . . . . . . . . . . . . . . . . . 8

1.3 Chromosomale Aberrationen klarzelliger Nierenzellkarzinome und deren Metastasen . . . . . . . . . . . . . . . . . . 10

1.4 Chromosomale Aberrationen von Hirnmetastasen . . . . . . . . . . 11

1.5 Einfluss chromosomaler Aberrationen klarzelliger Nierenzellkarzinome auf den klinischen Verlauf . . . . . . . . . . . . . . . . 12

1.6 Transformation normaler Zellen in maligne Tumore . . . . . . . . . 12

1.7 Komparative genomische Hybridisierung . . . . . . . . . . . . . . . 13

1.8 Zielsetzung dieser Dissertation . . . . . . . . . . . . . . . . . . 14

2 Material und Methoden $\quad 15$

2.1 Patientenkollektiv . . . . . . . . . . . . . . . . . 15

2.2 Material . . . . . . . . . . . . . . . . 16

2.3 Methoden . . . . . . . . . . . . . . . . . 20

2.3.1 Komparative Genomische Hybridisierung . . . . . . . . . . . 20

2.3.2 Agarose-Gelelektrophorese von DNS . . . . . . . . . . . . . 22

2.3.3 Durchführung der Agarose-Gelelektrophorese . . . . . . . . . 22

2.3.4 Photometrische DNS-Konzentrationsbestimmung . . . . . . 23

2.3.5 Gewinnung genomischer Tumor-DNS aus Paraffinblöcken . . 24

2.3.6 Gewinnung genomischer Referenz-DNS . . . . . . . . . . 27

2.3 .7 Nick-Translation . . . . . . . . . . . . . . . . 27

2.3.8 Hybridisierung . . . . . . . . . . . . . . . . . . . . 31 
2.3.9 Detektion . . . . . . . . . . . . . . . . . 32

2.3.10 Digitalisierung der Metaphasenchromosomen . . . . . . . . . 34

2.3.11 Auswertung . . . . . . . . . . . . . . . . 35

2.4 Beschreibung der CGH-Daten . . . . . . . . . . . . . . . . 36

2.4.1 Nomenklatur . . . . . . . . . . . . . . . . . 36

2.4.2 Kritische Bereiche . . . . . . . . . . . . . . . . . 37

2.4.3 Darstellung der CGH-Ergebnisse . . . . . . . . . . . . 37

2.5 Literaturrecherche . . . . . . . . . . . . . . . . . . . . . 37

2.6 Datentransformation . . . . . . . . . . . . . . . . . . . . . 39

2.7 Statistische Auswertung . . . . . . . . . . . . . . . . . . . . . . . . 39

2.7.1 Graphische Darstellung der gewonnenen Ergebnisse . . . . . 40

2.7.2 Korrelation von CGH-Ergebnissen und Intervall bis zum Auftreten der Hirnmetastase . . . . . . . . . . . . . . . . 40

3 Ergebnisse 41

3.1 Klinische Angaben zu den untersuchten Hirnmetastasen . . . . . . . 41

3.2 Tumorstaging und Tumorgrading der untersuchten Primärtumore . 42

3.3 Ergebnisse der Primärtumore . . . . . . . . . . . . . . . . . . 43

3.3.1 Auswertung nach Chromosomenbanden . . . . . . . . . . . . 43

3.3.2 Auswertung nach Chromosomenarmen . . . . . . . . . . . . 44

3.4 Ergebnisse der Hirnmetastasen . . . . . . . . . . . . . . . . . . . . 45

3.4.1 Auswertung nach Chromosomenbanden . . . . . . . . . . . . 45

3.4.2 Auswertung nach Chromosomenarmen . . . . . . . . . . . . 46

3.5 Vergleich der Ergebnisse der Hirnmetastasen mit den Ergebnissen der Primärtumore . . . . . . . . . . . . . . . . . . . . . . . 47

3.6 Korrelation chromosomaler Aberrationen mit dem rezidivfreien Überleben . . . . . . . . . . . . . . . . . . . . . 48

4 Diskussion $\quad 51$

4.1 Kritische Betrachtung der Komparativen Genomischen Hybridisierung 52

4.2 Kritische Betrachtung der manuellen Auswertung der CGH-Ergebnisse 53

4.3 Kritische Betrachtung der Ergebnisse . . . . . . . . . . . . . . . . . 54

4.3.1 Interpretation der Ergebnisse mit unterschiedlicher Auflösung 58 
4.4 Kritische Betrachtung der chromosomalen Veränderungen auf 18q, 9q34 und 17q und deren Einfluss auf das rezidivfreie Überleben . . 59

4.4.1 Chromosom 18q . . . . . . . . . . . . . . . . 59

4.4 .2 Chromosom 9q34 . . . . . . . . . . . . . . . . . 60

4.4 .3 Chromosom 17q . . . . . . . . . . . . . 61

4.5 Ausblick . . . . . . . . . . . . . . . . . 63

5 Zusammenfassung $\quad 65$

6 Literaturverzeichnis 68

$\begin{array}{lll}7 & \text { Abbildungsverzeichnis } & 85\end{array}$

8 Tabellenverzeichnis $\quad 86$

$\begin{array}{ll}\text { A Anhang } & 88\end{array}$

A.1 Ergebnisse der statistischen Auswertung nach Chromosomenarmen . 89

A.2 Ergebnisse der statistischen Auswertung nach Chromosomenbanden 91

A.3 CGH-Ergebnisse der untersuchten Hirnmetastasen . . . . . . . . . . 99

A.4 CGH-Ergebnisse der verwendeten Primärtumore . . . . . . . . . . . 105 


\section{Abkürzungsverzeichnis}

$\begin{array}{ll}\text { A } & \text { Adenin } \\ \text { abl } & \text { Abelson } \\ \text { Agarose-LE } & \text { Agarose-low electroendosmosis } \\ \text { Aqua bidest. } & \text { Aqua bidestillata } \\ \text { bcl-2 } & \text { B-cell lymphoma } 2 \\ \text { bp } & \text { Basenpaare } \\ \text { CCD } & \text { Charge-coupled Device } \\ \text { CGH } & \text { Comparative Genomic Hybridization, } \\ \text { DAPI } & \text { Komparative Genomische Hybridisierung } \\ \text { dATP } & \text { 4,6-Diamidino-2-phenylindol } \\ \text { dCTP } & \text { Desoxyadenosintriphosphat } \\ \text { dGTP } & \text { Desoxycytidintriphosphat } \\ \text { dim } & \text { Desoxyguanosintriphosphat } \\ \text { DNA } & \text { diminished } \\ \text { DNAse I } & \text { Deoxyribonucleic Acid } \\ \text { DNS } & \text { Desoxyribonuklease I } \\ \text { dNTP } & \text { Desoxyribonukleinsäure } \\ \text { dTTP } & \text { Desoxyribonukleosidtriphosphat } \\ \text { dUTP } & \text { Desoxythymidintriphosphat } \\ \text { Desoxyuridintriphosphat } \\ \text { DN }\end{array}$




$\begin{array}{ll}\text { EcoRI } & \text { Escherichia coli RI } \\ \text { EDTA } & \text { Ethylendiamintetraessigsäure } \\ \text { EGFR } & \text { epidermal growth factor receptor } \\ \text { enh } & \text { enhanced } \\ \text { FDR } & \text { false discovery rate } \\ \text { FITC } & \text { Fluoresceinisothiocyanat }\end{array}$

Fluorescein Avidin DCS Fluorescein Avidin D cell sorting

\begin{tabular}{ll} 
HER2/neu & human epidermal growth factor receptor 2 \\
$\mathbf{H C I}$ & Salzsäure (Chlorwasserstoff) \\
ISCN & International System for Human Cytogenetic \\
& Nomenclature \\
$\mathbf{L O H}$ & loss of heterocygosity \\
$\mathbf{M b}$ & Megabasen \\
$\mathbf{M E D L I N E}$ & Medical Literature Analysis and Retrieval \\
$\mathbf{M e S H}$ & System Online \\
$\mathbf{N a C l}$ & Medical Subject Heading \\
$\mathbf{N C B I}$ & Kochsalz (Natriumchlorid) \\
$\mathbf{N C I}$ & National Center for Biotechnology Information \\
$\mathbf{N L M}$ & National Cancer Institute \\
$\mathbf{r e v}$ ish & United States National Library of Medicine \\
$\mathbf{r p m}$ & Reverse-in-situ-Hybridization \\
$\mathbf{S S C}$ & revolutions per minute \\
$\mathbf{T}$ & Saline Sodium Citrate \\
$\mathbf{T B E}$ & Thymin \\
$\mathbf{T N M}$ & Tris/Borat/EDTA Nodes, Metastasis \\
\hline
\end{tabular}


Tris

TRITC

UMG

UV

VHL

WHO
Tris(hydroxymethyl)-aminomethan

Tetramethylrhodamin-5-(6)-isothiocyanat

Universitätsmedizin Göttingen

Ultraviolettstrahlung

von-Hippel-Lindau

World Health Organization 


\section{Einleitung}

\subsection{Nierenzellkarzinome}

Nierenzellkarzinome treten mit einem Anteil von 1,9\% aller malignen Tumore und weltweit 208.000 Neuerkrankungen relativ selten auf (Parkin et al., 2005). Die jährliche Neuerkrankungsrate maligner Erkrankungen der Niere in Deutschland wird für Männer auf 21,4 und für Frauen auf 9,9 Fälle pro 100.000 für den Zeitraum 2004 geschätzt. Zwischen 1980 und 2004 konnte ein deutlicher Anstieg der Inzidenz für beide Geschlechter in Deutschland verzeichnet werden, bei Männern hat sich die Inzidenz in diesem Zeitraum fast verdoppelt (Batzler et al., 2008). Seit 1990 ist die Mortalität bei beiden Geschlechtern rückläufig, für Männer liegt sie bei 8,1 und für Frauen bei 3,3 Fällen pro 100.000 (Batzler et al., 2008). Ab dem 55 . Lebensjahr kommt es bei beiden Geschlechtern zu einem deutlichen Anstieg der Inzidenz sowie der Mortalität (Batzler et al., 2008). Für Deutschland wird die jährliche Neuerkrankungsrate auf 10.750 Neuerkrankungen bei Männern und 6.500 bei Frauen geschätzt (Batzler et al., 2008). In 2004 starben in Deutschland 4.140 Männer und 1.987 Frauen an einer malignen Erkrankung der Niere (Batzler et al., 2008).

Nierenzellkarzinome können sporadisch sowie als hereditäre Form auftreten. Die häufigste hereditäre Form ist assoziiert mit dem von-Hippel-Lindau-Syndrom (VHLSyndrom), bei dem es vor allem zur Entstehung klarzelliger Nierenzellkarzinome kommt (Lamiell et al., 1989). Diese treten aufgrund der vorliegenden Keimbahnmutation gehäuft bilateral und multizentrisch auf. Das Patientenalter zum Zeitpunkt der Diagnose ist daher deutlich niedriger als bei sporadischen Tumorerkrankun- 
gen. Dies lässt sich u.a. mit der two-hit-Theorie ${ }^{1}$ von Alfred G. Knudson erklären (Knudson, 1971). In molekularzytogenetischen Untersuchungen von hereditär und sporadisch aufgetretenen klarzelligen Nierenzellkarzinomen konnte als herausragende Veränderung ein Verlust genetischen Materials durch Translokation oder Deletion auf dem kurzen Arm jeweils eines Chromosoms 3 (3p) nachgewiesen werden (Kovacs et al., 1997).

Risikofaktoren für das Auftreten eines Nierenzellkarzinoms sind Tabakabusus, ein hoher Body-mass-index, vor allem bei Frauen, und Hypertonie (Dhote et al., 2000; Flaherty et al., 2005; Mellemgaard et al., 1995). Als weitere Risikofaktoren gelten die Einnahme von Amphetaminen bei Männern sowie die Exposition gegenüber Schwermetallen und chlorierten Lösungsmitteln (Mellemgaard et al., 1995; Pesch et al., 2000). Protektive Faktoren für Frauen sind die Einnahme von oralen Kontrazeptiva und ein moderater Alkoholkonsum. Ein positiver Effekt von Alkohol bei Männern konnte nicht nachgewiesen werden (Dhote et al., 2000).

Typische Lokalisationen einer möglichen Metastasierung sind nach Wagle und Scal (1970) die Lunge (43,7\%), Knochen (21,5\%), Leber (15,2\%) und Gehirn $(6,0 \%)$. Es zeigte sich außerdem, dass $15,2 \%$ der Nierenzellkarzinome lymphogen metastasieren (Wagle und Scal, 1970).

Nierenzellkarzinome werden heute dank Sonographie, Computertomographie und Magnetresonanztomographie vermehrt in Frühstadien diagnostiziert. Die Rate von inzidentell diagnostizierten Nierenzellkarzinomen liegt bei bis zu 40 \% (Figlin, 1999; Oberneder et al., 2003). Für die Diagnose von Hirnmetastasen wird zum Einsatz der Magnetresonanztomographie geraten, da diese die sensitivere Methode gegenüber der Computertomographie darstellt (Griffin et al., 2007).

1 Diese Theorie besagt, dass bei hereditären Tumorerkrankungen bereits seit Geburt eine für die Tumorentstehung relevante genetische Veränderung vorliegt und eine zweite im Verlauf erworben wird. Bei sporadischen Tumorerkrankungen müssen dagegen beide genetischen Veränderungen im Verlauf erworben werden, damit es zur Entstehung eines Tumors kommt. Sporadische Tumore treten daher später als hereditäre auf. 
Als Therapie der Wahl gilt die totale Nephrektomie mit Entfernung der umgebenden Fettkapsel, der Gerota-Faszie sowie der regionären Lymphknoten (Fischer, 1999; Foley et al., 1952; Ljungberg et al., 2007). Diese führt zu einer signifikanten Verlängerung der 3-, 5- und 10-Jahresüberlebensrate (Chen et al., 2007). Tumore bis $4 \mathrm{~cm}$ Größe, ein bilateraler Tumorbefall, eine eingeschränkte Nierenfunktion bzw. das Fehlen der zweiten Niere stellen eine Indikation zur organerhaltenden Operation dar. Die organerhaltende Therapie erreicht eine 5-Jahresüberlebenswahrscheinlichkeit von $80-98 \%$ (Fischer, 1999).

Die medikamentöse Therapie ist indiziert bei bereits metastasierten Primärtumoren als palliative Therapie sowie als adjuvante Therapie nach Resektion des Primärtumors und bestehenden Risikofaktoren wie Lymphknotenmetastasen (Fischer, 1999; Ljungberg et al., 2007). Interleukin-2 und Interferon-alpha-2a in Kombination mit 5-Fluoruracil gelten als wirksame Immunchemotherapie, welche die bei Nierenzellkarzinomen bekannte Multi-drug-resistence durchbrechen kann (Fischer, 1999). Eine alleinige Chemotherapie ist bei metastasierten Nierenzellkarzinomen nicht empfohlen, dagegen kann eine Immuntherapie in dieser Situation nützlich sein (Ljungberg et al., 2007).

Zur Abschätzung der Prognose ist die Unterscheidung zwischen inzidentell diagnostizierten und symptomatischen Nierenzellkarzinomen nötig. Sonographisch diagnostizierte inzidentelle Nierenzellkarzinome sind signifikant kleiner, befinden sich in einem niedrigeren Tumorstadium, besitzen eine günstigere Differenzierung und haben seltener Lymphknoten- bzw. Fernmetastasen. Sie haben außerdem eine signifikant bessere Überlebenszeit (Siemer et al., 2000).

Die Prognose eines Nierenzellkarzinom ist abhängig vom genauen Staging und Grading des Primärtumors sowie der sarkomatoiden Differenzierung. Staging und Grading gelten als wichtigste unabhängige Faktoren zur Beurteilung der Prognose (Ficarra et al., 2002; Gudbjartsson et al., 2005; Moch et al., 2000).

Eine radikale Nephrektomie führt zu einer signifikant verbesserten 3-, 5- und 10Jahresüberlebensrate (Chen et al., 2007). Die 5-Jahresüberlebensrate nach totaler 
Nephrektomie klarzelliger Nierenzellkarzinome ist mit 68,9\% die niedrigste aller Nierenzellkarzinomtypen (Cheville et al., 2003). Mit der Diagnose von Fernmetastasen sinkt die 5-Jahresüberlebensrate auf 5-10\% und die 10-Jahresüberlebensrate auf $0-7 \%$ (Ficarra et al., 2002).

Als wichtigstes Kriterium für die Einschätzung der Prognose gilt die Länge des Zeitintervalls zwischen der Diagnose des Primärtumors und dem Auftreten der Hirnmetastase, da diese als Indikator für die Tumorverdoppelungszeit gilt (Pomer et al., 1997). Ein die Prognose negativ beeinflussender Faktor ist das Vorliegen von weiteren Metastasen, wobei Patienten mit Lungenmetastasen eine bessere Prognose haben als Patienten mit Leber- oder Knochenmetastasen (Maldazys und deKernion, 1986). Die Lokalisation zerebraler Metastasen , supra- bzw. infratentoriell und cerebral bzw. cerebellär, scheint dagegen keinen Einfluss auf die Prognose zu haben. Als weitere prognostisch wichtige Faktoren gilt das Alter des Patienten bei Diagnosestellung ( $<50$ vs. $>50$ ), die Anzahl der Hirnmetastasen $(<3$ vs. $>3$ ), der Allgemeinzustand des Patienten (Karnofski-Index ${ }^{1}<70$ vs. $>70$ ) sowie das Vorliegen neurologischer Defizite (Pomer et al., 1997).

Nierenzellkarzinome werden heutzutage nach der $\mathrm{WHO}^{2}$ in zehn histologische Gruppen unterteilt (Eble 2004):

- Klarzellige Nierenzellkarzinome

- Multilokulär klarzellige Nierenzellkarzinome

- Papilläre Nierenzellkarzinome

- Chromophobe Nierenzellkarzinome

- Karzinome der Sammelrohre

1 Eigentlich Karnofsky performance status scale genannt, ermöglicht die Bewertung der Aktiviät, Selbstbestimmung und Selbstversorgung von Patienten, $100=$ Keine Beschwerden, keine Zeichen der Krankheit, 70 = Selbstversorgung, normale Aktivität oder Arbeit nicht möglich, $0=$ Tod (Karnofsky und Burchenal 1949)

2 World Health Organization 
- Medulläre Nierenzellkarzinome

- Nierenzellkarzinome mit Xp11-Translokation

- mit Neuroblastomen assoziierte Nierenzellkarzinome

- Muzinös tubuläre und Spindelzellkarzinome

- unklassifizierbare Nierenzellkarzinome.

Mit $75 \%$ aller Nierenzellkarzinome ist dabei der klarzellige Typ der häufigste (Lopez-Beltran et al., 2006). Klarzellige Nierenzellkarzinome kommen in $95 \%$ der sporadischen Fälle vor, können aber auch mit familiären Syndromen wie dem VHL ${ }^{1}$ Syndrom assoziiert sein. Sie neigen bereits in frühen Stadien zu Gefäßeinbrüchen und Fernmetastasierungen (Mai et al., 2001).

\subsection{Hirnmetastasen}

Die genaue Inzidenz von Hirnmetastasen, unabhängig vom Ursprung des Primärtumors, ist unklar. Im Gegensatz zur gleichbleibenden Inzidenz von Primärtumoren und ihrer sinkenden Mortalität scheint die Inzidenz von Hirnmetastasen anzusteigen (Gavrilovic und Posner, 2005). Smith et al. (1998) erklären die steigende Inzidenz von Tumoren im Zentralnervensystem mit einer verbesserten Bildgebung. Eine adjuvante Chemotherapie verlängert durch gutes systemisches Ansprechen das Überleben der Patienten und führt bei fehlender Wirksamkeit im Zentralnervensystem zu einer erhöhten Inzidenz von Hirnmetastasen bei diesen Patienten (Bendell et al., 2003; Paterson et al., 1982).

Das Auftreten von Hirnmetastasen gilt als Terminalstadium in der Behandlung von Nierenzellkarzinomen. In der Reihenfolge der absoluten Häufigkeiten der Hirnmetastasierung belegt das Nierenzellkarzinom hinter dem Bronchialkarzinom und dem Mammakarzinom noch vor den gastrointestinalen Karzinomen den dritten

1 von-Hippel-Lindau 
Platz. Sektionsstatistiken führen das Nierenzellkarzinom hinter dem malignen Melanom mit $11 \%$ auf Platz zwei (Pomer et al., 1997). Barnholtz-Sloan et al. (2004) konnten eine Inzidenz von 6,5\% für Hirnmetastasen von Nierenzellkarzinomen dokumentieren.

Hirnmetastasen von Nierenzellkarzinomen treten solitär und unregelmäßig in allen Bereichen des Groß- und Kleinhirns auf. Eine bevorzugte Region konnte nicht gefunden werden (Pomer et al., 1997). In weiteren Studien konnte gezeigt werden, dass Hirnmetastasen von Nierenzellkarzinomen häufiger bei Männern als bei Frauen auftreten (Barnholtz-Sloan et al., 2004; Harada et al., 1999).

Das Intervall zwischen Diagnose des Primärtumors und einer Hirnmetastasierung liegt im Median zwischen 15 Monaten und 5,2 Jahren, wobei einzelne Metastasen bereits nach einem Monat oder erst 20 Jahre nach Diagnose des Primärtumors auftreten können (Shuto et al., 2006).

Eine Hirnmetastasierung wird bei den meisten Patienten durch typische Symptome wie Kopfschmerzen, epileptische Anfälle, Lähmungserscheinungen und psychische Veränderungen, welche durch ein perifokales Ödem und dadurch steigenden Hirndruck entstehen, symptomatisch (Pomer et al., 1997).

Die chirurgische Therapie von Hirnmetastasen gilt als Therapie der Wahl bei Patienten mit einer günstigen Prognose und einer solitären Hirnmetastase. Liegt die Metastase in einem weniger sensitiven Bereich, kann die chirurgische Therapie unter kurativem Ansatz erfolgen. Patienten in einem palliativen Stadium sollten zur Verlängerung des symptomfreien Intervalls ebenfalls einer chirurgischen Therapie unterzogen werden (Pomer et al., 1997). Bei nichtresektablen symptomatischen Hirnmetastasen sollten Patienten eine stereotaktische Einzelbestrahlung mit anschließender Nachbestrahlung erhalten (Ljungberg et al., 2007; Pomer et al., 1997).

Als Methode der Wahl bei Vorliegen multipler zerebraler Metastasen und einer ungünstigen Gesamtprognose gilt die Ganzhirnbestrahlung (Astner et al., 2008) 
Da das Vorliegen einer Hirnmetastase zu raschem Handeln zwingt, sollte bei systemischer Metastasierung die Therapie der Hirnmetastase vor der systemischen Therapie erfolgen (Pomer et al., 1997).

\subsection{Chromosomale Aberrationen klarzelliger Nierenzellkarzinome und deren Metastasen}

In einer Metaanalyse von 195 ausschließlich mittels CGH gewonnener Ergebnisse von Nierenzellkarzinomen zeigten sich in abnehmender Häufigkeit Zugewinne auf den Chromosomen 7, 5q31, 8q23q24, 20, 17q, 1qter, 3q, 12 und 16 (Baudis, 2007). Die häufigsten Verluste dieser Metaanalyse fanden sich in abnehmender Häufigkeit auf den Chromosomen 3p, 14q, 6q, 1p, 9, 8p, 13q, 17p, 18q, 2, 4 und 10 (Baudis, 2007).

Bei sporadisch entstandenen sowie VHL-Syndrom-assoziierten klarzelligen Tumoren kommt es zu einem Verlust auf dem kurzen Arm des Chromosoms 3 oder zu unbalancierten chromosomalen Translokationen $(3 ; 5,3 ; 6,3 ; 8,3 ; 11$ ) (Bodmer et al., 2002; Cohen et al., 1979; Pathak et al., 1982). Dies betrifft den Abschnitt 3p12 bis 3p26, in dem das VHL-Gen lokalisiert ist (3p25.3) (Bodmer et al., 2002). Ein Verlust im Bereich zwischen 3p14.2 bis 3p25 konnte in $96 \%$ hereditärer klarzelliger Nierenzellkarzinome gefunden werden (Sükösd et al., 2003).

Neben dem häufigsten Verlust auf dem kurzen Arm von Chromosom 3 konnten in klarzelligen Nierenzellkarzinomen Verluste auf den Chromosomen 9, 10, 14 und ein Zugewinn auf Chromosom 5 nachgewiesen werden (Gunawan et al., 2001; Junker et al., 2003).

Publikationen, welche chromosomale Veränderungen von Nierenzellkarzinommetastasen zeigen, finden sich äußerst selten. Junker et al. (2003) untersuchten 40 Lungenmetastasen von Nierenzellkarzinomen mittels $\mathrm{CGH}^{1}$ und fanden als

1 Comparative Genomic Hybridization, Komparative Genomische Hybridisierung 
häufigste Veränderungen Verluste auf den Chromosomen 3p, 8p, 9/9q, 14 und 18q sowie Zugewinne auf den Chromosomen 5/5q, 7 und 12 (Junker et al., 2003).

In einer Studie über Knochenmetastasen von Nierenzellkarzinomen untersuchten Junker et al. (2004) 31 Metastasen und fanden als häufigste Veränderungen Verluste auf den Chromosomen 3p, 6, 8p, 9, 14q und 18 sowie Zugewinne auf den Chromosomen 5, 8q und 17.

Die Untersuchung von Metastasen unterschiedlicher Lokalisation zeigte die häufigsten Zugewinne auf den Chromosomen 1, 5, 16, 17, 19, 20 und 22. Die häufigsten Verluste fanden sich auf den Chromosomen 3, 9, 14 und Y (Gronwald et al., 1997).

Bissig et al. (1999) untersuchten 32 Metastasen unterschiedlichster Lokalisationen und fanden als häufigste Veränderungen Verluste auf den Chromosomen 3p, 4q, 6q, 8p, und 9p. Die häufigsten Zugewinne fanden sich auf den Chromosomen 17q und $\mathrm{Xq}$.

\subsection{Chromosomale Aberrationen von Hirnmetastasen}

Publikationen, welche große Fallzahlen mittels CGH untersuchten, fanden sich äuBerst selten. Petersen et al. (2000) untersuchten 40 Hirnmetastasen solider Tumore und fanden dabei als häufigste Veränderungen Zugewinne auf den Chromosomen 8q24, 17q24q25, 20q13, 1q23 und 7p12. Die meisten Verluste fanden sich auf den Chromosomen 4q26, 4q22, 5q21, 9q21, 17p12, 4q32q34, 10q21, 10q23q24 und 18q21q22 (Petersen et al., 2000).

Publikationen, welche Hirnmetastasen von klarzelligen Nierenzellkarzinomen mittels CGH untersuchten, konnten bis zum Abschluss dieser Dissertation nicht gefunden werden. Petersen et al. (2000) untersuchten 4 Hirnmetastasen von Tumoren der Niere und fanden dabei als häufigste Veränderungen Verluste auf 3p und 14q sowie Zugewinne auf 5q (Petersen et al., 2000). 


\subsection{Einfluss chromosomaler Aberrationen klarzelliger Nierenzellkarzinome auf den klinischen Verlauf}

Eine Korrelation von chromosomalen Veränderungen und klinischen Daten wurde 2001 von Gunawan et al. publiziert. Dabei konnte gezeigt werden, dass der Zugewinn in der Region 5q31qter für eine signifikant bessere Prognose und bei fortgeschrittenen Nierenzellkarzinomen für eine längere Überlebenszeit spricht. Dagegen scheint ein Verlust auf Chromosom 9 bzw. dem kurzen Arm dieses Chromosoms, 9p, für eine frühzeitige Metastasierung zu sprechen (Gunawan et al., 2001; Junker et al., 2009).

Brunelli et al. (2008) konnten zeigen, dass ein Verlust im Bereich 9p zu einer Abnahme der 5-Jahresüberlebensrate von $88 \%$ bei Patienten ohne Verlust auf $43 \%$ bei Patienten mit Verlust führt (Brunelli et al., 2008).

\subsection{Transformation normaler Zellen in maligne Tumore}

Die Tumorentstehung im Menschen ist bedingt durch eine Abfolge genetischer Aberrationen, welche eine fortschreitende Transformation einer normalen Zelle in eine hochmaligne Form bewirkt. Das Konzept der schrittweisen Tumorprogression wurde erstmals von Foulds untersucht (Foulds, 1954). Ein Modell der Tumorprogression basierend auf genetischer Instabilität und klonaler Selektion wurde von Nowell 1976 vorgestellt (Nowell, 1976). Bei genetischer Instabilität handelt es sich größtenteils um chromosomale Instabilität, welche zu massiven chromosomalen Veränderungen während des Zellzyklus führt (Michor, 2005). Nach Renan (1993) benötigen menschliche Tumore zur Transformation einer normalen zu einer malignen Zelle vier bis sieben stochastische Ereignisse (Renan, 1993). Dabei entstehen Tumore aus einem monoklonalen Ursprung (Fearon et al., 1987; Korczak et al., 1988). Während der Transformation einer normalen menschlichen Zelle in eine maligne Tumorzelle unterliegt diese dem evolutionären Wettbewerb zwischen Tumorzellen und normalen Zellen sowie zwischen Tumorzellen untereinander (Gatenby, 1995; Hanahan und Weinberg, 2000). Es kommt zu einem kompetitiven Wettbewerb um 
lokal verfügbare Ressourcen (Gatenby, 1991).

Nach Hanahan und Weinberg (2000) sind für die Tumorentstehung sechs wesentliche Veränderungen nötig, welche zu einem malignen Wachstum führen. Diese sind (Hanahan und Weinberg, 2000):

- Unabhängigkeit von Wachstumsfaktoren

- Resistenz gegenüber das Wachstum inhibierenden Signalen

- Umgehung des programmierten Zelltodes, der Apoptose

- uneingeschränkte Teilungsfähigkeit

- dauerhafte Angiogenese

- die Fähigkeit der Gewebeinfiltration und Metastasierung.

\subsection{Komparative genomische Hybridisierung}

Die von Kallioniemi A et al. (1992) und du Manoir et al. (1993) beschriebene komparative genomische Hybridisierung (CGH) ermöglicht einen umfassenden Überblick über chromosomale Verluste und Zugewinne des gesamten Genoms eines Tumors (du Manoir et al., 1993; Kallioniemi A et al., 1992). Es werden dazu mit Fluoreszenzfarbstoffen markierte Tumor-DNS ${ }^{1}$ sowie Referenz-DNS aus gesundem Normalgewebe auf menschliche Metaphasenchromosomen männlicher Spender hybridisiert. Dabei hybridisieren Tumor-DNS sowie Referenz-DNS komparativ an die jeweilige homologe Region der Metaphasenchromosomen. Zusätzlich werden die Metaphasenchromosomen mit Diamidinophenylindol $\left(\mathrm{DAPI}^{2}\right)$ gefärbt. Dies führt zur Darstellung des typischen G-Banden-Musters, welches für die eindeutige Identifikation der Chromosomen nötig ist. Mit Hilfe eines Fluoreszenz-Mikroskops, einer $\mathrm{CCD}^{3}$-Kamera und spezieller Software lassen sich die einzelnen Chromosomen

1 Desoxyribonukleinsäure

2 4,6-Diamidino-2-phenylindol

3 Charge-coupled Device 
eindeutig erkennen und analysieren. Das Verhältnis zwischen den unterschiedlich fluoreszierenden Anteilen entlang der Chromosomenachse repräsentiert Verluste bzw. Zugewinne genetischen Materials im Tumor (du Manoir et al., 1993, 1995; Kallioniemi A et al., 1992; Weiss et al., 1999). Die CGH erreicht eine Auflösung von 10-20 Megabasen $\left(\mathrm{Mb}^{1}\right)$ (Kallioniemi OP et al., 1994).

\subsection{Zielsetzung dieser Dissertation}

Als Terminalstadium im Verlauf von Nierenzellkarzinomen gilt das Auftreten von Hirnmetastasen, was zu einer deutlich schlechteren Prognose dieser Patienten führt (Pomer et al., 1997; Wronski et al., 1996).

Ziel dieser Arbeit ist es, chromosomale Aberrationen in Hirnmetastasen von klarzelligen Nierenzellkarzinomen mittels CGH erstmals zu quantifizieren und ein für diesen Typ von Hirnmetastasen spezifisches Muster zu finden.

Ein Vergleich der CGH-Ergebnisse der Hirnmetastase mit CGH-Ergebnissen des korrespondierenden Primärtumors würde hirnmetastasenspezifische Veränderungen nur schlecht oder nicht detektieren, da eine direkte klonale Beziehung zwischen Primärtumor und Hirnmetastase bestünde. Daher soll in dieser Dissertation versucht werden, CGH-Ergebnisse von Hirnmetastasen mit CGH-Ergebnissen von klarzelligen Nierenzellkarzinomen unterschiedlicher Kollektive zu vergleichen. Es bestünde also keine direkte klonale Abhängigkeit zwischen diesen beiden Gruppen. So kann vermutet werden, dass die auf diese Art und Weise gefundenen Unterschiede zwischen beiden Gruppen ein für Hirnmetastasen klarzelliger Nierenzellkarzinome typisches Muster widerspiegeln werden.

Durch Korrelation von CGH-Ergebnissen der Hirnmetastasen und dem Intervall zwischen Erstdiagnose und Diagnose einer Hirnmetastase soll versucht werden, prognostisch bedeutsame chromosomale Aberrationen zu finden.

1 Megabasen 


\section{Material und Methoden}

\subsection{Patientenkollektiv}

Das in dieser Dissertation untersuchte Kollektiv bestand aus 181 in Paraffin eingebetteten und asservierten Gewebeproben, die im Rahmen diagnostischer und therapeutischer Zwecke gewonnen wurden und für evtl. weiterführende diagnostische Zusatzuntersuchungen im Zentrum Pathologie zentral asserviert wurden. Es wurde ausschließlich Untersuchungsmaterial eingesetzt, welches unabhängig von der Studie im Rahmen medizinisch indizierter diagnostischer und therapeutischer Maßnahmen gewonnen wurde. Es wurden keine weiteren Eingriffe am Menschen für die geplanten Untersuchungen durchgeführt und es wurde kein zusätzliches Körpermaterial entfernt. Die Patientendaten waren im Labor nicht bekannt. Die Proben wurden im Labor anonymisiert behandelt, eine Re-Identifizierung der betroffenen Patienten war somit nicht möglich. Für die statistische Auswertung lagen folglich ausschließlich pseudonymisierte Patientendaten vor. 


\subsection{Material}

Geräte

Tabelle 2.1: verwendete Geräte

\begin{tabular}{|c|c|c|}
\hline Geräte & Hersteller & Firmensitz \\
\hline Anregungsfilter DAPI & Genetix & New Milton, Großbritannien \\
\hline Anregungsfilter FITC & Genetix & New Milton, Großbritannien \\
\hline Anregungsfilter TRITC/TxRed & Genetix & New Milton, Großbritannien \\
\hline BioPhotometer & Eppendorf & Hamburg \\
\hline Brutschrank & Memmert & Schwabach \\
\hline CCD-Kamera & Photometrics SENSYS & München \\
\hline $\begin{array}{l}\text { Elektrophoresekammer BlueMarine } \\
100\end{array}$ & Serva Electrophoresis & Heidelberg \\
\hline Feinwaage BL $1500 \mathrm{~S}$ & Sartorius & Göttingen \\
\hline Hybridisierungskammer HYBrite & Vysis & Downers Grove, USA \\
\hline Magnetrührer MR 3001 & Heidolph Instruments & Schwabach \\
\hline Mikroskop Axioskop $40 \mathrm{FL}$ & Carl Zeiss & Jena \\
\hline Mikrotom HM 400 & Microm & Volketswil, Schweiz \\
\hline Objektiv Plan-Neofluar 10x/0,30 & Carl Zeiss & Jena \\
\hline Objektiv Plan-Neofluar 63x/1,25 Oil & Carl Zeiss & Jena \\
\hline pH-Meter CG820 & Schott Geräte & Mainz \\
\hline Pipetten & Eppendorf & Hamburg \\
\hline Polaroid-Kamera MP4+ ICS & Polaroid & Dreieich-Sprendlingen \\
\hline Power Mac G3 & Apple & Cupertino, USA \\
\hline Power Mac G5 & Apple & Cupertino, USA \\
\hline Thermomixer comfort & Eppendorf & Hamburg \\
\hline UV-Transluminator FLX 20.M & Vilber Lourmat & Eberhardzell \\
\hline Vortex-Genie 2 & Scientific Industries & Bohemia, USA \\
\hline Zentrifuge Centrifuge 5417R & Eppendorf & Hamburg \\
\hline Zentrifuge Concentrator 5301 & Eppendorf & Hamburg \\
\hline
\end{tabular}


Chemikalien und Biochemikalien

Tabelle 2.2: verwendete Chemikalien und Biochemikalien

\begin{tabular}{|c|c|c|}
\hline Chemikalien & Hersteller & Firmensitz \\
\hline 6X Loading-Dye-Solution & Fermentas & St. Leon-Rot \\
\hline Actinomycin-D-Mannitol & Sigma-Aldrich & Hamburg \\
\hline Agarose-LE & Biozym & Hessisch Oldendorf \\
\hline Albumin-Fraktion $\mathrm{V}$ & Merck & Darmstadt \\
\hline Aqua ad iniectabilia & Fresenius Kabi & Bad Homburg \\
\hline Aqua bidest. & UMG & Göttingen \\
\hline Borsäure & Merck & Darmstadt \\
\hline DAPI & Sigma-Aldrich & Hamburg \\
\hline Dextransulfat & Merck & Darmstadt \\
\hline DNS-Puffer & Fermentas & St. Leon-Rot \\
\hline EDTA & Serva Electrophoresis & Heidelberg \\
\hline Ethanol $100 \%$ & Sigma-Aldrich & Hamburg \\
\hline Ethanol $70 \%$ & Sigma-Aldrich & Hamburg \\
\hline Ethanol $85 \%$ & Sigma-Aldrich & Hamburg \\
\hline Ethidiumbromid & Sigma-Aldrich & Steinheim \\
\hline Formamid & Sigma-Aldrich & Hamburg \\
\hline $\mathrm{Na}_{2} \mathrm{HPO}_{4}$ & Merck & Darmstadt \\
\hline $\mathrm{NaH}_{2} \mathrm{PO}_{4}$ & Merck & Darmstadt \\
\hline Natriumacetat & Merck & Darmstadt \\
\hline Natriumchlorid & Merck & Darmstadt \\
\hline Polysorbat 20 & Sigma-Aldrich & Hamburg \\
\hline Resin & Bio-Rad & München \\
\hline Salzsäure 1 molar & Merck & Darmstadt \\
\hline Salzsäure $37 \%$ & Merck & Darmstadt \\
\hline Salzsäure 5 molar & Merck & Darmstadt \\
\hline tri-Natriumcitratdihydrat & Merck & Darmstadt \\
\hline Tris $^{1}$ & Merck & Darmstadt \\
\hline Tris $^{2}-\mathrm{HCl}^{3}$ & Merck & Darmstadt \\
\hline Vectashield Mounting Medium & Vector Laboratories & Burlingame, USA \\
\hline Xylol & Carl Roth & Karlsruhe \\
\hline
\end{tabular}


Verbrauchsmaterialien

Tabelle 2.3: verwendete Verbrauchsmaterialien

\begin{tabular}{lll} 
Verbrauchsmaterialien & Hersteller & Firmensitz \\
Deckgläser & Menzel-Gläser & Braunschweig \\
Fixogum & Marabu & Tamm \\
Küvetten & Eppendorf & Hamburg \\
Objektträger & Menzel-Gläser & Braunschweig \\
Pipettenspitzen & Sarstedt & Nümbrecht \\
Reagiergefäße $1,5 \mathrm{ml}$ & Sarstedt & Nümbrecht \\
\hline
\end{tabular}

Isolierungssysteme

Tabelle 2.4: verwendete Isolierungssysteme

\begin{tabular}{lll} 
Isolierungssysteme & Hersteller & Firmensitz \\
QiAmp DNA ${ }^{1}$ Mini Kit & Qiagen & Hilden \\
\hline
\end{tabular}

Molekulare Standards

Tabelle 2.5: verwendete Molekulare Standards

\begin{tabular}{lll} 
Molekulare Standards & Hersteller & Firmensitz \\
Lambda-DNA $/$ EcoRI ${ }^{2}$ Marker & Fermentas & St. Leon-Rot \\
pUC19 DNA/Mspl (Hpall) Marker & Fermentas & St. Leon-Rot \\
\hline
\end{tabular}

Nukleotide und DNS-Präparate

Tabelle 2.6: verwendete Nukleotide und DNS-Präparate

\begin{tabular}{lll} 
Nukleotide und DNS-Präparate & Hersteller & Firmensitz \\
Biotin-16-dUTP & Roche & Penzberg \\
COT Human DNA & Roche & Penzberg \\
Digoxigenin-11-dUTP & Roche & Penzberg \\
Sequencing Grade dNTP 5 Set & Amersham Biosciences & Piscataway, USA \\
\hline
\end{tabular}


Fluoreszenzfarbstoff-Konjugate

Tabelle 2.7: verwendete Fluoreszenzfarbstoff-Konjugate

\begin{tabular}{lll} 
Fluoreszenzfarbstoff-Konjugate & Hersteller & Firmensitz \\
Anti-Digoxigenin-Rhodamin & Roche & Penzberg \\
Fluorescein Avidin DCS & Vector Laboratories & Burlingame, USA \\
\hline
\end{tabular}

Enzyme

Tabelle 2.8: verwendete Enzyme

\begin{tabular}{lll} 
Enzyme & Hersteller & Firmensitz \\
DNA-Polymerase I, E.coli & Fermentas & St. Leon-Rot \\
DNAse $\mathrm{I}^{2}$ & Roche & Mannheim \\
Pepsin & Sigma-Aldrich & Hamburg \\
Proteinase K & Roche & Mannheim \\
\hline
\end{tabular}

Metaphasenpräparate

Tabelle 2.9: verwendete Metaphasenpräparate

\begin{tabular}{lll} 
Metaphasenpräparate & Hersteller & Firmensitz \\
CGH Metaphase Target Slides & Abbott Molecular & Wiesbaden \\
\hline
\end{tabular}

CGH-Auswertungssoftware

Tabelle 2.10: verwendete CGH-Auswertungssoftware

\begin{tabular}{lll} 
Software & Hersteller & Firmensitz \\
Quips Karyotyping/CGH Software & Vysis & Downers Grove, USA \\
\hline
\end{tabular}

Referenzgewebe für die Komparative Genomische Hybridisierung

Als Referenzgewebe für die Gewinnung der Referenz-DNS diente Lebergewebe. Lebergewebe eignet sich besonders gut als Referenzgewebe, da es aufgrund einer hohen Zelldichte viel DNS enthält. 


\subsection{Methoden}

Alle Puffer und Lösungen wurden, soweit nicht anders angegeben, mit Aqua bidest. ${ }^{1}$ angesetzt.

\subsubsection{Komparative Genomische Hybridisierung}

Die Qualität der erstmals von Kallioniemi A et al. (1992) und von du Manoir et al. (1993) beschriebene Komparative Genomische Hybridisierung ist abhängig von verschiedenen Faktoren (Kallioniemi OP et al., 1994). Ist die zu untersuchende Tumor-DNS verunreinigt oder liegt zu wenig Tumor-DNS vor, so kann dies zu falsch positiven oder falsch negativen Ergebnissen führen. Die bei der Nicktranslation entstehenden DNS-Fragmente sollten eine Länge von 600 bis 2000 Basenpaare (bp $\left.{ }^{2}\right)$ besitzen. Für die Markierung der Tumor- bzw. Referenz-DNS haben sich Biotin bzw. Digoxigenin markierte Nukleotide als besonders geeignet erwiesen (Brigati et al., 1983; Komminoth, 1992). Die Zugabe von Cot-1-DNS ${ }^{3}$ zu dem DNS-Gemisch verhindert die Bindung repetitiver Sequenzen der zu untersuchenden DNS an perizentromerische sowie an heterochromatinhaltige Regionen der Metaphasenchromosomen während der Hybridisierung (Landegent et al., 1987). Die Detektion der DNS erfolgt indirekt durch Zugabe des grünfluoreszierenden FITC ${ }^{4}$-Avidin und des rotfluoreszierenden Antidigoxigeninrhodamin. FITC-Avidin bindet dabei an Biotin und Antidigoxigeninrhodamin an Digoxigenin (Brigati et al., 1983; Komminoth, 1992). Die Metaphasenchromosomen werden mit blaufluoreszierendem DAPI, welches an $\mathrm{A}^{5}-\mathrm{T}^{6}$-reiche Regionen bindet, und Actinomycin-D-Mannitol gefärbt und erhalten so das charakteristische G-Bandenmuster (Schweizer, 1976 a,b; Schweizer und Nagl, 1976). Die einzelnen Metaphasen werden mittels Fluoreszenzmikroskop, spezieller Filter und einer CCD-Kamera aufgenommen. Die Aufarbeitung und

1 Aqua bidestillata

2 Basenpaare

3 Aufgereinigte humane DNS mit einer Länge von ca. 400 bp, welche zunächst durch Hitze denaturiert und dann in $0.3 \mathrm{M} \mathrm{NaCl}$ bei $65^{\circ} \mathrm{C}$ renaturiert wurde. Diese besitzt x mol Nukleotide pro Liter für t Sekunden, wobei xt $=1.0$ ist (frei überserzt aus Strachan und Read (1999)).

4 Fluoresceinisothiocyanat

5 Adenin

6 Thymin 
Auswertung der Metaphasen erfolgt mit Hilfe spezieller Software am Computer. Die Qualität der Hybridisierung ist der bestimmende Faktor für die Auswertbarkeit der Ergebnisse. Die Metaphasen müssen daher bestimmten Kriterien gerecht werden. Sie müssen eine gleichmäßige hochintense Hybridisierung besitzen. Die Färbung des Schwesterchromatins eines Chromosoms, die Färbung der homologen Chromosomen einer Metaphase sowie die Färbung gleicher Chromosomen in unterschiedlichen Metaphasen müssen gleich sein. Die Bindung markierter DNS an die Zentromerregion sowie an heterochromatinreiche Regionen sollte gering sein. Des Weiteren sollten die Metaphasen eine geringe Hintergrundfärbung besitzen. Die verwendeten Metaphasenpräparate sollten möglichst wenig überlappende Chromosomen beinhalten. Chromosomen, welche eine zu kurze bzw. zu lange Achse besitzen, sollten aus der Analyse ausgeschlossen werden (Kallioniemi OP et al., 1994).

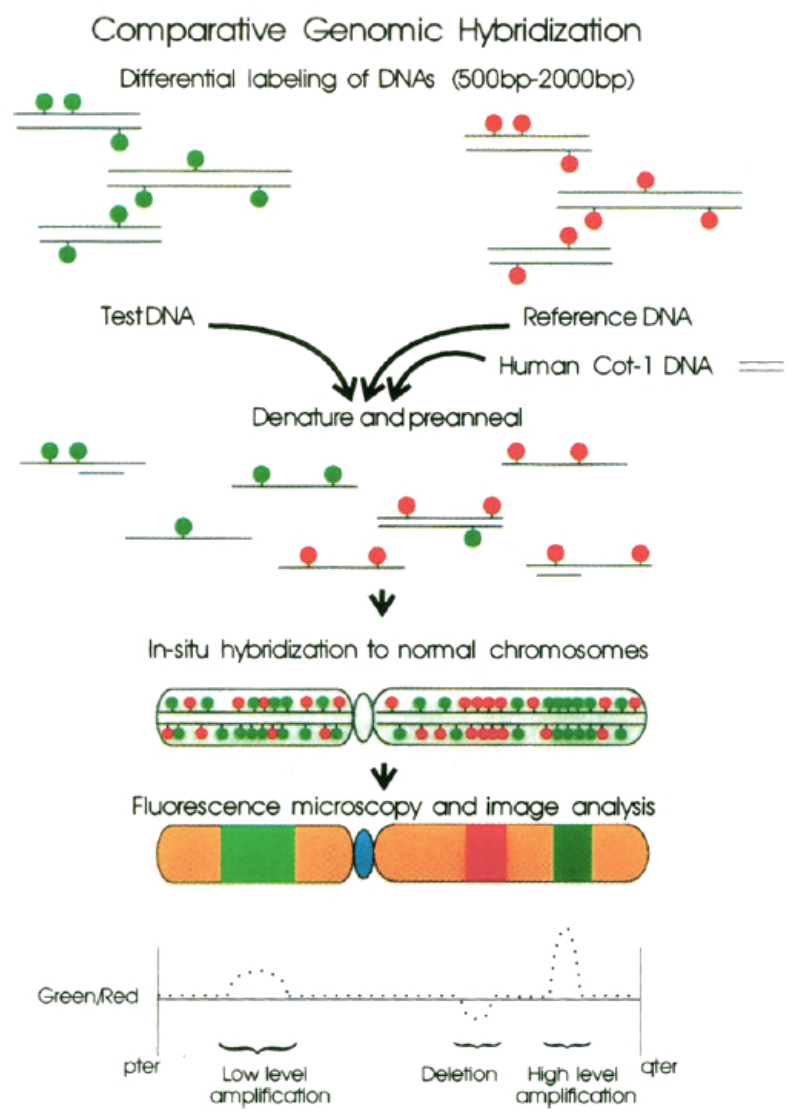

Abbildung 2.1: Schema der CGH aus Houldsworth und Chaganti (1994), S. 1255 


\subsubsection{Agarose-Gelelektrophorese von DNS}

Mit Hilfe der von Thorne (1963) erstmals beschriebenen Agarose-Gelelektrophorese lassen sich DNS-Fragmente elektrophoretisch trennen (Thorne, 1963, 1966). Die Wanderungsgeschwindigkeit der DNS-Fragmente ist dabei umgekehrt proportional zum Logarithmus ihres Molekulargewichts (Helling et al., 1974). Mittels Ethidiumbromid werden die DNS-Fragmente gefärbt und so unter UV ${ }^{1}$-Licht sichtbar gemacht (Sharp et al., 1973). Die Bestimmung der DNS-Fragmentlänge erfolgt durch Vergleich mit DNS-Längenstandards.

\subsubsection{Durchführung der Agarose-Gelelektrophorese}

Tabelle 2.11: Zusammensetzung des $\mathrm{TBE}^{2}-$ Puffers

\begin{tabular}{llr} 
TBE-Puffer & $\mathbf{1 0 0 0 ~} \mathbf{~ m l}$ \\
Tris & $89 \mathrm{mmol} / \mathrm{l}$ & $10,78 \mathrm{~g}$ \\
Borsäure & $89 \mathrm{mmol} / \mathrm{I}$ & $5,5 \mathrm{~g}$ \\
EDTA $^{3}$ & $2 \mathrm{mmol} / \mathrm{l}$ & $0,58 \mathrm{~g}$ \\
\hline
\end{tabular}

Tabelle 2.12: Zusammensetzung des Probenpuffers

\begin{tabular}{lr} 
Probenpuffer & 6X Loading Dye Solution \\
Tris- $\mathrm{HCl}$ & $10 \mathrm{mmol} / \mathrm{l}$ \\
Bromphenolblau & $0,03 \%$ \\
Xylencyanol FF & $0,03 \%$ \\
Glycerol & $60 \%$ \\
EDTA & $60 \mathrm{mmol} / \mathrm{l}$ \\
\hline
\end{tabular}

Tabelle 2.13: Zusammensetzung der Ethidiumbromid-Lösung

\begin{tabular}{lrr} 
Ethidiumbromid-Lösung & $\mathbf{1 0 ~} \mathbf{~ m l}$ \\
Ethidiumbromid & $1 \mathrm{mg} / \mathrm{l}$ & $10 \mathrm{mg}$ \\
\hline
\end{tabular}

1 Ultraviolettstrahlung 
Tabelle 2.14: Zusammensetzung des Gelansatzes

\section{Gelansatz}

Agarose-LE ${ }^{1}$

$$
1,5 \%(w / v)
$$

$100 \mathrm{ml}$

$1,5 \mathrm{~g}$

ad $100 \mathrm{ml}$ TBE-Puffer

Die Lösung wurde zusätzlich mit $15 \mu$ l Ethidiumbromid-Lösung versetzt.

Tabelle 2.15: Zusammensetzung des Laufpuffers

\begin{tabular}{lr} 
Laufpuffer & $100 \mathrm{ml}$ \\
TBE & \\
Die Lösung wurde mit $15 \mu$ l Ethidiumbromid-Lösung versetzt. & \\
\hline
\end{tabular}

In die Taschen des Agarosegels wurden $5 \mu \mathrm{l}$ der zu analysierenden DNS zusammen mit $3 \mu$ l Probenpufffer pipettiert. Zur Bestimmung der Länge der DNS-Fragmente wurden $1,5 \mu \mathrm{l}$ des Längenstandards zusammen mit $3 \mu$ l Probenpufffer und $5 \mu$ l sterilem Wasser pipettiert. Als Längenstandard nach der DNS-Isolierung diente der Lambda-DNA/EcoRI Marker mit Fragmentlängen von 21.226, 7421, 5804, 5643, 4878 und 3530 Basenpaaren. Als Längenstandard nach der Nick-Translation diente der pUC19 DNA/MspI (HpaII) Marker mit Fragmentlängen von 501, 489, 404, 331, 242, 190, 147, 111, 110, 67, 34, 34 und 26 Basenpaaren. Die Auftrennung nach Fragmentlängen erfolgte in einer mit Laufpuffer gefüllten Elektrophoresekammer bei $80 \mathrm{~V}$ für 45 Minuten. Das Agarosegel sowie der Laufpuffer wurden mit dem interkalierenden DNS-Fluoreszenzfarbstoff Ethidiumbromid versetzt. Nach erfolgreicher Elektrophorese wurden die DNS-Fragmente mit Hilfe eines UV-Transluminators dargestellt und fotografiert.

\subsubsection{Photometrische DNS-Konzentrationsbestimmung}

Die Photometrie diente der Gewährleistung einer gleichbleibenden DNS-Konzentration der einzelnen DNS-Proben von Referenz- und Tumor-DNS nach erfolgter Gelelektrophorese.

Zur photometrischen DNS-Konzentrationsbestimmung der doppelsträngigen DNS wurden $5 \mu \mathrm{l}$ DNS zu $95 \mu$ l Aqua ad iniectabilia gegeben. Die photometrische Messung erfolgte bei $260 \mathrm{~nm}$. Dabei gilt 


$$
E=-\lg (T)
$$

wobei E für Extinktion und $\mathrm{T}$ für Transmission steht. Mit Hilfe des LambertBeer'schen Gesetz lässt sich aus

$$
\Delta E=\varepsilon_{\mathrm{mol}} \cdot c \cdot d
$$

die Konzentration einer Lösung berechnen. Dabei steht $\Delta E$ für die Extinktionsdifferenz, $\varepsilon_{\text {mol }}$ ist der molare Extinktionskoeffizient in $L \cdot \mathrm{mol}^{-1} \cdot \mathrm{cm}^{-1}$, c die Konzentration der Verbindung in mol/l und d die Schichtdicke der Küvette in $\mathrm{cm}$. Die DNS-Konzentration wurde in $\mu \mathrm{g} / \mathrm{ml}$ angegeben. Die Reinheit der DNS-Lösung wurde mittels photometrischer Messung des Verhältnisses von Salzkonzentration zu DNS-Konzentration bestimmt. Dazu wurde die Probe bei $230 \mathrm{~nm}$ und $260 \mathrm{~nm}$ gemessen und das Verhältnis aus beiden Extinktionen berechnet. Wird die DNSKonzentration bei neutralem oder leicht basischem pH gemessen, so entspricht ein Extinktionskoeffizient von 1,0 einer Konzentration doppelsträngiger DNS von $50 \mu \mathrm{g} / \mathrm{ml}$. Um die Reinheit der DNS zu bestimmen, wurde die Probe bei $260 \mathrm{~nm}$ und $280 \mathrm{~nm}$ gemessen (Glasel, 1995; Wilfinger et al., 1997). Als Zielwert galt dabei ein Wert von 2,0.

\subsubsection{Gewinnung genomischer Tumor-DNS aus Paraffinblöcken}

Eine aus formalinfixiertem und in Paraffin eingebettetem Gewebe gewonnene DNS ist häufig nicht intakt und liegt unterschiedlich stark fragmeniert vor (Goelz et al., 1985). Trotzdem ist eine Analyse mittels CGH möglich (Isola et al., 1994; Speicher et al., 1993).

Tabelle 2.16: Zusammensetzung des DNS-Isolierungspuffers

\begin{tabular}{llr} 
DNS-Isolierungspuffer & $\mathbf{1 0 0 0} \mathbf{~ m l}$ \\
Tris-HCl & $50 \mathrm{mmol} / \mathrm{l}$ & $\mathbf{7 , 8 8 \mathrm { g }}$ \\
EDTA & $1 \mathrm{mmol} / \mathrm{l}$ & $0,37 \mathrm{~g}$ \\
Polysorbat 20 & $0,5 \%(\mathrm{v} / \mathrm{v})$ & $5 \mathrm{ml}$ \\
\hline
\end{tabular}


Tabelle 2.17: Anforderung an Schnittdicke und Anzahl der Schnitte

\section{Schnittdicke}

$10 \mu \mathrm{m}$
Anzahl der Schnitte

$10-20$

Für die Gewinnung der Tumor-DNS aus Paraffinblöcken wurden mit Hilfe des Mikrotoms jeweils 10 bis 20 Schnitte mit einer Stärke von $10 \mu \mathrm{m}$ angefertigt. Um die Tumorzellen aus den Paraffinschnitten zu gewinnen erfolgte zunächst eine zweimalige je 10 minütige Inkubation der Schnitte in $1000 \mu$ Xylol gefolgt von einer zweimaligen je 10 minütigen Inkubation in $100 \%$ Ethanol. Nach jedem Inkubationsschritt wurde die Lösung zentrifugiert und der Überstand verworfen. Nachdem die Entparaffinierung abgeschlossen war, wurden die Zellen der Proteinase K Behandlung unterzogen. Proteinase K führt zur Freisetzung der DNS aus den Zellen. Hierzu wurde den entparaffinierten Zellen $200 \mu \mathrm{l}$ DNS-Isolierungspuffer sowie $40 \mu \mathrm{l}$ Proteinase K hinzugegeben. Das erhaltene Gemisch wurde bei $55^{\circ} \mathrm{C}$ und $850 \mathrm{rpm}^{1}$ auf dem Thermomixer inkubiert. Anschließend erfolgte die Inaktivierung der Proteinase K durch eine achtminütige Inkubation bei $95^{\circ} \mathrm{C}$. Nach der Inkubation wurde die DNS-Lösung 10 Minuten mit $13.500 \mathrm{rpm}$ zentrifugiert und der erhaltene Überstand zur weiteren Verarbeitung abpipettiert.

Aufreinigen der DNS-Proben über QiAmp DNA Mini Kit

Tabelle 2.18: Zusammensetzung des AL-Puffers

\begin{tabular}{l} 
AL-Puffer \\
Guadiniumchlorid \\
Der Puffer lag dem QiAmp DNA Mini Kit bei, der Hersteller macht keine genauen Angaben. \\
\hline
\end{tabular}

1 revolutions per minute 
Tabelle 2.19: Zusammensetzung des AW1-Puffers

\begin{tabular}{l} 
AW1-Puffer \\
$\begin{array}{l}\text { Guadiniumchlorid } \\
50-100 \%\end{array}$ \\
Der Puffer lag dem QiAmp DNA Mini Kit bei, der Hersteller macht keine genauen Angaben. \\
\hline
\end{tabular}

Tabelle 2.20: Zusammensetzung des AW2-Puffers

AW2-Puffer

Der Puffer lag dem QiAmp DNA Mini Kit bei, der Hersteller macht keine genauen Angaben.

Tabelle 2.21: Zusammensetzung des AE-Puffers

\section{AE-Puffer}

Der Puffer lag dem QiAmp DNA Mini Kit bei, der Hersteller macht keine genauen Angaben.

Die so vorbehandelte DNS-Lösung wurde nun mit Hilfe des QiAmp DNA Mini Kit der Firma Qiagen aufgereinigt. Dazu wurden $650 \mu \mathrm{l}$ der erhaltenen DNS-Lösung mit $200 \mu \mathrm{l}$ AL-Puffer bei $70^{\circ} \mathrm{C}$ und $1400 \mathrm{rpm}$ für 10 Minuten auf dem Thermomixer gemischt. Anschließend erfolgte eine fünfminütige Inkubation mit $240 \mu 1100 \%$ igem Ethanol. Dieses Gemisch wurde in Reaktionsgefäßen der Firma Qiagen, welche spezielle Filter beinhalten, mit 10.000 rpm für zwei Minuten zentrifugiert. Das dabei gewonnene Filtrat wurde verworfen. Anschließend folgten weitere Aufreinigungen der DNS unter Zugabe von $500 \mu \mathrm{l}$ AW1-Puffer gefolgt von einer zweiminütigen Zentrifugation mit $10.000 \mathrm{rpm}$ und $500 \mu \mathrm{l}$ AW2-Puffer gefolgt von einer dreiminütigen Zentrifugation mit 14.000 rpm. Das erhaltene Filtrat wurde jeweils verworfen. Die Filter mit der so aufgereinigten DNS wurden nun auf Reagiergefäße gesetzt. Durch fünfminütige Inkubation mit $50 \mu \mathrm{l}$ AE-Puffer und einer anschließenden zweiminütigen Zentrifugation mit $10.000 \mathrm{rpm}$ wurde die DNS aus dem Filter gelöst. Dieser Schritt wurde einmal wiederholt. Man erhielt so ein Endvolumen von $100 \mu \mathrm{l}$ aufgereinigter DNS. 
Nun erfolgte die photometrische Bestimmung der DNS-Konzentration sowie die Bestimmung der DNS-Fragmentlänge mittels Gelelektrophorese wie oben beschreiben.

\subsubsection{Gewinnung genomischer Referenz-DNS}

Tabelle 2.22: Zusammensetzung des ATL-Puffers

\section{ATL-Puffer}

Der Puffer lag dem QiAmp DNA Mini Kit bei, der Hersteller macht keine genauen Angaben.

Aus dem bei $-80^{\circ} \mathrm{C}$ gelagerten Lebergewebe wurde ein ca. $5 \mathrm{~mm}^{3}$ großes Stück herausgelöst und zerkleinert. Anschließend wurde das zerkleinerte Gewebe in ein Reaktionsgefäßgegeben und $360 \mu \mathrm{l}$ ATL-Puffer sowie $40 \mu$ l Proteinase K hinzupipettiert. Danach folgte eine Inkubationsphase auf dem Thermomixer bei $55^{\circ} \mathrm{C}$. Nach der Proteinase K Behandlung erfolgte die weitere Verarbeitung der Referenz-DNS gemäß den oben beschriebenen Arbeitsschritten für die Tumor-DNS.

Die Länge der einzelnen DNS-Fragmente wurde wie oben beschrieben mittels Gelelektrophorese bestimmt. Anschließend erfolgte die photometrische Konzentrationsbestimmung der DNS nach den oben beschriebenen Angaben.

\subsubsection{Nick-Translation}

Die von Rigby et al. (1977) erstmals beschriebene Nick-Translation ist eine Markierungstechnik, bei der unmarkierte DNS durch neu synthetisierte, markierte DNS ersetzt wird (Rigby et al., 1977). Bei diesem Verfahren werden zunächst durch die Desoxyribonuklease I im DNS-Doppelstrang Einzelstrangbrüche, sogenannte „nicks“ (engl. = Kerben), erzeugt. Dabei entsteht ein 3'-Ende in der DNS mit einer freien Hydroxylgruppe (Ehrlich et al., 1973). Zur Synthese des neuen DNS-Strangs dient die von Kornberg et al. (1955 a) erstmals beschriebene DNA-Polymerase I (Kornberg et al., 1955 a,b; Lieberman et al., 1955). Diese entfernt zunächst mittels ihrer 5 ' $\rightarrow 3^{\prime}$ 'Exonukleaseaktivität bis zu 10 Nukleotide und ersetzt danach 
als DNS-Polymerase unmarkierte durch markierte Nukleotide (Kelly et al., 1970).

\section{Markierung der DNS}

Die Markierung der DNS-Sonden kann mit indirekten Verfahren wie auch mit direkten Verfahren erfolgen (Komminoth, 1992). Um die DNS-Sonden indirekt zu markieren werden während der Nick-Translation spezifische an Nukleotide gebundene Markermoleküle in die DNS eingebaut. Als besonders geeignet gelten Biotin zur Markierung der Tumor-DNS und Digoxigenin zur Markierung der ReferenzDNS (Brigati et al., 1983; Komminoth, 1992). Nach erfolgreicher Hybridisierung erfolgt die Färbung der DNS-Sonden mit Hilfe von mit fluoreszierenden Farbstoffen markierten Molekülen, welche spezifisch an die Markermoleküle binden (Kallioniemi OP et al., 1994). Die indirekte Markierung erfolgte mit FITC-Avidin, welches an Biotin bindet, und dem Antikörper Antidigoxigeninrhodamin, welcher an Digoxigenin bindet (Brigati et al., 1983; Komminoth, 1992).

\section{Fragmentlänge der DNS}

Als optimale Fragmentlänge nach Nicktranslation gelten Längen von 150 bis 650 Basenpaaren. DNS-Sonden mit einer Länge in diesem Bereich führen zu einer verstärkten Intensität und einheitlicheren Ergebnissen bei der Hybridisierung. Durch Änderungen der Konzentrationen von DNAse I und DNA-Polymerase sowie der Reaktionszeit kann die Länge der DNS-Fragmente beeinflusst werden (Kallioniemi OP et al., 1994).

Durchführung der Nick-Translation

Tabelle 2.23: Zusammensetzung des 10x Reaction Buffers

\section{0x Reaction Buffer}

Tris- $\mathrm{HCl}$

$500 \mathrm{mmol} / \mathrm{I}$

Magnesiumchlorid

$100 \mathrm{mmol} / \mathrm{I}$

Dithiothreitol

$10 \mathrm{mmol} / \mathrm{I}$

Der Puffer war der DNA-Polymerase I beigefügt. 
Für die Nick-Translation wurden $3 \mu \mathrm{g}$ Tumor- bzw. Referenz-DNS in ein Reaktionsgefäß, welches auf Eis gelagert wurde, pipettiert. Das benötigte Volumen der DNS wurde zuvor mit Hilfe der oben beschrieben photometrischen Konzentrationsbestimmung errechnet. $\mathrm{Zu}$ den $3 \mu \mathrm{g}$ DNS wurden nun $10 \mu \mathrm{l} 10 \mathrm{x}$ Reaction Buffer, je $2 \mu \mathrm{dATP}^{1}$, dGTP ${ }^{2}$, dCTP ${ }^{3}, 1 \mu \mathrm{l} \mathrm{dTTP}^{4}, 1 \mu$ l Desoxyribonuklease, $2 \mu \mathrm{l}$ DNA-Polymerase I pipettiert. Der Tumor-DNS wurden $1 \mu$ l Biotin-16-dUTP und der Referenz-DNS $1 \mu$ l Digoxigenin-11-dUTP hinzugegeben. Diese Lösung wurde mit sterilem Wasser auf $100 \mu$ l aufgefüllt, gemischt und anschließend zentrifugiert. Nun erfolgte eine sechzigminütige Inkubation bei $15^{\circ} \mathrm{C}$ der Referenz-DNS sowie eine fünfzigminütige Inkubation bei gleicher Temperatur der Tumor-DNS, da diese aufgrund der Paraffineinbettung bereits teilweise fragmentiert vorlag. Die Inkubation wurde anschließend durch Abkühlen auf $-20^{\circ} \mathrm{C}$ gestoppt und eine Fragmentlängenbestimmung der DNS mittels oben beschriebener Gelelektrophorese durchgeführt. Lagen die DNS-Fragmente im gewünschten Bereich von 150-600 Basenpaaren so wurden die Desoxyribonuklease sowie der DNA-Polymerase I durch Zugaben von EDTA inaktiviert. Waren die DNS-Fragmente länger als gefordert, so wurde die Inkubation für weitere 5 bis 10 Minuten bei $15^{\circ} \mathrm{C}$ fortgesetzt. Anschließend folgte eine erneute DNS-Fragmentlängenbestimmung.

Die bei der Nicktranslation gewonnenen DNS-Sonden der Tumor- bzw. ReferenzDNS mussten vor der Hybridisierung auf die Metaphasenchromosomen einer Vorbehandlung unterzogen werden. Zunächst pipettierten wir zu jeder Probe $5 \mu \mathrm{l}$ 0,5 M EDTA. Danach wurden jeweils $67 \mu \mathrm{l}$ der Tumor- sowie der gegengeschlechtlichen Referenz-DNS, $80 \mu \mathrm{l}$ Cot-1-DNA und $12 \mu \mathrm{l}$ Natriumacetat zu $580 \mu \mathrm{l} 100 \%$ igem Ethanol pipettiert. Dieser Ansatz wurde zunächst gemischt. Anschließend wurde die DNS bei $-80^{\circ} \mathrm{C}$ für 30 Minuten gefällt. Nach der Fällung erfolgte die Aufreinigung der DNS-Sonden durch Zentrifugation bei $4^{\circ} \mathrm{C}$ und $14.000 \mathrm{rpm}$ für 45 Minuten. Der dabei gebildete Überstand wurde verworfen. Nun wurden zu dem erhaltenen DNS-Pellet $800 \mu \mathrm{l} 70 \%$ iges Ethanol hinzugegeben und für 45 Minuten bei $45^{\circ} \mathrm{C}$ und

\footnotetext{
1 Desoxyadenosintriphosphat

2 Desoxyguanosintriphosphat

3 Desoxycytidintriphosphat

4 Desoxythymidintriphosphat
} 
1400 rpm auf dem Thermomixer inkubiert. Nach dieser Inkubationsphase erfolgte eine erneute Zentrifugation für 5 Minuten bei $4{ }^{\circ} \mathrm{C}$ und $14.000 \mathrm{rpm}$. Der dabei entstandene Überstand wurde wiederum verworfen und das DNS-Pellet getrocknet. Die Denaturierung der so aufgereinigten DNS-Sonden erfolgte durch Zugabe von $6 \mu \mathrm{l}$ deionisiertem Formamid und einer Inkubation bei $37^{\circ} \mathrm{C}$ und $1400 \mathrm{rpm}$ für 60 Minuten auf dem Thermomixer. Danach wurden $7 \mu$ l Master-Mix hinzugegeben und bei $78^{\circ} \mathrm{C}$ für 6 Minuten auf dem Thermomixer inkubiert. Anschließend folgte eine Vorhybridisierung bei $37^{\circ} \mathrm{C}$ für 30 Minuten auf dem Thermomixer.

Aufarbeitung der Metaphasen

Tabelle 2.24: Zusammensetzung der Pepsinlösung

\begin{tabular}{lr} 
Pepsinlösung & $\mathbf{1 0 0 ~} \mathbf{~ l l}$ \\
Pepsin & $28,57 \mu l$ \\
$1 \mathrm{M}$ Salzsäure & $1 \mathrm{ml}$ \\
Die Lösung wurde in der Hybridisierungskammer auf $37^{\circ} \mathrm{C}$ erwärmt. & \\
\hline
\end{tabular}

Tabelle 2.25: Zusammensetzung der Denaturierungslösung

$\begin{array}{lr}\text { Denaturierungslösung } & \mathbf{5 0 ~} \mathbf{~ l} \\ 20 \times \mathrm{SSC}^{1} & 5 \mathrm{ml} \\ \mathrm{NaH}_{2} \mathrm{PO}_{4} & 5 \mathrm{ml} \\ \text { Aqua bidest. } & 5 \mathrm{ml} \\ \text { deionisiertes Formamid } & 35 \mathrm{ml} \\ \text { Die Lösung wurde mit } 37 \text { \%iger Salzsäure auf pH 7,0 eingestellt und im Wasserbad auf } 69^{\circ} \mathrm{C} \\ \text { erwärmt. }\end{array}$

Bevor die Hybridisierung der DNS-Fragmente auf die Metaphasenpräparate durchgeführt werden konnte, mussten die Metaphasenpräparate, welche auf einem Objektträger vorliegen, einer Vorbehandlung und Denaturierung unterzogen werden. Dazu wurde zunächst das Hybridisierungsfeld, in dem die Metaphasenchromosomen liegen, mit einem Diamantstift markiert. Anschließend wurden die Objektträger einer Pepsinbehandlung unterzogen. Dafür wurden die Objektträger für 5 Minuten 
in eine Pepsinlösung gegeben, gefolgt von einer fünfminütigen Inkubation in $2 \mathrm{x}$ SSC. Diesem Schritt folgte eine Inkubation in einer aufsteigenden Alkoholreihe mit $70 \%$ igem, $85 \%$ igem und $100 \%$ igem Ethanol, welches eine Temperatur von $-20^{\circ} \mathrm{C}$ besaß, für je 5 Minuten. Danach trockneten die Objektträger 30 Minuten bei Raumtemperatur. Nun erfolgte die Denaturierung der Metaphasen durch eine zweiminütige Inkubation in der Denaturierungslösung. Anschließend wurden die Objektträger wiederum in der oben beschriebenen Alkoholreihe für je 5 Minuten inkubiert. Durch fünfzehnminütiges Trocknen bei Raumtemperatur und anschließendem fünfzehnminütigem Vorhybridisieren in der Hybridisierungskammer wurde die Vorbereitung der Metaphasenpräparate abgeschlossen.

\subsubsection{Hybridisierung}

Unbehandelte DNS liegt in ihrer natürlichen Form als Doppelstrang vor. Durch Erhitzen trennt sich dieser Doppelstrang zu zwei Einzelsträngen auf. Dieser Schritt wird als Denaturierung bezeichnet (Meselson und Stahl, 1958). Durch Abkühlen kehrt sich dieser Prozess wieder um. Es kommt durch eine mehr oder weniger komplementäre Bindung der DNS-Einzelstränge zur Bildung sog. Hybriden (Doty et al., 1960; Marmur und Lane, 1960). Es handelt sich also um eine Hybridisierung. Findet diese Hybridisierung zwischen DNS und Metaphasenchromosomen statt, bleibt also die Struktur der Chromosomen erhalten, so handelt es sich hierbei um eine In-situ-Hybridisierung (Pardue und Gall, 1969).

Die Stabiliät der so gebildeten Hybride ist abhängig von äußeren Faktoren wie dem Gehalt an Salzen (Schildkraut, 1965), dem pH-Wert (Wetmur und Davidson, 1968) sowie der Konzentration von Formamid (Bonner et al., 1967) und Dextransulfat (Wetmur, 1975).

Im menschlichen Genom finden sich repetitive Sequenzen, welche sich untereinander stark ähneln (Schmid und Jelinek, 1982; Singer, 1982). Da die zu untersuchenden DNS-Sonden wahllos an diese repetitiven Sequenzen binden würden, wäre eine Analyse somit nicht mehr möglich. Daher wird vor der Hybridisierung der DNS-Sonden Cot-1-DNA hinzugegeben. Cot-1-DNA bindet besonders an repetitive Sequenzen 
und verhindert so die unspezifische Hybridisierung der DNS-Sonden. Diesen Schritt nennt man preannealling (Landegent et al., 1987; Lichter et al., 1988; Pinkel et al., 1988).

Tabelle 2.26: Zusammensetzung der 20x SSC Lösung zur Hybridisierung

\begin{tabular}{|c|c|c|}
\hline $20 \times$ SSC & & $1000 \mathrm{ml}$ \\
\hline Natriumchlorid & $3 \mathrm{~mol} / \mathrm{l}$ & $175,5 \mathrm{~g}$ \\
\hline tri-Natriumcitratdihydrat & $300 \mathrm{mmol} / \mathrm{l}$ & $88,29 \mathrm{~g}$ \\
\hline
\end{tabular}

Vor der Hybridisierung wurden die DNS-Sonden zunächst bei 3500 rpm für 30 Sekunden zentrifugiert. Danach pipettierten wir $13 \mu$ l der DNS-Sonden auf das bereits markierte Hybridisierungsfeld der Metaphasenpräparate. Das Hybridisierungsfeld wurde nun mit einem Deckglas abgedeckt und die Ränder mit Fixogum verschlossen. Die Hybridisierung erfolgte während einer dreitägigen Inkubation bei $37^{\circ} \mathrm{C}$ im Brutschrank.

\subsubsection{Detektion}

Tabelle 2.27: Zusammensetzung der 20x SSC Lösung zur Detektion $20 \times$ SSC

Die Lösung wurde mit 1molarer Salzsäure auf pH 7,0 eingestellt.

Tabelle 2.28: Zusammensetzung der Waschlösung I

\begin{tabular}{lrr} 
Waschlösung I (Lösung A) & $\mathbf{1 0 0 0 ~} \mathbf{~ l}$ \\
Formamide & $50 \%(\mathrm{v} / \mathrm{v})$ & $500 \mathrm{ml}$ \\
$20 \times \mathrm{SSC}$ & $10 \%(\mathrm{v} / \mathrm{v})$ & $100 \mathrm{ml}$ \\
Die Lösung wurde mit 5 molarer Salzsäure auf pH 7,0 eingestellt. & \\
\hline
\end{tabular}


Tabelle 2.29: Zusammensetzung der Waschlösung II

Waschlösung II (Lösung A)

$1000 \mathrm{ml}$

$20 \times$ SSC

$200 \mathrm{ml}$

Polysorbat 20

$1 \mathrm{ml}$

Die Lösung wurde mit 1 molarer Salzsäure auf pH 7,0 eingestellt.

Tabelle 2.30: Zusammensetzung der Blockinglösung

Blockinglösung

$100 \mathrm{ml}$

Polysorbat 20

$$
0,1 \%(v / v)
$$

$0,1 \mathrm{ml}$

$20 \times$ SSC

Albumin-Fraktion $\mathrm{V}$

$5 \%(\mathrm{v} / \mathrm{v})$

$20 \mathrm{ml}$

$3 \%(\mathrm{w} / \mathrm{v})$

$3 \mathrm{~g}$

Die Lösung wurde mit 1 molarer Salzsäure auf pH 7,0 eingestellt.

Tabelle 2.31: Zusammensetzung der Anti-Digoxigenin-Rhodamin-Lösung

\begin{tabular}{|c|c|c|}
\hline $\begin{array}{l}\text { Anti-Digoxigenin-Rhodamin } \\
\text { Lösung }\end{array}$ & & $1 \mathrm{ml}$ \\
\hline Anti-Digoxigenin-Rhodamin & $200 \mu \mathrm{g} / \mathrm{ml}$ & $200 \mu \mathrm{g}$ \\
\hline
\end{tabular}

Tabelle 2.32: Zusammensetzung der Detektionslösung

\begin{tabular}{lcr} 
Detektionslösung & & $\mathbf{1 ~ m l}$ \\
Polysorbat 20 & $0,1 \%(\mathrm{v} / \mathrm{v})$ & $0,001 \mathrm{ml}$ \\
$20 \times \mathrm{SSC}$ & $5 \%(\mathrm{v} / \mathrm{v})$ & $0,2 \mathrm{ml}$ \\
Albumin-Fraktion V & $1 \%(\mathrm{w} / \mathrm{v})$ & $0,01 \mathrm{~g}$ \\
Anti-Digoxigenin-Rhodamin & & $15 \mu \mathrm{l}$ \\
Fluorescein Avidin DCS & $5 \mu \mathrm{l}$ \\
Die Lösung wurde lichtgeschützt hergestellt und mit 1 molarer Salzsäure auf pH 7,0 eingestellt. \\
\hline
\end{tabular}

Tabelle 2.33: Zusammensetzung der DAPI-Lösung

\begin{tabular}{llr} 
DAPI-Lösung & $\mathbf{1 ~ m l}$ \\
Actinomycin-D-Mannitol & $50 \mu \mathrm{l}$ & $12,5 \mu \mathrm{g} / \mathrm{ml}$ \\
DAPI & $1 \mu \mathrm{l}$ & $2,5 \mu \mathrm{g} / \mathrm{ml}$ \\
Vectorshield & $1 \mathrm{ml}$ & $1 \mathrm{ml}$ \\
\hline
\end{tabular}


Nach der Hybridisierung folgte das Aufbringen der fluoreszierenden Farbstoffe auf die Metaphasenpräparate. Um gebrauchsfertige Detektionslösung zu erhalten wurde diese für 10 Minuten bei $37^{\circ} \mathrm{C}$ und $1000 \mathrm{rpm}$ auf dem Thermomixer inkubiert und danach für 3 Minuten bei 8000 rpm zentrifugiert.

Die Metaphasenpräparate wurden für 2 Minuten bei $42^{\circ} \mathrm{C}$ in $2 \times$ SSC inkubiert. Nach diesem Schritt wurde das Fixogum entfernt. Durch dreimaliges je fünfminütiges Waschen der Metaphasenpräparate in Waschlösung I bei $42{ }^{\circ} \mathrm{C}$ wurden die unspezifischen Bindungen der DNS-Fragmente aus dem Hybridisierungsfeld entfernt. Diesem Schritt folgte ein dreimaliges je fünfminütiges Waschen in $2 \mathrm{x}$ SSC bei $42^{\circ} \mathrm{C}$. Durch Aufbringen von $300 \mu$ B Blockinglösung und dreißigminütiger Inkubation bei $37^{\circ} \mathrm{C}$ im Brutschrank wurde die Hybridisierungsreaktion gestoppt. Nach der Inkubation im Brutschrank wurden die Metaphasenpräparate mit 2 ml Waschlösung II abgewaschen. Jetzt wurden auf die Metaphasenpräparate $300 \mu$ l Detektionslösung pipettiert und für 60 Minuten inkubiert. Danach folgte ein dreimaliger je fünfminütiger Waschschritt in Waschlösung II bei $42^{\circ} \mathrm{C}$. Durch Aufbringen von $25 \mu$ l DAPI-Lösung erfolgte die Übersichtsfärbung der Chromosomen. Anschließend wurden die Metaphasenpräparate mit Deckgläsern abgedeckt.

\subsubsection{Digitalisierung der Metaphasenchromosomen}

Um eine möglichst große Genauigkeit in der Erfassung der Metaphasenchromosomen zu gewährleisten wurden Techniken welche Fluoreszenzmikroskope mit digitaler Bilderfassung kombinieren entwickelt (du Manoir et al., 1995; Lundsteen et al., 1995; Piper et al., 1995). Hierzu wurden von jeder Metaphase mittels einer an das Mikroskop angeschlossenen CCD-Kamera bei 880-facher Vergrößerung je 3 monochrome Bilder mit einer 8bit-Farbtiefe angefertigt. Die Metaphasenpräparate wurden mittels einer Quecksilberdampflampe durchleuchtet. Durch Verwendung spezifischer Spektralbereiche konnte jeweils einer der fluoreszierenden Farbstoffe, DAPI, FITC-Avidin oder Anti-Digoxigenin-Rhodamin sichtbar gemacht werden und jeweils ein monochromes Bild angefertigt werden. Die Intensität der Fluoreszensfarbstoffe spiegelt das Verhältnis von Tumor-DNS und Referenz-DNS wider. Es entsteht so ein Profil der Fluoreszensintensität entlang der Chromosomenlängsachse 
(Piper et al., 1995).Von jedem Fall wurden die besten 20 Metaphasen fotografiert und analysiert.

\subsubsection{Auswertung}

Am Computer wurde mittels Quips Karyotyping/CGH Software für jede Metaphase aus den 3 monochromen Bilder ein zusammengesetztes Bild erstellt. Danach wurde jede Metaphase auf die Qualität der Bilder überprüft und die Chromosomen in ein Karyogramm eingefügt. Chromosomen, welche den Qualitätskriterien nicht entsprachen wurden von der weiteren Analyse ausgeschlossen. Für jeden Fall wurde aus den einzelnen Karyogrammen ein Summenkaryogramm erstellt. Es konnten so unerwünschte Effekte minimiert werden, fallspezifische Veränderungen traten verstärkt zum Vorschein.
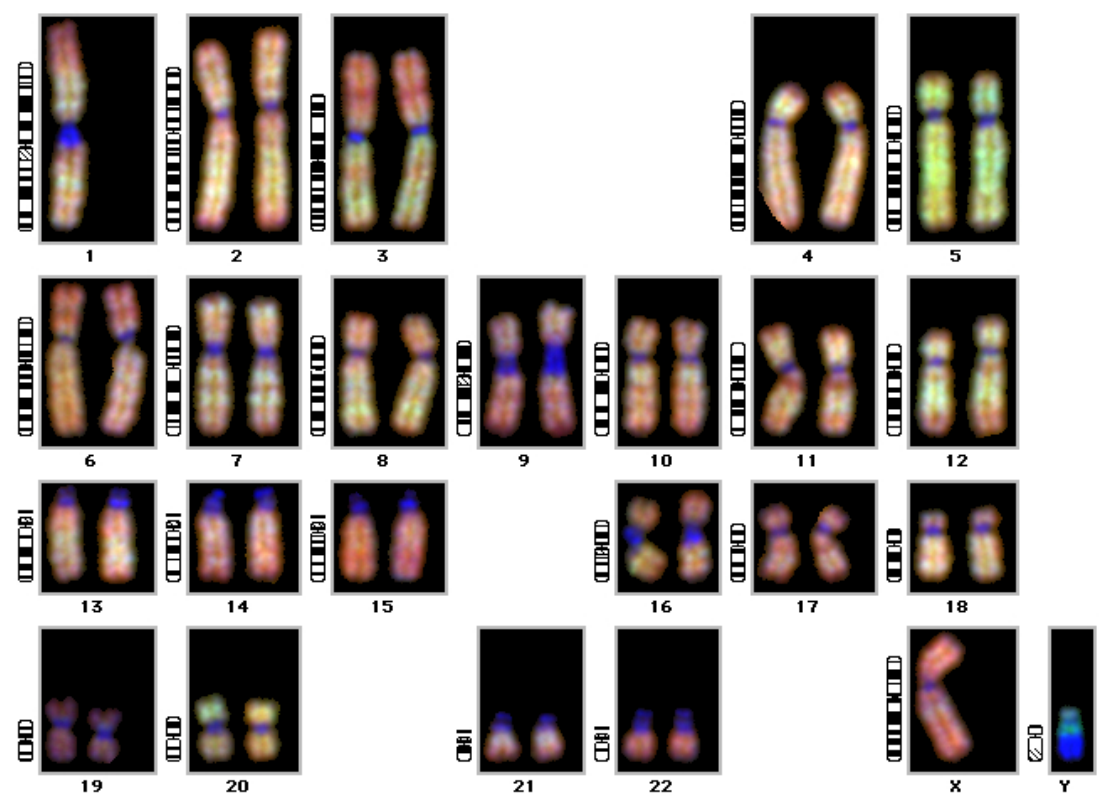

Abbildung 2.2: Zusammengesetztes Bild aus 3 monochromen Bildern der jeweiligen Fluoreszenzfarbstoffe 


\subsection{Beschreibung der CGH-Daten}

Mittels der Quips Karyotyping/CGH Software konnten für jeden Fall ein CGHProfildiagramm erstellt werden, welches Verluste bzw. Zugewinne in Form von Graphen darstellt. Überschreitet oder unterschreitet das Verhältnis von Tumor-DNS zu Referenz-DNS einen bestimmten Schwellenwert, so handelt es sich um einen Zugewinn bzw. Verlust. Die Schwellenwerte für Verluste lagen bei 0,80 bis 0,85, für Zugewinne bei 1,15 und 1,20. Eine Amplifikation lag vor, wenn Zugewinne über einem Wert von 1,5 lagen.

\subsubsection{Nomenklatur}

Die gewonnen Karyogramme entsprachen der Nomenklatur humaner Chromosomen für in-situ Hybridisierung des International System for Human Cytogenetic Nomenclature (ISCN) (Shaffer et al., 2009). Notiert werden CGH-Ergebnisse in der reverse-in-situ-hybridization-Schreibweise (rev ish). Am Anfang jeder Formel steht
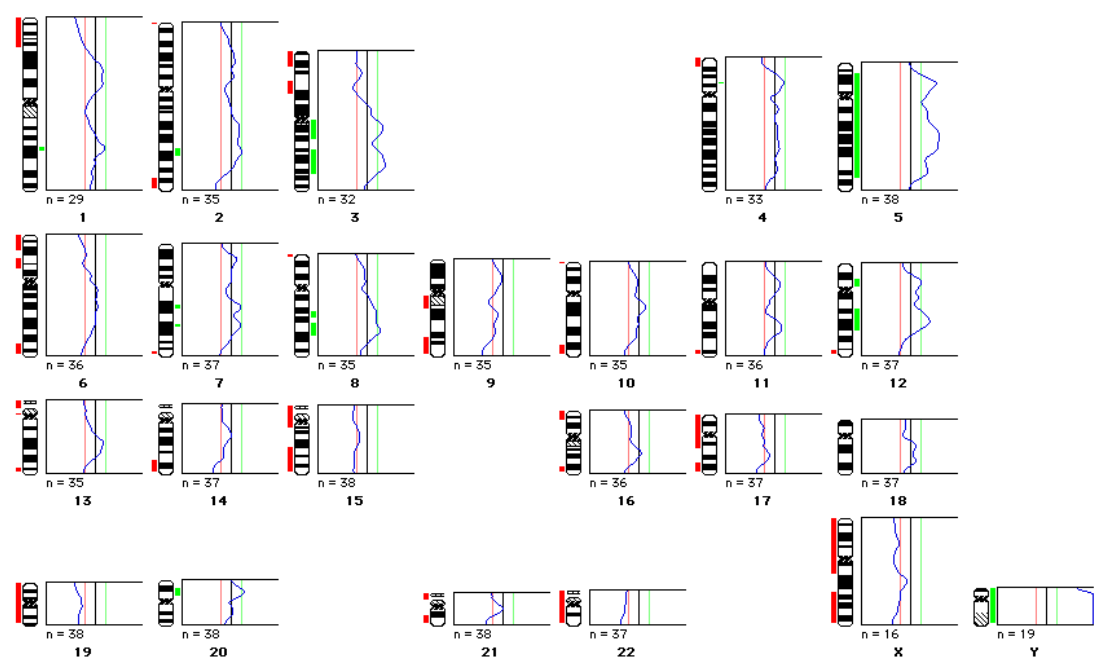

Abbildung 2.3: Mittels Quips Karyotyping/CGH Software erstelltes Summenideogramm 
dabei rev ish gefolgt von dim ${ }^{1}$ für Verluste und $e^{2}{ }^{2}$ für Zugewinne. Anhand eines wie in Abbildung $2.3 \mathrm{zu}$ sehenden Summenideogramms wurden die Ergebnisse der CGH in einer Expertenkonferenz der Abteilung Gastroenteropathologie in die rev ish-Schreibweise überführt.

\subsubsection{Kritische Bereiche}

Von der Bewertung ausgeschlossen wurden chromosomale Aberrationen welche in den Bereichen 1p32-pter, 13p, 14p, 15p, 19, 21p, 22p, den Zentromeren und Telomeren sowie in den heterochromatinreichen Abschnitten von 1q, 9q, 16q und Yq lagen (Kallioniemi OP et al., 1994). Chromosomale Aberrationen, welche sich auf dem X-Chromosom und Y-Chromosom befanden wurden von der Bewertung ausgeschlossen, da die Metaphasenchromosomen ausschließlich einen männlichen Chromosomensatz besaßen, die Proben aber von männlichen und weiblichen Patienten stammten.

\subsubsection{Darstellung der CGH-Ergebnisse}

Zur grafischen Darstellung der gewonnen Ergebnisse wurde neben der bereits erwähnten Quips Karyotyping/CGH Software die Analysefunktion der Website der molekularzytogenetischen Online-Datenbank für Krebserkrankungen, Progenetix, verwendet (Baudis, 2000; Baudis und Cleary, 2001). Eine Dokumentation sowie Hinweise zur Nutzung der Website findet sich unter Baudis (2009 a,b).

\subsection{Literaturrecherche}

Um eine möglichst vollständige Übersicht über CGH-Untersuchungen von klarzelligen Nierenzellkarzinomen und deren Metastasen bzw. Hirnmetatsasen zu erhalten, wurde am 16.07.2008 eine Online Recherche in MEDLINE ${ }^{3}$, der Mitelman Datenbank, der Progenetix Datenbank sowie der SKY/M-FISH \& CGH-Datenbank

1 diminished

2 enhanced

3 Medical Literature Analysis and Retrieval System Online 
durchgeführt. Die Datenbanken wurden mit folgenden Suchkriterien durchsucht: „Carcinoma, Renal Cell" [MeSH $\left.{ }^{1}\right]$ AND (cgh OR „comparative genomic hybridisation“ OR „comparative genomic hybridization".

Ziel dieser Suche war es Publikationen zu finden, welche Einzelfallbeschreibungen klarzelliger Nierenzellkarzinome und deren mittels CGH gefundenen chromosomalen Veränderungen beinhalteten. Diese mussten der unter 2.4.1 beschriebenen Nomenklatur humaner Chromosomen entsprechen. Auf diese Weise konnten CGHErgebnisse von 189 Primärtumoren des klarzelligen Typs gefunden werden.

\section{MEDLINE}

MEDLINE (Medical Literature Analysis and Retrieval System Online) ist eine bibliografische Datenbank der U.S. National Library of Medicine (NLM). Eine Besonderheit dieser Datenbank sind die sogenannten Medical Subject Headings (MeSH), welche einen Thesaurus darstellen, der ein genaues Durchsuchen sämtlicher Artikel ermöglicht. Die Suche erfolgte mit Hilfe des Online-Portal PubMed (http://www.ncbi.nlm.nih.gov/pubmed/) (MEDLINE, 2009).

\section{Mitelman-Datenbank}

Die Mitelman-Datenbank ist eine Datenbank für chromosomale Aberrationen bei Krebserkrankungen (http://cgap.nci.nih.gov/Chromosomes/Mitelman) (Mitelman et al., 2009).

\section{Progenetix}

Progenetix ist eine molekularzytogenetische Online-Datenbank für Krebserkrankungen (www.progenetix.net) (Baudis, 2000).

1 Medical Subject Heading 
SKY/M-FISH \& CGH

SKY/M-FISH \& CGH ist ebenfalls eine molekularzytogenetische Datenbank, die ein gemeinsames Projekt des National Center for Biotechnology Information (NC$\mathrm{BI}^{1}$ ), welches Teil der United States National Library of Medicine (NLM ${ }^{2}$ ) ist, und dem National Cancer Institute $\left(\mathrm{NCI}^{3}\right)$, welches dem Gesundheitsministerium der Vereinigten Staaten von Amerika (United States Department of Health and Human Services) untersteht (http://www.ncbi.nlm.nih.gov/sky/skyweb.cgi) (SKY/M-FISH \& CGH, 2001).

\subsection{Datentransformation}

Die Daten der Primärtumore wurden aus der jeweiligen Publikation manuell extrahiert und in eine digitale tabellarische Form transformiert, um sie für die weitere Auswertung nutzen zu können. Die eigenen CGH-Ergebnisse sowie die Ergebnisse der Primärtumore, welche beide in der rev ish ${ }^{4}$-Schreibweise vorlagen, wurden mittels Microsoft Excel für die weitere statistische Auswertung aufgearbeitet.

\subsection{Statistische Auswertung}

Die statistische Auswertung der Ergebnisse erfolgte durch die Abteilung Medizinische Statistik der Georg-August-Universität Göttingen.

Für jede einzelne Bande bzw. jeden Chromosomenarm wurden die Anteile an Gewinnen, Nicht-Veränderungen und Verluste mit dem $\chi^{2}-$ Test auf signifikante Unterschiede zwischen den Hirnmetastasen und Primärtumoren verglichen. Um zu vermeiden, dass unter all diesen Tests eine zu große Anzahl an falsch positiven Testergebnissen auftritt - also fälschlicherweise auf signifikante Unterschiede geschlossen wird - wurden die p-Werte bzgl. der false discovery rate (FDR) adjustiert. Hierzu

1 National Center for Biotechnology Information

2 United States National Library of Medicine

3 National Cancer Institute

4 Reverse-in-situ-Hybridization 
wurde das Verfahren nach Y. Benjamini und Y. Hochberg angewand (Benjamini und Hochberg, 1995). Die FDR ${ }^{1}$ ist der Anteil an falsch positiven Testergebnissen unter allen positiven Testergebnissen. Orientiert man sich an den adjustiert p-Werten (anstatt an den rohen p-Werten) so ist garantiert, dass der Anteil an falsch positiven Testergebnissen unter allen positiven Testergebnissen höchstens gleich $\alpha$ beträgt. Als globales Signifikanzniveau wurde $\alpha=5 \%$ festgelegt.

\subsubsection{Graphische Darstellung der gewonnenen Ergebnisse}

Die Ergebnisse der statistischen Berechnungen wurden mittels Analysefunktion der molekularzytogenetischen Datenbank Progenetix in Summenideogramme überführt (Baudis, 2000).

\subsubsection{Korrelation von CGH-Ergebnissen und Intervall bis zum Auftreten der Hirnmetastase}

Bei jeder der 320 Banden wurde gezählt wieviele der 106 Patienten einen Gewinn, eine Nicht-Veränderung oder einen Verlust aufwiesen. Die Wahrscheinlichkeit keine Hirnmetastase zu bekommen, in Abhängigkeit von der Zeit nach der Erstdiagnose, wurde mit den Kaplan-Maier-Schätzer geschätzt. Ob der zeitliche Verlauf dieser Wahrscheinlichkeiten signifikant verschieden ist wurde mit dem Logrank-Test getestet. Alle resultierenden p-Werte wurden wieder bzgl. der false discovery rate (FDR) adjustiert, um unter den 320 ausgeführten Tests den Anteil an falsch positiven Testresultaten einzuschränken. Als globales Signifikanzniveau wurde $\alpha=5 \%$ festgelegt.

1 false discovery rate 


\section{Ergebnisse}

Die in dieser Arbeit untersuchten Kollektive bestanden aus 189 Primärtumoren, welche histologisch dem klarzelligen Nierenzellkarzinom zugeordnet werden konnten, und 181 Hirnmetastasen, welche histologisch als Metastasen klarzelliger Nierenzellkarzinome klassifiziert wurden.

Das 189 Primärtumore umfassende Kollektiv wurde wie unter 2.5 beschrieben zusammengestellt und umfasste ausschließlich CGH-Ergebnisse, welche in der rev ish-Schreibweise vorlagen.

Das aus 181 Hirnmetastasen bestehende Kollektiv, wurde mittels Komparativer Genomischer Hybridisierung auf chromosomale Veränderungen hin untersucht und die dabei gewonnenen Ergebnisse gemäß der rev ish-Schreibweise fallspezifisch dokumentiert.

Die statistische Auswertung erfolgte wie unter 2.7 beschrieben mit Hilfe der Medizinischen Statistik der Georg-August-Universität Göttingen. Dabei wurden die gewonnenen Ergebnisse zum einen auf dem Niveau von Chromosomenbanden sowie auf dem häufig verwendeten Niveau von Chromosomenarmen ausgewertet. Es erfolgte außerdem eine Korrelation von chromosomalen Veränderungen der Hirnmetastasen und dem Intervall zwischen Erstdiagnose und Diagnose einer Hirnmetastase.

\subsection{Klinische Angaben zu den untersuchten Hirnmetastasen}

Die hier untersuchten 181 Hirnmetastasen stammten von 132 (73,0 \%) männlichen sowie $49(27,0 \%)$ weiblichen Patienten. Das Patientenalter bei Diagnose der 
Hirnmetastase lag bei 60,4 \pm 10,4 Jahre (Median 62,0 Jahre). Bei 115 (85,0 \%) der hier untersuchten Hirnmetastasen handelte es sich um singuläre Hirnmetastasen, bei $21(15,0 \%)$ bestanden multiple Hirnmetastasen. Die meisten Hirnmetastasen, $101(70,0 \%)$, lagen supratentoriell, gefolgt von infratentoriell, 24 (17,0\%), und spinal, 17 (12,0\%), gelegenen Hirnmetastasen. Als häufigstes Tumorstadium der Primärtumore, welche zu den hier untersuchten Hirnmetastasen führten zeigte sich ein Tumorstadium T2 (40,0\%), N0 (74,0 \%), G2 (71,0\%).

\subsection{Tumorstaging und Tumorgrading der untersuchten Primärtumore}

Die hier präsentierten CGH-Ergebnisse beruhen auf der Auswertung von 189 primären Nierenzellkarzinomen des klarzelligen Typs, welche aus verschiedenen Publikationen zusammengetragen wurden. Das Tumorstadium sowie das Tumorgrading dieser Primärtumore konnte aufgrund fehlender Angaben nicht von allen der 189 Tumore dokumentiert werden. Im Durchschnitt zeigte sich als häufigstes Stadium T1 (46,0 \%), N0 (57,0 \%), M1 (81,0 \%), G2 (55,0\%). 
Tabelle 3.1: Tumorstadium und Tumorgrading der Primärtumore

\begin{tabular}{lll} 
& $\begin{array}{l}\text { untersuchte } \\
\text { Primärtumore }\end{array}$ & $\begin{array}{l}\text { Primärtumore der } \\
\text { untersuchten Hirnmetastasen }\end{array}$ \\
T1 & $46,0 \%(52)$ & $13,0 \%(7)$ \\
T2 & $12,0 \%(14)$ & $40,0 \%(22)$ \\
T3 & & $15,0 \%(8)$ \\
T3a & $17,0 \%(19)$ & $11,0 \%(6)$ \\
T3b & $20,0 \%(23)$ & $18,0 \%(10)$ \\
T4 & $4,0 \%(5)$ & $4,0 \%(2)$ \\
Tx & 76 & 126 \\
N0 & $57,0 \%(20)$ & $74,0 \%(29)$ \\
N1 & $20,0 \%(7)$ & $18,0 \%(7)$ \\
N2 & $23,0 \%(8)$ & $8,0 \%(3)$ \\
Nx & 154 & 142 \\
M0 & $46,0 \%(17)$ & $0,0 \%(0)$ \\
M1 & $81,0 \%(30)$ & $100,0 \%(181)$ \\
Mx & 142 & $0,0 \%(0)$ \\
G1 & $10,0 \%(12)$ & $12,0 \%(6)$ \\
G2 & $55,0 \%(69)$ & $71,0 \%(36)$ \\
G3 & $32,0 \%(40)$ & $14,0 \%(7)$ \\
G4 & $4,0 \%(5)$ & $2,0 \%(2)$ \\
Gx & $63 \%$ & 130 \\
\hline
\end{tabular}

\subsection{Ergebnisse der Primärtumore}

\subsubsection{Auswertung nach Chromosomenbanden}

Die meisten Verluste zeigten sich auf den Banden 3p22, 3p25 und 3p26 mit jeweils 71,4\%. Die meisten Zugewinne fanden sich auf den Banden 5q31 mit 40,7\%, 5q32 mit 39,7\% und 5q33 mit 39,2\%. Am häufigsten unverändert waren die Banden 11q11, 11q12 und 11q13 mit jeweils 96,3\% (Abbildung 3.1, Tabellen A.2 und A.4 auf S. 91 und 105 im Anhang). 

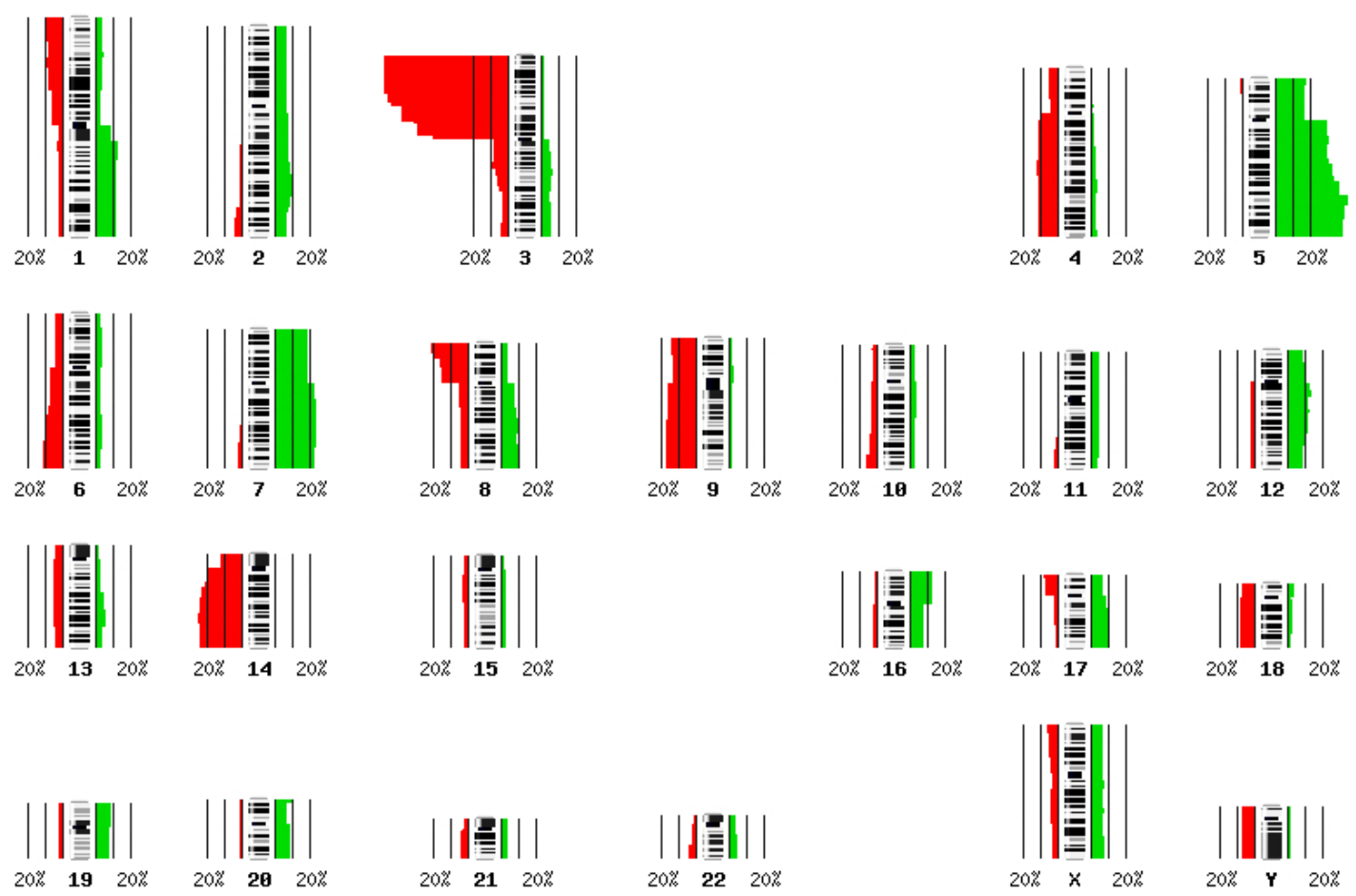

Abbildung 3.1: Histogramm chromosomaler Veränderungen der 189 Primärtumore nach Chromosomenbanden, erstellt mittels Baudis und Cleary (2001)

\subsubsection{Auswertung nach Chromosomenarmen}

Die Auswertung auf dem Niveau von Chromosomenarmen zeigt die meisten Verluste auf dem kurzen Arm von Chromosomen 3 mit 74,6\%, dem langen Arm von Chromosom 14 mit 25,9\% und dem kurzen Arm von Chromosom 8 mit 21,2\%. Die häufigsten Zugewinne finden sich auf dem langen Arm von Chromosom 5 mit 42,3\%, dem langen Arm von Chromosom 7 mit 23,3\% und dem kurzen Arm von Chromosom 7 mit 18,0\% (Abbildung 3.2, Tabellen A.1 und A.4 auf S. 89 und 105 im Anhang). 

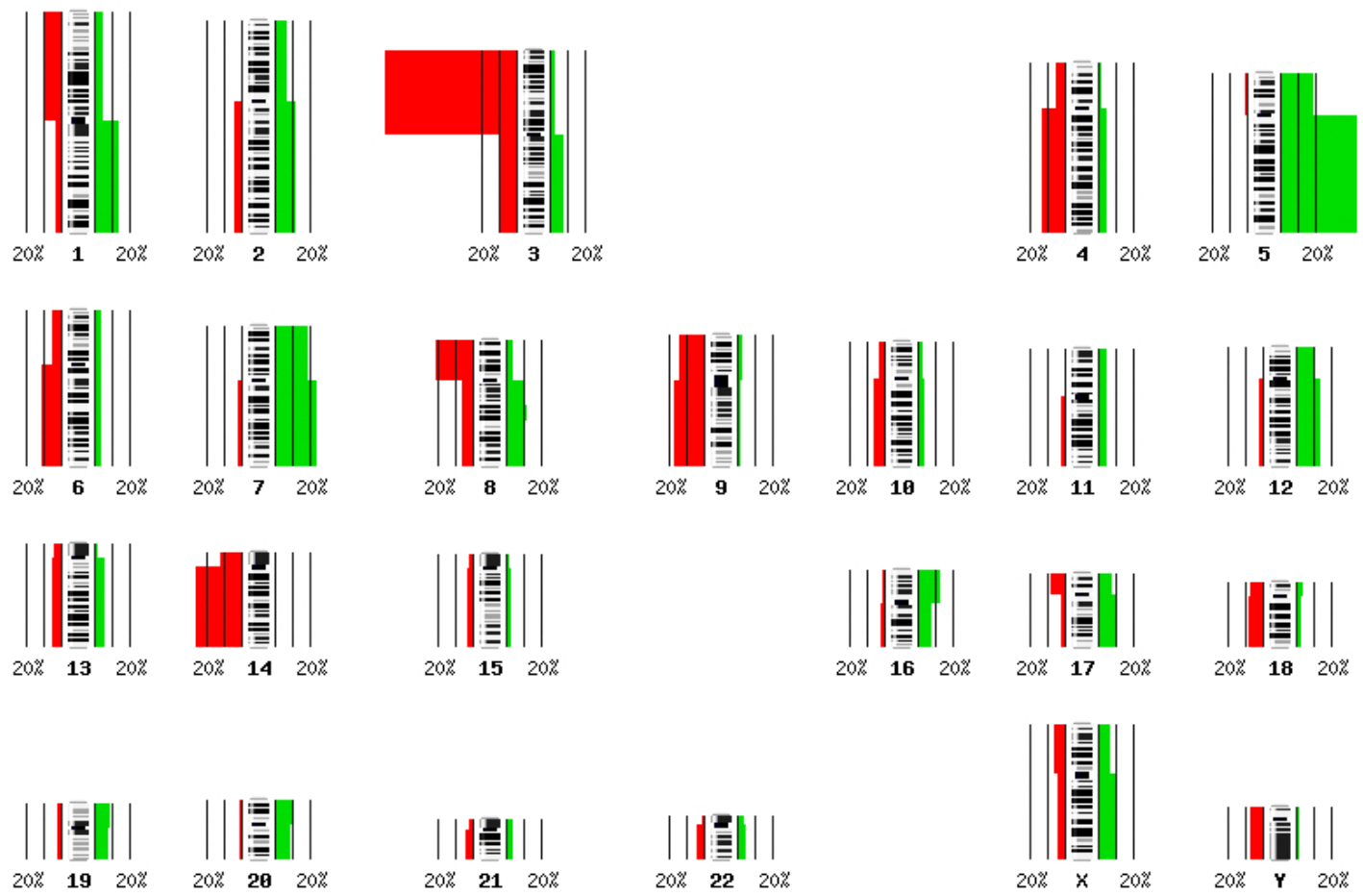

Abbildung 3.2: Histogramm chromosomaler Veränderungen der 189 Primärtumore nach Chromosomenarmen, erstellt mittels Baudis und Cleary (2001)

\subsection{Ergebnisse der Hirnmetastasen}

Die in dieser Arbeit präsentierten Ergebnisse entstammen von 181 Hirnmetastasen klarzelliger Nierenzellkarzinome. Initial bestand das untersuchte Kollektiv aus 204 Gewebeproben von Hirnmetastasen, von diesen 204 Gewebeproben wurden 23 aufgrund histologischer Typen, welche nicht dem klarzelligen Typ zugeordnet werden konnten, bzw. Fehlern während der CGH von der weiteren Analyse ausgeschlossen.

\subsubsection{Auswertung nach Chromosomenbanden}

Die meisten Verluste im Kollektiv der Hirnmetastasen fanden sich auf den Banden 3p21 mit 77,9\% und 3p24, 3p23 und 3p22 mit jeweils 76,8\%. Die meisten Zugewinne fanden sich auf den Banden 5q34, 5q33 und 5q32 mit jeweils 38,7\%. Die häufigsten unveränderten Banden waren 16p11, 16p12 sowie 17q11 und 17q12 mit jeweils 95,6\% (Abbildung 3.3, Tabellen A.2 und A.3 auf S. 91 und 99 im Anhang). 

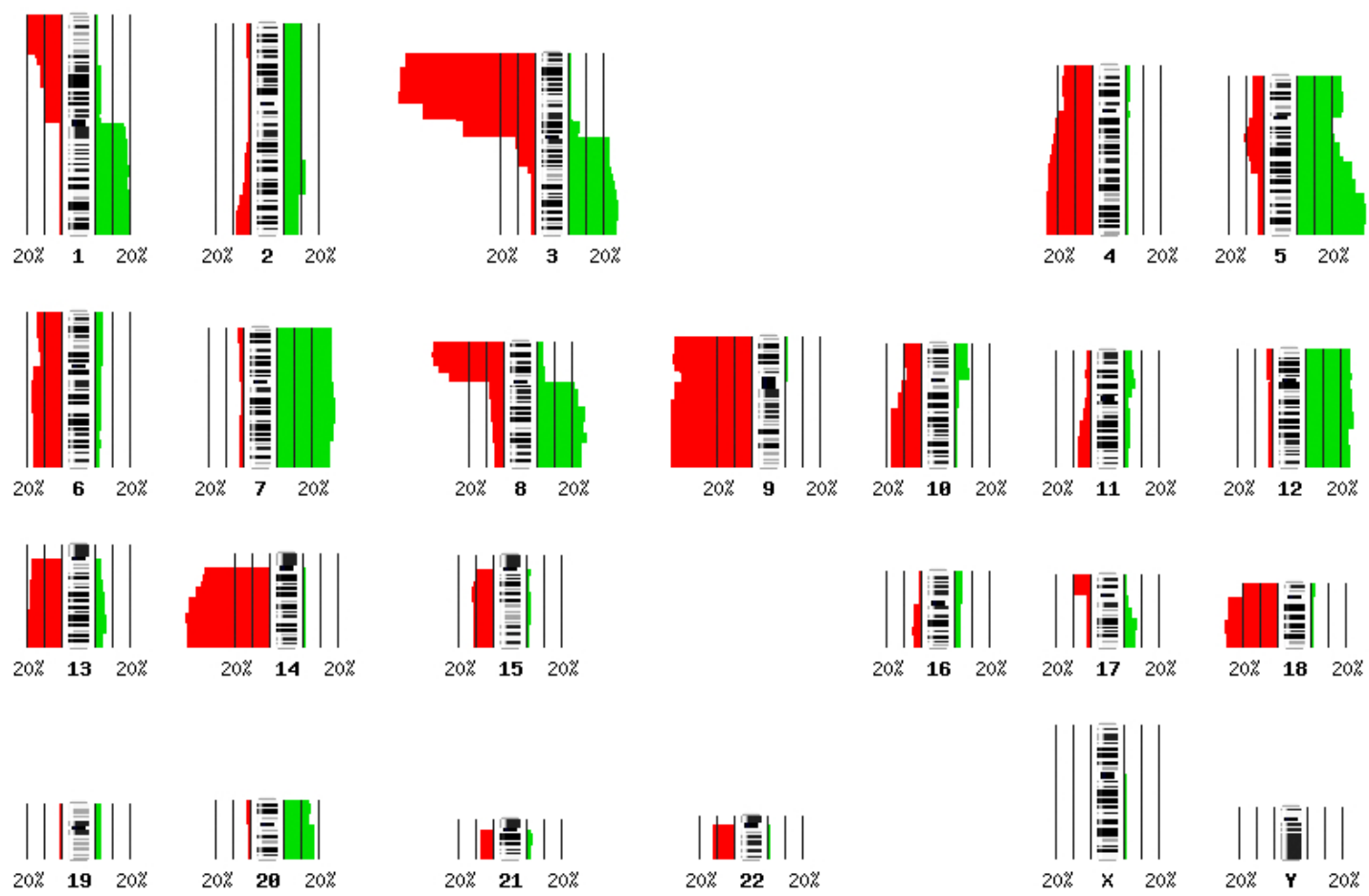

Abbildung 3.3: Histogramm chromosomaler Veränderungen der 181 Hirnmetastasen nach Chromosomenbanden, erstellt mittels Baudis und Cleary (2001)

\subsubsection{Auswertung nach Chromosomenarmen}

Die Auswertung der CGH-Ergebnisse auf dem Niveau von Chromosomenarmen zeigt die häufigsten Verluste für den kurzen Arm von Chromosom 3 mit 77,9\%, dem langen Arm von Chromosom 9 mit 46,7\% sowie dem kurzen Arm von Chromosom 9 mit 45,3\%. Die meisten Zugewinne finden sich auf dem langen Arm von Chromosom 5 mit 40,3\%, dem langen Arm von Chromosom 7 mit 32,6\% sowie dem kurzen Arm von Chromosom 7 mit 30,4\% (Abbildung 3.4, Tabellen A.1 und A.3 auf S. 89 und 99 im Anhang). 

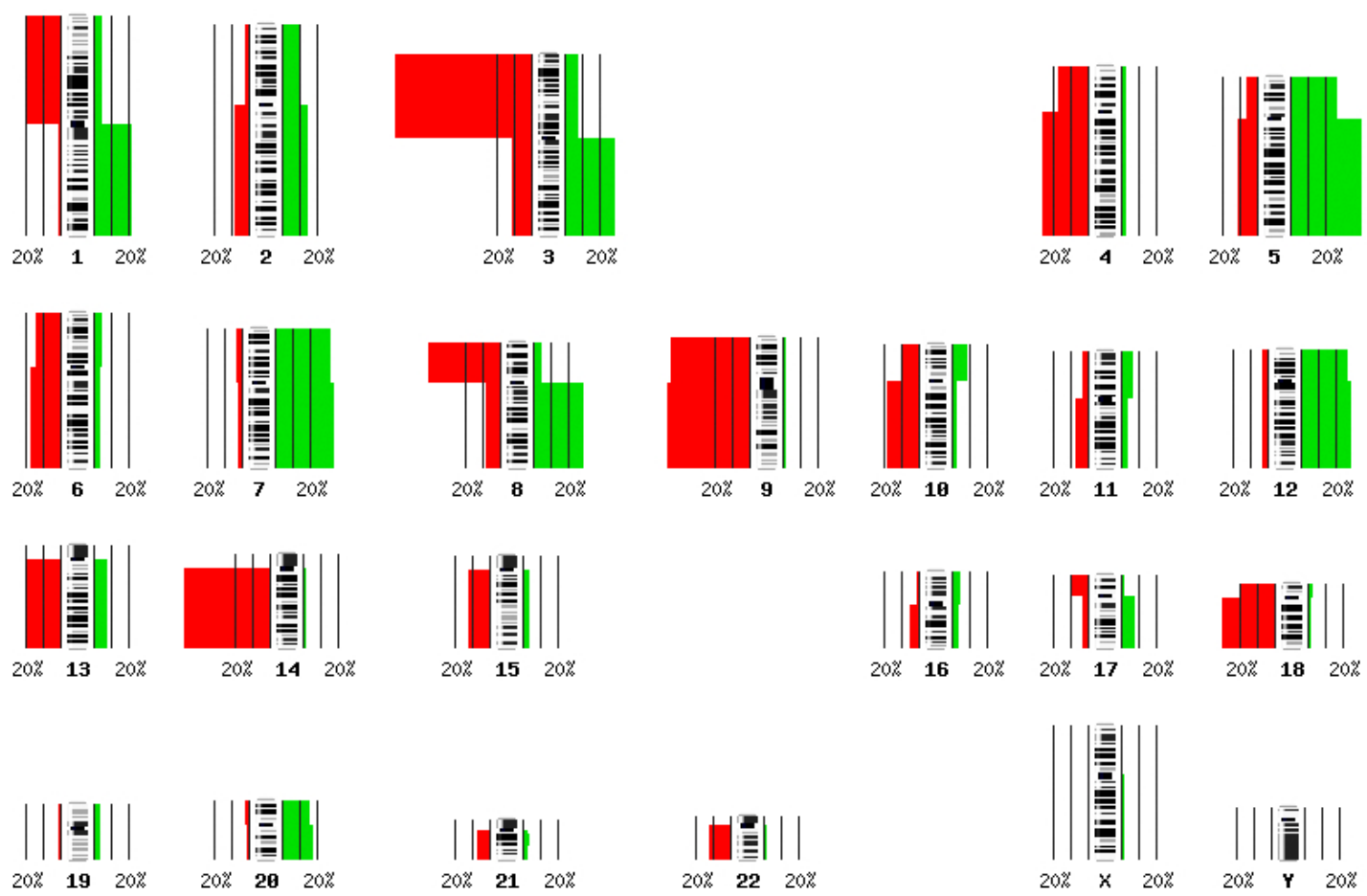

Abbildung 3.4: Histogramm chromosomaler Veränderungen der 181 Hirnmetastasen nach Chromosomenarmen, erstellt mittels Baudis und Cleary (2001)

\subsection{Vergleich der Ergebnisse der Hirnmetastasen mit den Ergebnissen der Primärtumore}

Vergleicht man die Ergebnisse der Hirnmetastasen mit den Ergebnissen der Primärtumore so zeigen sich auf dem Niveau der Chromosomenbanden die signifikantesten Unterschiede im Bereich des kurzen Arms von Chromosom 9. Insgesamt stellen sich von den 320 Chromosomenbanden 163 als signifikant unterschiedlich zwischen diesen beiden Gruppen dar. Aufgrund des Adjustierungsverfahren für die p-Werte besteht für $5 \%$ dieser 163, also für ca. 9 Banden, immer noch die Möglichkeit, dass fälschlicherweise auf einen signifikanten Unterschied geschlossen wurde. Auf dem Niveau der Chromosomenarme sind von den 48 Chromosomenarmen 45 signifikant unterschiedlich. Hierbei könnten aufgrund des beschriebenen Adjustierungsverfahrens 2 Chromosomen fälschlicherweise als signifikant unterschiedlich gelten. 
Die Abbildung 3.5 zeigt die unterschiedlichen Häufigkeiten chromosomaler Verluste, chromosomaler Zugewinne und chromosomaler Nicht-Veränderungen.
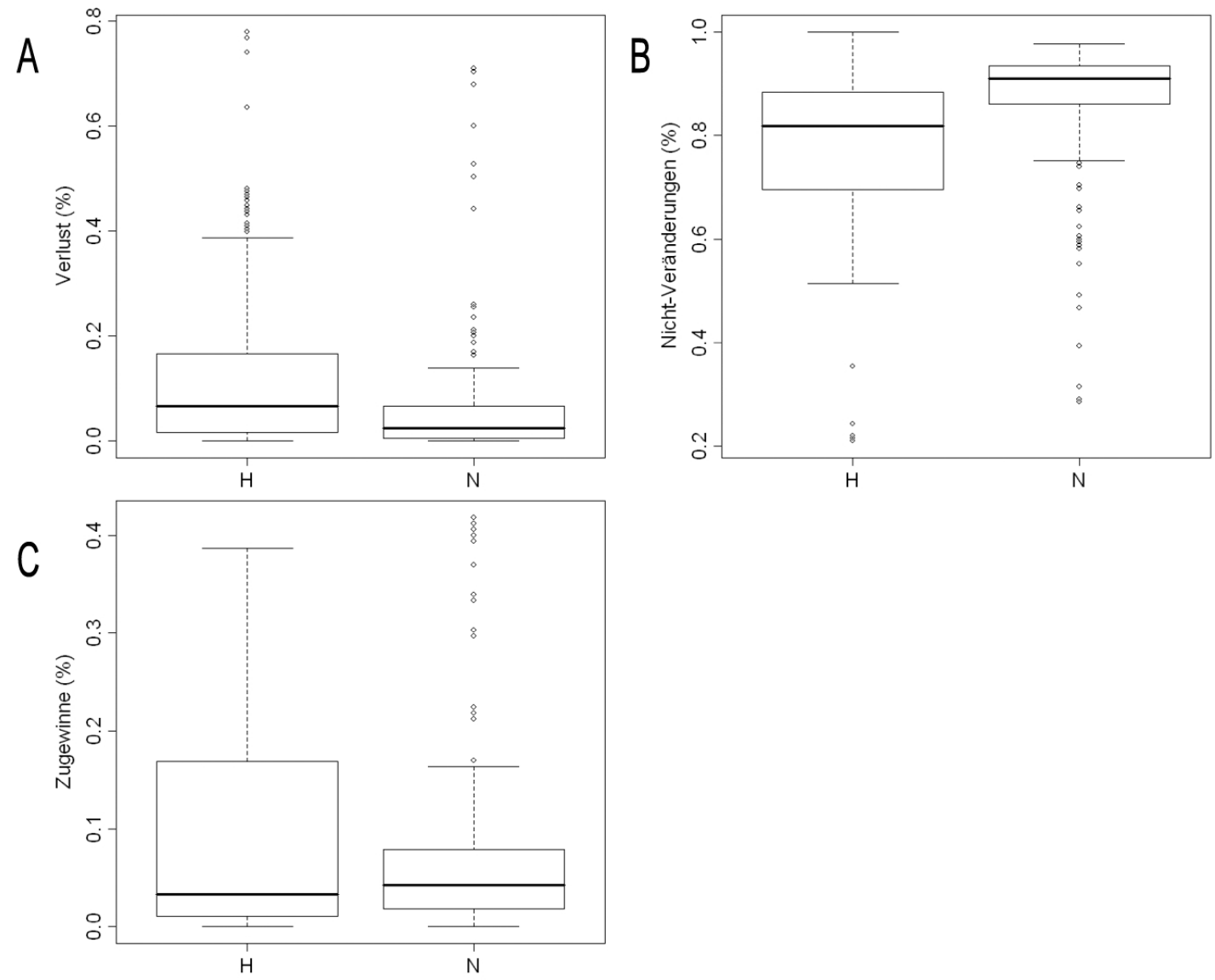

Abbildung 3.5: Vergleichende Dot-blot-Darstellung chromosomaler Veränderungen von Primärtumoren $(\mathrm{N})$ und Hirnmetastasen $(\mathrm{H})$, Verluste $(\mathrm{A})$, konstante Bereiche (B), Zugewinne (C)

\subsection{Korrelation chromosomaler Aberrationen mit dem rezidivfreien Überleben}

Das Intervall zwischen Erstdiagnose und Diagnose der Hirnmetastase konnte von 106 Patienten eruiert werden. Im Durchschnitt lagen zwischen Erstdiagnose und Diagnose der Hirnmetastase 53,2 \pm 64,1 Monate (Median 24 Monate).

Ein Verlust oder ein Gewinn im Bereich 18q führt im Mittel nach 60 Monaten 

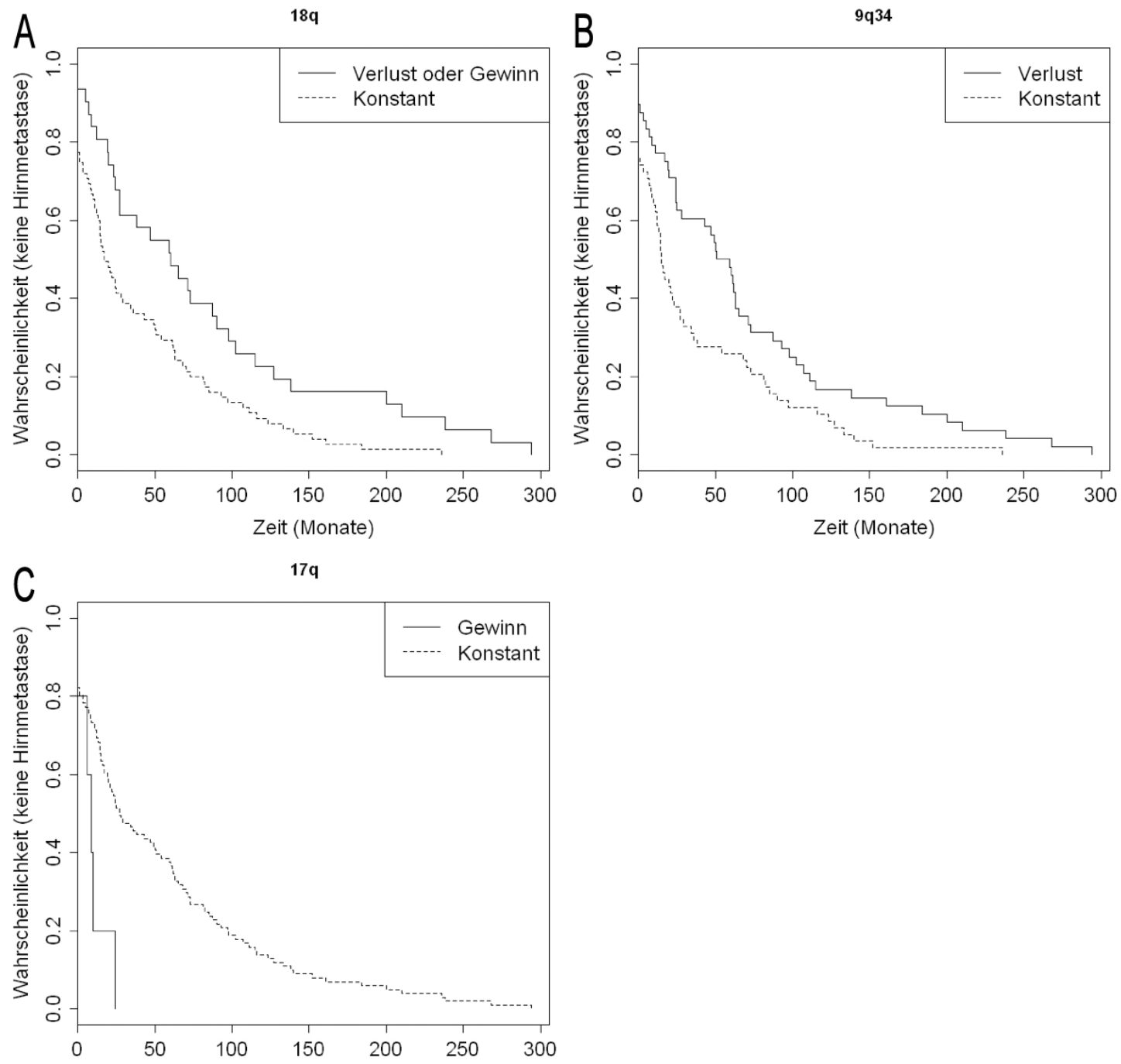

Abbildung 3.6: Wahrscheinlichkeit des Auftretens einer Hirnmetastase bezogen auf 18q (A), 9q34 (B) und 17q (C)

(95\% KI-Intervall 27 bis 102 Monate) zum Auftreten einer Hirnmetastase, ist dieser Bereich hingegen unverändert, so tritt eine Hirnmetastase im Mittel bereits nach 17 Monaten (95\% KI-Intervall 13 bis 36 Monate) auf (p-Wert 0,024) (Abbildung 3.6).

Ein Verlust im Bereich der Bande 9q34 führt im Mittel nach 59 Monaten (95\% KI-Intervall 28 bis 71 Monate) zum Auftreten einer Hirnmetastase. Kommt es in diesem Bereich zu keinem Verlust, so tritt eine Hirnmetastase im Mittel bereits nach 
15 Monaten (95\% KI-Intervall 12 bis 27 Monate) auf (p-Wert 0,042) (Abbildung $3.6)$.

Ein Zugewinn im Bereich 17q führt im Mittel innerhalb von 9 Monaten (95\% KI-Intervall 6 bis NA Monate) zum Auftreten einer Hirnmetastase. Ist dieser Bereich unverändert, liegen also weder Zugewinne noch Verluste in diesem Bereich vor, führt dies im Mittel erst nach 27 Monaten (95\% KI-Intervall 20 bis 54 Monate) zum Auftreten einer Hirnmetastase (p-Wert 0,049) (Abbildung 3.6).

Da für alle 3 beschriebenen chromosomalen Veränderungen der p-Wert unter 0,05 liegt, stellen diese Ergebnisse Veränderungen dar, welche das Intervall zwischen Erstdiagnose eines Nierenzellkarzinoms und dem Auftreten einer Hirnmetastase signifikant beeinflussen. 


\section{Diskussion}

Dies ist die erste Arbeit in der die Methode der CGH bei Hirnmetastasen klarzelliger Nierenzellkarzinome Anwendung findet und die sich mit chromosomalen Mustern dieses Metastasentyps beschäftigt. Mit 181 untersuchten Hirnmetastasen klarzelliger Nierenzellkarzinome umfasst sie gleichzeitig das bisher größte Kollektiv an untersuchten Metastasen von Nierenzellkarzinomen. Die Ergebnisse dieser Arbeit sind gerade mit Blick auf Publikationen mit weit unter 100 Proben als besonders aussagekräftig einzuschätzen.

Die Analyse der CGH-Ergebnisse von 189 Primärtumoren unterschiedlicher Publikationen spiegelt eine aussagekräftige und unabhängige Darstellung chromosomaler Muster klarzelliger Nierenzellkarzinome wider.

Als Einschlusskriterium für diese Arbeit galt eine histologisch gesicherte Hirnmetastase eines klarzelligen Nierenzellkarzinom-Primärtumors. Die Untersuchung mittels CGH erfolgte ausschließlich von Hirnmetastasen des klarzelligen Typs.

Als Einschlusskriterium für die Auswahl der CGH-Ergebnisse der Primärtumore galt ebenso eine histologische Zuordnung zum klarzelligen Typ.

Faktoren wie Größe, Stadium und Grading des Primärtumors sowie Geschlecht oder Alter der Patienten wurden mit Blick auf die ansonsten zu kleinen und damit statistisch nicht eindeutig verwertbaren Ergebnisse bewusst nicht berücksichtigt. 


\subsection{Kritische Betrachtung der Komparativen Genomischen Hybridisierung}

Die CGH wurde 1992 von Kallioniemi A et al. sowie 1993 von du Manoir et al. erstmals vorgestellt und ermöglicht eine genomweite Untersuchung chromosomaler Aberrationen (du Manoir et al., 1993; Kallioniemi A et al., 1992). Dabei ist es möglich Zugewinne sowie Verluste gleichzeitig in einer Untersuchung zu detektieren (James, 1999). Die Aufösung liegt zwischen 10 und 20 Megabasenpaare (Mbp) für Zugewinne bzw. Verluste (du Manoir et al., 1995; Joos et al., 1993; Kallioniemi A et al., 1992; Piper et al., 1995). Speicher et al. (1993) sowie Isola et al. (1994) konnten zeigen, dass sich diese Methode zur Untersuchung für in Paraffin eingebettete oder tief gefrorene Proben solider Tumore eignet.

Die CGH ist eine arbeitsintensive Methode, bei deren Durchführung viel Erfahrung nötig ist. Die Aussagekraft der Ergebnisse ist besonders abhängig von der Qualität der Proben-DNS (James, 1999). Chromosomale Veränderungen lassen sich mit Hilfe der CGH detektieren, wenn sie wenigstens in 30-50\% der Zellen, aus denen die Proben-DNS extrahiert wurde, vorhanden sind (du Manoir et al., 1995). Mit dieser Methode lassen sich relative Veränderungen bezüglich der Kopienzahl einzelner Chromosomenabschnitte feststellen. Aussagen über numerische Veränderungen des Chromosomensatzes können mit Hilfe der CGH nicht getroffen werden(du Manoir et al., 1995).

Weitere Faktoren, welche die CGH-Ergebnisse beeinflussen sind die Qualität der Metaphasenchromosomen sowie die Hybridisierung der Proben- bzw. Referenz-DNS auf diese Chromosomen. Die Metaphasenchromosomen nach Hybridisierung der DNS müssen den unter 2.3.1 beschriebenen und von Kallioniemi OP et al. (1994) empfohlenen Kriterien entsprechen.

Um zuverlässige Ergebnisse mittels CGH zu erhalten, empfehlen du Manoir et al. (1995) fünf bis 12 Metaphasen zu analysieren. Die in dieser Arbeit präsentierten CGH-Ergebnisse beruhen auf einer Auswertung von mindestens 20 Metaphasen je Tumor. Durch diesen Mehraufwand konnten negative Einflussfaktoren noch weiter 
minimiert und die Aussagekraft der Ergebnisse erhöht werden.

Aussagen über die Qualität der für diese Arbeit aus anderen Publikationen herangezogenen CGH-Ergebnisse können nicht getroffen werden.

\subsection{Kritische Betrachtung der manuellen Auswertung der CGH-Ergebnisse}

Die mit Hilfe der o.g. Software erstellten fallspezifischen Summenideogramme der Hirnmetastasen, wie beispielhaft in Abbildung $2.3 \mathrm{zu}$ sehen, wurden manuell in die international übliche rev ish-Schreibweise transformiert um sie so der weiteren Auswertung zugänglich zu machen. Bei dieser Transformation wurde versucht die fallspezifischen Verluste bzw. Zugewinne möglichst genau zu notieren. Die chromosomalen Regionen, welche für methodenbedingte Verfälschungen anfällig waren, wurden von der Umwandlung in die rev ish-Schreibweise ausgeschlossen. Diese manuelle Transformation der Ergebnisse aus einem Summenideogramm in eine vergleichbare Schreibweise stellt zugleich den Schritt mit der größten Fehleranfälligkeit dar, da eine manuelle Auswertung nie absolut frei von subjektiven Eindrücken und Einflüssen ist.

Die Transformation der CGH-Ergebnisse in die rev ish-Schreibweise führt abhängig vom jeweiligen Betrachter zu interindividuellen Unterschieden. Um die Variabilität der Ergebnisse so gering wie möglich zu halten wurden diese in einer Konferenz der Abteilung Gastroenteropathologie abschließend besprochen.

Die CGH-Ergebnisse der Primärtumore in Form der rev ish-Scheibweise wurden aus verschiedenen Publikationen gewonnen. Eine Aussage über die Qualität der einzelnen Ergebnisse kann also nicht getroffen werden.

Durch die hohe Fallzahl der in diesem Kollektiv untersuchten Hirnmetastasen und Primärtumore wurde versucht die interindividuellen Unterschiede jeder einzelnen Hirnmetastase bzw. jedes einzelnen Primärtumors sowie die durch die manuelle 
Auswertung bedingte Variabilität der Ergebnisse so gering wie möglich zu halten.

Der Vergleich der CGH-Ergebnisse von Primärtumoren und Hirnmetastasen, welche beide aus unabhängigen Kollektiven stammten, ergab signifikant unterschiedliche chromosomale Bereiche, welche frei von klonalen Einflüssen waren. Es handelte sich also hierbei um Veränderungen, die sich nur in Hirnmetastasen fanden nicht jedoch in den Primärtumoren. Diese Veränderungen scheinen die metastasierten Zellen im Zeitraum zwischen der ersten Absiedelung bis hin zur Diagnose erworben haben.

\subsection{Kritische Betrachtung der Ergebnisse}

Die histologisch gesicherte Abstammung der Metastasen von klarzelligen Nierenzellkarzinome konnte anhand ähnlicher chromosomaler Muster widergespiegelt werden. Wie man in den Abbildungen 3.1, 3.2 sowie 3.3 und 3.4 sehen kann treten Veränderungen, welche sich in Primärtumoren finden ebenso in den Hirnmetastasen auf. Abbildung 4.1 zeigt mit Hämatoxilin-Eosin gefärbte histologische Schnitte eines klarzelligen Nierenzellkarzinoms sowie einer Hirnmetastase aus dem in dieser Dissertation untersuchten Kollektiv. Die Abbildung 4.2 zeigt ein aus den gewonnen Histogrammen der Primärtumore und der Hirnmetastasen zusammengesetztes Histogramm, welches die Ähnlichkeit der chromosomalen Muster beider Gruppen verdeutlicht. Die histologische Ähnlichkeit spiegelt sich also auch auf chromosomaler Ebene wider. Dies beweist zum einen die Richtigkeit der Diagnosestellung anhand der histologischen Präparate und zeigt zum anderen, dass an Hand des chromosomalen Musters eine Zuordnung einer Metastase zu diesem speziellen Tumortyp möglich ist. Die in dieser Arbeit gefundenen chromosomalen Veränderungen der Primärtumore spiegeln die von Gunawan et al. (2001) und Junker et al. (2003) für klarzellige NZK beschriebenen Veränderungen wider.

Im Kollektiv der Hirnmetastasen traten insgesamt mehr Veränderungen als im Kollektiv der Primärtumore auf. Diese Beobachtung wird gestützt durch das von Peter C. Nowell 1976 vorgestellte Modell zur klonalen Evolution von Tumorzellpopulationen. Dieses Modell besagt, dass ein Tumor aus einer einzigen Zelle aufgrund von Wachstumsvorteilen entsteht. Aus einer einzelnen veränderten Zelle kommt es 


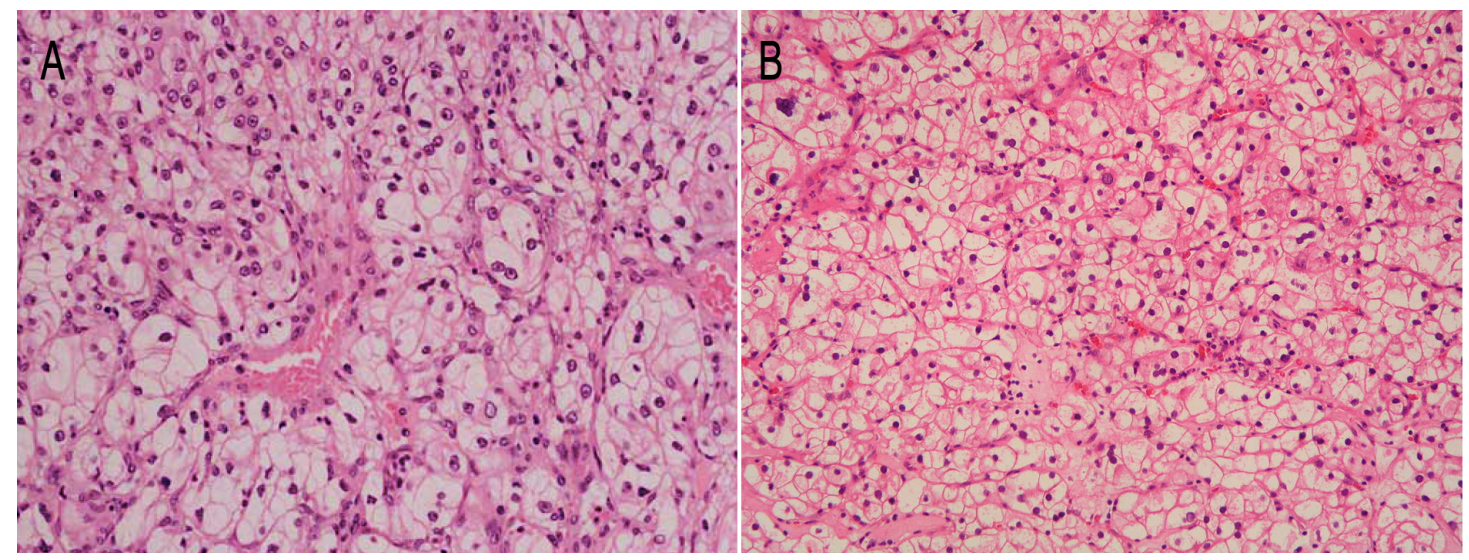

Abbildung 4.1: $\mathrm{A}=$ Histologie eines primären klarzelligen Nierenzellkarzinoms aus Brunelli et al. (2008) S. 3, B = Histologie einer Hirnmetastase eines klarzelligen Nierenzellkarzinoms

so zu einer klonalen Expansion mit Zunahme genetischer Veränderungen. Durch Selektionsdruck entwickelt sich ein dominierender Subklon, welcher zusätzlich zu den bereits bestehenden genetischen Veränderungen weitere neu entstandene Veränderungen besitzt. Während der Tumorprogression treten zu einem unbekannten Zeitpunkt Fähigkeiten invasiv zu wachsen bzw. zu metastasieren auf (Nowell, 1976). Nach Hanahan und Weinberg (2000) gelten eine Unabhängigkeit von Wachstumsfaktoren, Resistenz gegenüber das Wachstum inhibierenden Signalen, Umgehung des programmierten Zelltodes, der Apoptose, uneingeschränkte Teilungsfähigkeit, dauerhafte Angiogenese sowie die Fähigkeit der Gewebeinfiltration und Metastasierung als die Eigenschaften, welche eine maligne Zelle ausmachen.

Fearon und Vogelstein beschrieben 1990 ein Modell der Tumorentstehung aufgrund von genetischen Veränderungen am Beispiel des Kolonkarzinoms. Sie konnten zeigen, dass sich bestimmte genetische Veränderungen sowohl in gutartigen Adenomen des Kolons sowie in metastasierten Kolonkarzinomen fanden, andere hingegen fanden sich nur in Kolonkarzinomen.

Im Gegensatz dazu finden sich im Kollektiv der Hirnmetastasen chromosomale Regionen welche im Vergleich zum Kollektiv der Primärtumore weniger häufig verändert sind. Dies und die Tatsache, dass einige Hirnmetastasen erst nach bis zu 24,5 

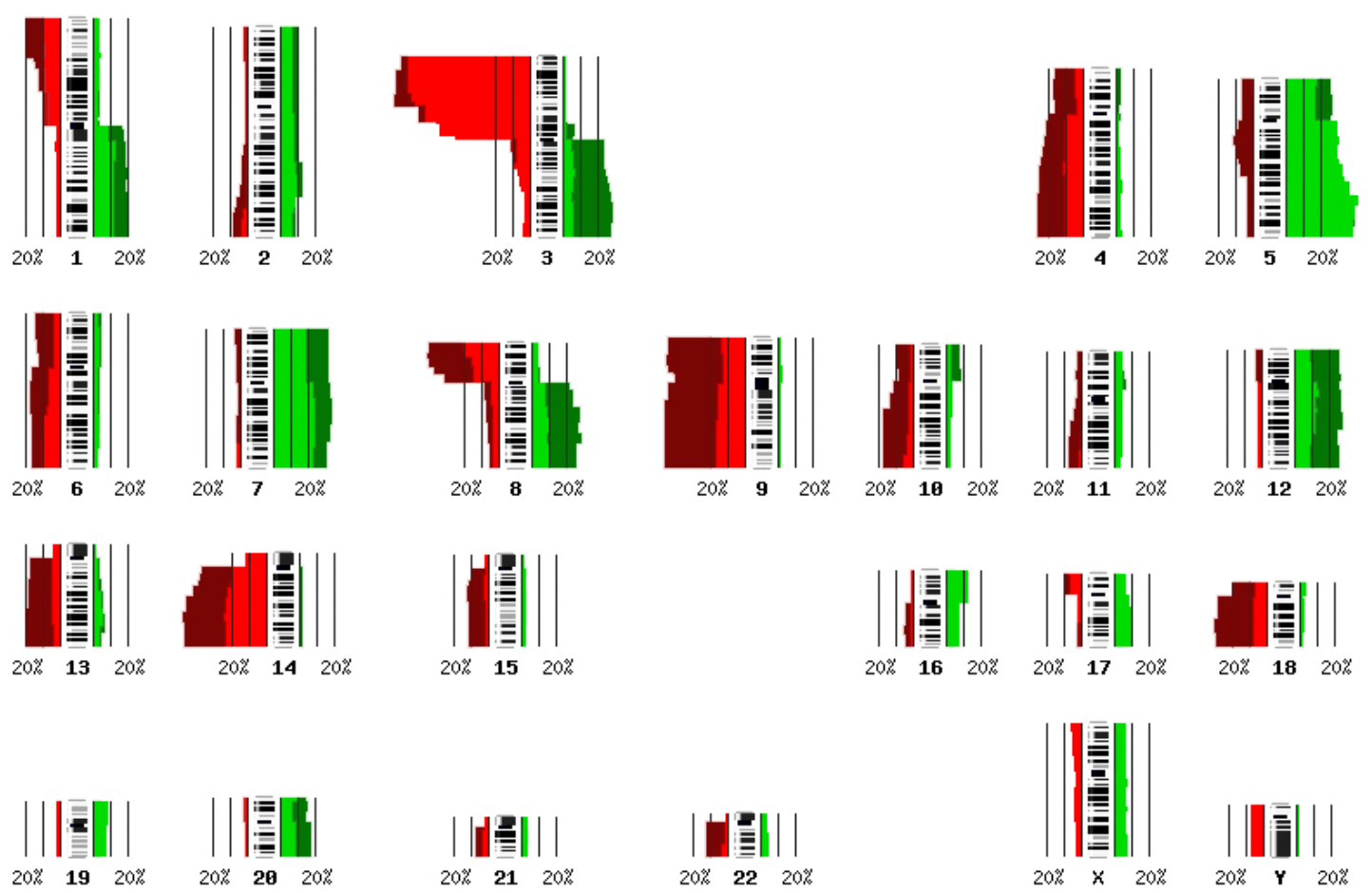

Abbildung 4.2: Summationshistogramm aus den Ergebnissen der Primärtumore (hellrot $=$ Verluste, hellgrün $=$ Zugewinne) und der Hirnmetastasen (dunkelrot $=$ Verluste, dunkelgrün = Zugewinne)

Jahren manifest wurden, sprechen für eine bereits früh in der Tumorentwicklung stattfindende Absiedelung von metastatischen Zellen. Diese Beobachtung deckt sich mit Beschreibungen von Schmidt-Kittler et al. (2003), die u.a. mittels CGH eine frühe Absiedelung von Tumorzellen bei Brustkrebspatienten nachweisen konnten. Studien über das Auftreten von Nierenzellkarzinom-Metastasen im Gehirn sowie in der Schilddrüse bzw. dem Pankreas nach bis zu 21,8 Jahren nach Operation des Primärtumors zeigen ebenso die für Nierenzellkarzinom-Metastasen charakteristische Eigenschafft, spät manifest zu werden (Heffess et al., 2002; Shuto et al., 2006; Wente et al., 2005).

Durch den Vergleich der Ergebnisse der Hirnmetastasen mit den Ergebnissen der Primärtumore konnten mit Hilfe statistischer Methoden signifikante Unterschiede gefunden werden. Diese Ergebnisse sind abhängig von der Auflösung der Auswertung. So stellen sich in der Auswertung auf dem Niveau der Chromosomenarme 
andere Chromosomen als signifikant unterschiedlich dar als auf dem Niveau der Chromosomenbanden. Untersucht man die beiden Kollektive auf dem Niveau der Chromosomenbanden so treten einzelne Chromosomenbanden als besonders signifikant hervor.

Als chromosomale Region mit den signifikantesten Unterschieden zwischen Primärtumoren und Hirnmetastasen stellte sich in dieser Untersuchung der Bereich zwischen 9p13 und 9p24 dar. In diesem Bereich treten Verluste von bis zu $45 \%$ in der Gruppe der Hirnmetastasen auf, wohingegen in der Gruppe der Primärtumore nur bis zu $14 \%$ Verluste vorkommen. Dieses Ergebnis wird durch zahlreiche Ergebnisse anderer Studien, welche den Bereich von 9p untersuchten, gestützt. In diesen Studien konnte der Einfluss dieses Chromosomenbereichs auf die Tumorentstehung sowie eine frühzeitige Metastasierung nachgewiesen werden (Gunawan et al., 2001; Moch et al., 1996; Schraml et al., 2000). Im Bereich der Region 9p21 konnten die Tumorsuppressorgene p15 und p16 gefunden werden (Cairns et al., 1994; Kamb et al., 1994). In Übereinstimmung mit Cairns et al. (1995) finden sich diese Veränderungen selten in Nierenzellkarzinom-Primärtumoren (Cairns et al., 1995). Die Gene p15 und p16 finden sich in Metastasen von Nichtkleinzelligen Lungenkarzinomen und scheinen eine Rolle bei der Metastasierung von Nierenzellkarzinomen zu spielen (Kinoshita et al., 1995; Okamoto et al., 1995).

Der Verlust auf Chromosom 3p ist typisch für klarzellige Nierenzellkarzinome (Linehan und Zbar, 1987). Er findet sich in dem hier untersuchten Kollektiv der Primärtumore bei 74,6\% und im Kollektiv der Hirnmetastasen bei 77,9\%. Dieses Ergebnis steht im Gegensatz zu Ergebnissen von Gronwald et al. (1997). Gronwald et al. (1997) untersuchten klarzellige Nierenzellkarzinome und deren Metastasen unterschiedlicher Lokalisationen und konnten zeigen, dass ein Verlust von 3p häufiger in Primärtumoren, 60 \%, als in deren Metastasen, 32 \%, zu finden ist. Nach Zbar et al. (1987) ist der Verlust auf Chromosom 3p ein früh in der Entstehung von Nierenzellkarzinomen eintretendes Ereignis. 


\subsubsection{Interpretation der Ergebnisse mit unterschiedlicher Auflösung}

Betrachtet man die gewonnenen Ergebnisse auf dem Niveau von Chromosomenarmen, so ergibt dies einen ersten Anhalt über die häufigsten Veränderungen des untersuchten Kollektivs. Eine detaillierte Betrachtung eines Chromosomenarms ist auf diesem Niveau allerdings nicht möglich. Um mögliche relevante Bereiche besser einschränken zu können ist also eine höhere Auflösung nötig. Dies zeigt sich in dem hier untersuchten Kollektiv der Hirnmetastasen besonders an den Chromosomen 3p, 5q und 8p. Analysiert man diese Chromosomenbereiche auf dem Niveau der Chromosomenbanden so zeigt sich, dass bei ca. $64 \%$ der untersuchten Hirnmetastasen der Verlust auf 3p den Bereich distal der Bande 3p14 betrifft. Die Bande 3p13 zeigt dagegen einen Verlust von ca. 48 \%. Dieser Unterschied zwischen den Banden 3p13 und 3p14 lässt vermuten, dass in diesem Bereich ein Bruchpunkt vorliegt. Auf Chromosom 5q kommt es bei ca. 31 \% der Hirnmetastasen im Bereich distal der Bande 5q21 zu Zugewinnen. Die Bande 5q15 zeigt dagegen nur bei ca. $27 \%$ einen Zugewinn. Zugewinne auf dem langen Arm von Chromosom 5 betreffen also hauptsächlich den Bereich distal von Bande 5q21 (Abbildung 4.3). Auf der Suche nach möglichen Kandidatengenen sollten also besonders diese Bereiche der beiden Chromosomen untersucht werden. Da eine Auswertung der mittels CGH gewonnenen Summenideogramme eine Notation mit einer Auflösung von Chromosomenbanden möglich macht, sollte diese, gerade mit Blick auf die hier präsentierten Ergebnisse erfolgen. Die Auswertung mit einer Auflösung von Chromosomenarmen führt zu einer Ungenauigkeit, welche den Möglichkeiten der Komparativen Genomischem Hybridisierung nicht gerecht wird. 

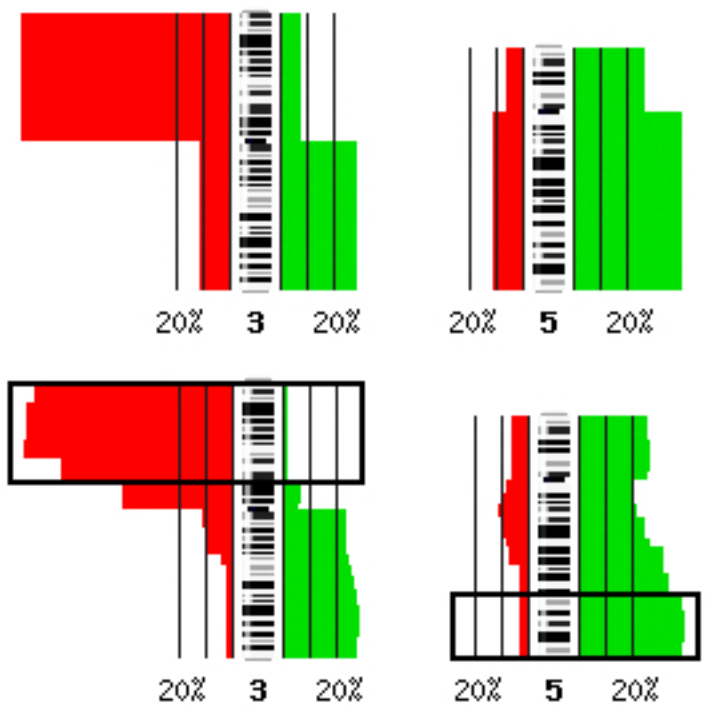

Abbildung 4.3: Summationshistogramm der Chromosomen 3 und 5 mit unterschiedlicher Auflösung

\subsection{Kritische Betrachtung der chromosomalen}

\section{Veränderungen auf 18q, 9q34 und $17 q$ und deren Einfluss auf das rezidivfreie Überleben}

Durch die Untersuchung des Intervalls zwischen Erstdiagnose und Diagnose einer Hirnmetastase bei 106 Patienten, konnten drei chromosomale Regionen detektiert werden, welche sich signifikant auf die Länge dieses Intervalls auswirken. Es handelt sich dabei um Veränderungen in den Bereichen von 18q, 9q34 und 17q.

\subsubsection{Chromosom 18q}

Die Region um den Bereich 18q21 wurde bereits für andere Tumore wie dem Kolorektalen Karzinom beschrieben. Ein Verlust in diesem Bereich führt zur Entstehung dieser Tumorentität (Fearon et al., 1990). Für die Region 18q21 wurde das Tumorsuppressorgen „Deleted in colorectal cancers“ (DCC) beschrieben (Bishop und Thomas, 1990; Hirata et al., 2005). Hirata et al. (2005) beschrieben ein vermehrtes 
Auftreten von $\mathrm{LOH}^{1}$ der Region 18q21 in Nierenzellkarzinomen bei Patienten mit familiär gehäuften Tumorerkrankungen.

Die in dieser Arbeit gefundenen Ergebnissen zeigen ein signifikant unterschiedlich langes Intervall zwischen Erstdiagnose und Diagnose einer Hirnmetastase bezogen auf einen Verlust bzw. einen Zugewinn in der Region um 18q im Vergleich zu einem unveränderten Bereich 18q. Betrachtet man diese Ergebnisse allerdings genauer so zeigt sich, dass es sich nur um einen Fall handelt, bei dem ein Zugewinn zu einem größeren Intervall bis zum Auftreten einer Hirnmetastase führte. Bei den anderen Patienten, zwischen 28 und $30 \%$ der untersuchten Hirnmetastasen, liegt ein Verlust im Bereich von 18q vor. Dieses Ergebnis steht also in Widerspruch zu den Ergbenissen der o.g. Studien. Es scheint also gerade ein Verlust im Bereich von 18q zu sein, welcher das Intervall bis zum Auftreten einer Hirnmetastase signifikant verlängert. Eine mögliche Erklärung für diese Beobachtung könnte das Onkogen bcl- $2^{2}$ sein, welches im Bereich $18 \mathrm{q} 21 \mathrm{zu}$ finden ist. Dieses wurde erstmals von Pegoraro et al. (1984) für die B-Zell-Leukämie als Ursache für eine vermehrte B-Zell-Proliferation beschrieben.

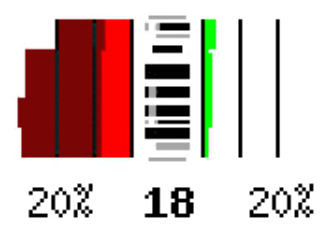

\begin{abstract}
Abbildung 4.4: Summationshistogramm von Chromosom 18 aus den Ergebnissen der Primärtumore (hellrot $=$ Verluste, hellgrün $=$ Zugewinne) und der Hirnmetastasen $($ dunkelrot $=$ Verluste, dunkelgrün $=$ Zugewinne $)$
\end{abstract}

\title{
4.4.2 Chromosom 9q34
}

Als weitere Region welche das Intervall zwischen Diagnose des Primärtumors und einer Hirnmetastase signifikant beeinflusst zeigte sich in dieser Arbeit der Bereich

1 loss of heterocygosity

2 B-cell lymphoma 2 
um Chromosom 9q34. Ist dieser Bereich unverändert, tritt eine Hirnmetastase signifikant früher auf als bei einem Verlust in diesem Bereich. Eine unveränderte Chromosomenbande 9q34 fand sich bei $54 \%$, ein Verlust dagegen bei $46 \%$ der untersuchten Hirnmetastasen. In der Region 9q34 liegt das abl ${ }^{1}$-Gen welches für eine Tyrosinkinase kodiert und durch eine Translokation auf Chromosom 22 das sog. Philadelphia-Chromosom bildet. Dieses spielt die entscheidende Rolle in der Entstehung der Chronisch Myeloischen Leukämie (Klein et al., 1982). Beschrieben wurde es erstmals als Teil eines onkogenen Virus der Maus (Abelson und Rabstein, 1970). Dies könnte erklären warum ein Verlust und damit eine Inaktivierung dieser Tyrosinkinase zu einer verminderten Zellproliferation führt.

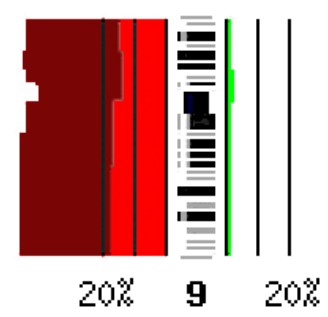

Abbildung 4.5: Summationshistogramm von Chromosom 9 aus den Ergebnissen der Primärtumore (hellrot $=$ Verluste, hellgrün = Zugewinne) und der Hirnmetastasen $($ dunkelrot $=$ Verluste, dunkelgrün $=$ Zugewinne $)$

\subsubsection{Chromosom $17 \mathrm{q}$}

Als dritter, das Intervall zwischen Erstdiagnose und Diagnose einer Hirnmetastase beeinflussende chromosomale Abschnitt fand sich die Region 17q. Ist dieser Bereich unverändert, so tritt eine Hirnmetastase erst nach 27 Monaten auf, bei einem Zugewinn in diesem Bereich bereits schon nach 9 Monaten. Bei 9 bis $10 \%$ der untersuchten Hirnmetastasen waren die Banden von Chromosom 17q unverändert, Zugewinne fanden sich bei 2 bis $7 \%$. In Übereinstimmung mit Ergebnissen von Hirasawa et al. (2003), welche klarzellige Adenokarzinome des Ovars mittels CGH untersuchten, zeigt sich als herausragende Veränderung, welche das Intervall zwischen

1 Abelson 
Erstdiagnose und Diagnose einer Hirnmetastase negativ beeinflusst, ein Zugewinn in der Region 17q21. Stumm et al. (1996) konnten zeigen, dass eine Überexpression des erbb2 Gens mit einer Dedifferenzierung und Metastasierung bei Nierenzellkarzinomen korreliert. Junker et al. (2000) untersuchten Nierenzellkarzinome und deren korrespondierenden Metastasen sowie nicht metastasierte Nierenzellkarzinome. Sie konnten zeigen, dass Zugewinne auf Chromosom 17 sowie Verluste auf den Chromosomen 6, 9, 10 und 18 in Zusammenhang mit dem Auftreten einer Metastase innerhalb von zwei Jahren nach Operation des Primärtumors steht. Ein Zugewinn auf Chromosom 17 steht in Zusammenhang mit dem Auftreten von Lymphknotenmetastasen bei invasiven Adenokarzinomen der Brust (Herrington et al., 1995). Im Bereich von 17q21q22 findet sich das Protoonkogen HER2/neu ${ }^{1}$, welches für den Epidermalen Wachstumsfaktor Rezeptor $\left(\mathrm{EGFR}^{2}\right)$ kodiert und eine Rolle u.a. in der Entstehung von Mammakarzinomen spielt (Coussens et al., 1985; King et al., 1985).

Von den drei in dieser Arbeit beschriebenen chromosomalen Veränderungen, welche das rezidivfreie Überleben signifikant beeinflussen, finden sich die Veränderungen im Bereich von Chromosom 9q sowie 18q unter den 163 Chromosomenbanden, in denen sich die hier untersuchten Primärtumore und Hirnmetastasen signifikant unterscheiden. Dies legt die Vermutung nahe, dass Veränderungen im Bereich von 9q sowie 18q nach Absiedelung vom Primärtumor von den Metastasen erworben wurden. Im Bereich von 17q hingegen unterscheiden sich die hier untersuchten Primärtumore und Hirnmetastasen nicht signifikant. Veränderungen in diesem Bereich müssen also bereits vor Absiedelung der metastatischen Zellen im Primärtumor vorgelegen haben.

Jiang et al. (2000) berechneten aus CGH-Ergebnissen ein Baummodell für klarzellige Nierenzellkarzinome und fanden so zwei Gruppen von Tumoren welche sich hinsichtlich ihrer Aberrationen auf den Chromosomen 9 und 17 unterschieden. Danach verfügt eine Gruppe über Verluste auf Chromosom 9p, die andere über Zugewinne auf Chromosom 17q. Dieses Ergebnis legt in Zusammenschau mit den

1 human epidermal growth factor receptor 2

2 epidermal growth factor receptor 
hier vorgestellten Ergebnissen die Vermutung nahe, dass es sich bei klarzelligen Nierenzellkarzinomen mit Zugewinn auf Chromosom 17q um eine eigenständige Untergruppe handelt, welche früh zu symptomatischen Hirnmetastasen führt.

Da die Methode der Komparativen Genomischen Hybridisierung mit einer Auflösung von maximal 10 bis $20 \mathrm{Mb}$ zu ungenau ist um einzelne Banden als verändert bewerten zu können, müssen diese Ergebnisse trotz starker signifikanter Unterschiede kritisch betrachtet werden. Vielmehr sollte man die gefundenen signifikant veränderten Banden als Anlass nehmen, in ihrem Bereich mit genaueren Methoden nach möglichen veränderten Genen zu suchen. Die Methode der Komparativen Genomischen Hybridisierung mit ihrer gegenüber neueren Methoden relativen Unschärfe dient also der Detektion veränderter Chromosomenabschnitte und stellt die Grundlage für präzisere Untersuchungen dar.

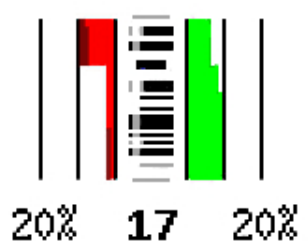

\begin{abstract}
Abbildung 4.6: Summationshistogramm von Chromosom 17 aus den Ergebnissen der Primärtumore (hellrot $=$ Verluste, hellgrün = Zugewinne) und der Hirnmetastasen $($ dunkelrot $=$ Verluste, dunkelgrün $=$ Zugewinne)
\end{abstract}

\title{
4.5 Ausblick
}

Die in dieser Arbeit vorgestellten Ergebnisse weisen auf chromosomale Regionen hin, welche den Zeitpunkt des Auftretens einer Hirnmetastase klarzelliger Nierenzellkarzinomen beeinflussen. In zukünftigen Studien sollten diese chromosomalen Regionen mit genaueren Methoden untersucht werden um mögliche Kandidatengene für eine Metastasierung nachweisen zu können. Nach Pomer et al. (1997) gilt die Länge des Intervalls zwischen Diagnose des Primärtumors und Diagnose der Hirnmetastase als wichtigster die Prognose bestimmende Faktor. Die Ergebnisse von Jiang et al. 
(2000) zeigen, dass Tumore mit Verlusten auf Chromosom 9p bzw. Zugewinnen auf Chromosom 17q zwei getrennt von einander zu betrachtende Untergruppen klarzelliger Nierenzellkarzinome darstellen. Daraus lässt sich folgern, dass klarzellige Nierenzellkarzinome zukünftig auf diese hier vorgestellten chromosomalen Regionen hin untersucht werden sollten, um bereits bei der Diagnose des Primärtumors das Risiko einer möglichen Hirnmetastasierung abschätzen zu können. Diese hier beschriebenen Veränderungen könnten also von diagnostischer und therapeutischer Bedeutung für Patienten mit Nierenzellkarzinomen des klarzelligen Typs sein. 


\section{Zusammenfassung}

Nierenzellkarzinome treten mit einem Anteil von 1,9\% aller malignen Tumore und weltweit 208.000 Neuerkrankungen pro Jahr relativ selten auf. Es finden sich sporadische sowie hereditäre Formen. Die Diagnose einer Hirnmetastase gilt als Terminalstadium in der Behandlung von Nierenzellkarzinomen. Maligne Tumore der Niere werden nach der Weltgesundheitsorganisation in zehn maligne Raumforderungen unterteilt:

- Klarzellige Nierenzellkarzinome

- Multilokulär klarzellige Nierenzellkarzinome

- Papilläre Nierenzellkarzinome

- Chromophobe Nierenzellkarzinome

- Karzinome der Sammelrohre

- Medulläre Nierenzellkarzinome

- Nierenzellkarzinome mit Xp11-Translokation

- mit Neuroblastomen assoziierte Nierenzellkarzinome

- Muzinös tubuläre und Spindelzellkarzinome

- unklassifizierbare Nierenzellkarzinome.

In molekularzytogenetischen Untersuchungen klarzelliger Nierenzellkarzinome konnte als herausragende Veränderung ein Verlust genetischen Materials durch Translokation oder Deletion auf dem kurzen Arm jeweils eines Chromosoms 3 (3p) 
nachgewiesen werden. Publikationen, welche Hirnmetastasen von klarzelligen Nierenzellkarzinomen mittels Komparativer Genomischer Hybridisierung untersuchten, konnten bis zum Abschluss dieser Dissertation nicht gefunden werden.

Eine Korrelation von chromosomalen Veränderungen und klinischen Daten wurde 2001 von Gunawan et al. und 2009 von Junker et al. publiziert. Dabei konnte gezeigt werden, dass ein Zugewinn in der Region 5q31qter für eine hervorragende Prognose und eine längere Überlebenszeit steht. Dagegen scheint ein Verlust auf Chromosom 9 bzw. dem kurzen Arm dieses Chromosoms, 9p, für eine frühzeitige Metastasierung zu sprechen.

Die von Kallioniemi A et al. (1992) und du Manoir et al. (1993) beschriebene komparative genomische Hybridisierung (CGH) ermöglicht einen umfassenden Überblick über chromosomale Verluste und Zugewinne des gesamten Genoms eines Tumors. Es werden dazu mit Fluoreszenzfarbstoffen markierte Tumor-DNS sowie Referenz-DNS aus gesundem Normalgewebe auf menschliche Metaphasenchromosomen hybridisiert. Das Verhältnis zwischen den unterschiedlich fluoreszierenden Anteilen entlang der Chromosomenachse repräsentiert Verluste bzw. Zugewinne genetischen Materials im Tumor.

Durch die Analyse von Hirnmetastasen klarzelliger Nierenzellkarzinome mittels CGH sowie durch den Vergleich dieser Resultate mit Ergebnissen von Primärtumoren des klarzelligen Typs konnten chromosomale Veränderungen gefunden werden, welche unabhängig von klonalen Einflüssen sind.

In dieser Dissertation wurden 181 Hirnmetastasen klarzelliger Nierenzellkarzinome mittels CGH untersucht und mit CGH-Ergebnissen von Primärtumoren des klarzelligen Typs verglichen. Hirnmetastasen klarzelliger Nierenzellkarzinome zeigen als herausragende Veränderungen Verluste auf den Chromosomen 3p und 9 sowie Zugewinne auf den Chromosomen 5q und 7. Als signifikantester Unterschied zwischen Primärtumor und Hirnmetastase zeigte sich Chromosom 9. 
Eine Analyse der Zeit zwischen Erstdiagnose und Diagnose einer Hirnmetastase zeigte ein durchschnittliches Intervall von 53 Monaten. Drei Chromosomenregionen scheinen dieses Intervall zu beeinflussen. Die Korrelation der CGH-Ergebnisse mit dem rezidivfreien Überleben zeigte, dass insbesondere chromosomale Veränderungen auf den Chromosomen 18q, 9q34 und 17q diesen Zeitraum negativ bzw. positiv beeinflussen.

Ein Verlust im Bereich von 18q führt zum Auftreten einer Hirnmetastase nach 60 Monaten; ist dieser Bereich unverändert, tritt eine Hirnmetastase bereits nach 17 Monaten auf. Ein Verlust im Bereich von Chromosom 9q34 führt zu einem Auftreten einer Hirnmetastase nach 59 Monaten. Keine Veränderung in diesem Bereich führt bereits nach 15 Monaten zum Auftreten einer Hirnmetastase. Ein Zugewinn im Bereich von Chromosom 17q führt bereits nach 9 Monaten zum Auftreten einer Hirnmetastase. Ist dieser Bereich dagegen unverändert, so kommt es erst nach 27 Monaten zum Auftreten einer Hirnmetastase.

Aus den beschriebenen Ergebnissen lässt sich schließen, dass eine Analyse der Primärtumore vom klarzelligen Typ auf chromosomale Veränderungen im Bereich von 18q, 9q34 und 17q eine prognostische Relevanz besitzt, welche das weitere diagnostische und therapeutische Vorgehen bei klarzelligen Nierenzellkarzinomen in Zukunft beeinflussen könnte. 


\section{Literaturverzeichnis}

Abelson HT, Rabstein LS (1970): Lymphosarcoma: Virus-induced Thymicindependent Disease in Mice. Cancer Res $\underline{30}$, 2213-2222 (Zitiert auf Seite 61)

Astner ST, Nieder C, Grosu AL, Molls M (2008): Radiotherapy for intracerebral metastases. Onkologe 14, 246-254 (Zitiert auf Seite 9)

Barnholtz-Sloan JS, Sloan AE, Davis FG, Vigneau FD, Lai P, Sawaya RE (2004): Incidence proportions of brain metastases in patients diagnosed (1973 to 2001) in the Metropolitan Detroit Cancer Surveillance System. J Clin Oncol 22, 2865-2872 (Zitiert auf Seite 9)

Batzler WU, Giersiepen K, Hentschel S, Husmann G, Kaatsch P, Katalinic A, Kieschke J, Kraywinkel K, Meyer M, Stabenow R: Krebs in Deutschland 20032004. Häufigkeiten und Trends. 6. überarbeitete Auflage, hrsg. v. Robert KochInstitut und Gesellschaft der epidemiologischen Krebsregister in Deutschland e.V.. Berlin 2008 (Zitiert auf Seite 4)

Baudis M: Progenetix - cytogenetic abnormalities in human cancer. 2000. Verfügbar unter: www.progenetix.net (Zitiert auf Seiten 37, 38 und 40)

Baudis M (2007): Genomic imbalances in 5918 malignant epithelial tumors: an explorative meta-analysis of chromosomal CGH data. BMC Cancer $\underline{7}, 226$ (Zitiert auf Seite 10)

Baudis M (2009a): ISCN2ProgenetiXML - ISCN annotation conversion and visualization. Progenetix Website. 2009. Verfügbar unter: http://www.progenetix. net/cgi-bin/front_ISCN2matrix.cgi (Zitiert auf Seite 37) 
Baudis M (2009b): (Preliminary) Guide to the Progenetix Analysis Tools. Progenetix Website. 2009. Verfügbar unter: http://www.progenetix.net/progenetix/ presentations/Progenetix_analysis_guide.pdf (Zitiert auf Seite 37)

Baudis M, Cleary ML (2001): Progenetix.net: an online repository for molecular cytogenetic aberration data. Bioinformatics $\underline{17}$, 1228-1229 (Zitiert auf Seiten 37, 44, 45, 46 und 47)

Bendell JC, Domchek SM, Burstein HJ, Harris L, Younger J, Kuter I, Bunnell C, Rue M, Gelman R, Winer E (2003): Central nervous system metastases in women who receive trastuzumab-based therapy for metastatic breast carcinoma. Cancer 97, 2972-2977 (Zitiert auf Seite 8)

Benjamini Y, Hochberg Y (1995): Controlling the False Discovery Rate: a Practical and Powerfull Approach to Multiple Testing. J R Stat Soc Series B Stat Methodol 57, 289-300 (Zitiert auf Seite 40)

Bishop DT, Thomas HJ (1990): The genetics of colorectal cancer. Cancer Surv $\underline{9}, 585-$ 604 (Zitiert auf Seite 59)

Bissig H, Richter J, Desper R, Meier V, Schraml P, Schaffer AA, Sauter G, Mihatsch MJ, Moch H (1999): Evaluation of the clonal relationship between primary and metastatic renal cell carcinoma by comparative genomic hybridization. Am J Pathol 155, 267-274 (Zitiert auf Seiten 11 und 106)

Bodmer D, van den Hurk W, van Groningen JJM, Eleveld MJ, Martens GJM, Weterman MAJ, van Kessel AG (2002): Understanding familial and non-familial renal cell cancer. Hum Mol Genet 11, 2489-2498 (Zitiert auf Seite 10)

Bonner J, Kung G, Bekhor I (1967): A method for the hybridization of nucleic acid molecules at low temperature. Biochemistry $\underline{6}, 3650-3653$ (Zitiert auf Seite 31)

Brigati DJ, Myerson D, Leary JJ, Spalholz B, Travis SZ, Fong CK, Hsiung GD, Ward DC (1983): Detection of viral genomes in cultured cells and paraffin-embedded tissue sections using biotin-labeled hybridization probes. Virology 126, 32-50 (Zitiert auf Seiten 20 und 28) 
Brunelli M, Eccher A, Gobbo S, Ficarra V, Novara G, Cossu-Rocca P, Bonetti F, Menestrina F, Cheng L, Eble JN, Martignoni G (2008): Loss of chromosome $9 \mathrm{p}$ is an independent prognostic factor in patients with clear cell renal cell carcinoma. Mod Pathol 21, 1-6 (Zitiert auf Seiten 12 und 55)

Cairns P, Mao L, Merlo A, Lee DJ, Schwab D, Eby Y, Tokino K, van der Riet P, Blaugrund JE, Sidransky D (1994): Rates of p16 (MTS1) mutations in primary tumors with 9p loss. Science 265, 415-417 (Zitiert auf Seite 57)

Cairns P, Tokino K, Eby Y, Sidransky D (1995): Localization of tumor suppressor loci on chromosome 9 in primary human renal cell carcinomas. Cancer Res $\underline{55}, 224$ 227 (Zitiert auf Seite 57)

Chen XF, Zhou FJ, Han H, Qin ZK, Liu ZW, Yu SL, Li YH, Wang H, Hou GL (2007): Transabdominal radical nephrectomy for renal cell carcinoma: an experience on 155 patients. Ai Zheng 26, 528-532 (Zitiert auf Seite 6)

Cheville JC, Lohse CM, Zincke H, Weaver AL, Blute ML (2003): Comparisons of outcome and prognostic features among histologic subtypes of renal cell carcinoma. Am J Surg Pathol 27, 612-624 (Zitiert auf Seite 7)

Cohen AJ, Li FP, Berg S, Marchetto DJ, Tsai S, Jacobs SC, Brown RS (1979): Hereditary renal-cell carcinoma associated with a chromosomal translocation. N Engl J Med 301, 592-595 (Zitiert auf Seite 10)

Coussens L, Yang-Feng TL, Liao YC, Chen E, Gray A, McGrath J, Seeburg PH, Libermann TA, Schlessinger J, Francke U (1985): Tyrosine kinase receptor with extensive homology to EGF receptor shares chromosomal location with neu oncogene. Science 230, 1132-1139 (Zitiert auf Seite 62)

de Klein A, van Kessel AG, Grosveld G, Bartram CR, Hagemeijer A, Bootsma D, Spurr NK, Heisterkamp N, Groffen J, Stephenson JR (1982): A cellular oncogene is translocated to the Philadelphia chromosome in chronic myelocytic leukaemia. Nature 300, 765-767 (Zitiert auf Seite 61) 
Dhote R, Pellicer-Coeuret M, Thiounn N, Debre B, Vidal-Trecan G (2000): Risk factors for adult renal cell carcinoma: a systematic review and implications for prevention. BJU Int $\underline{86}$, 20-27 (Zitiert auf Seite 5)

Doty P, Marmur J, Eigner J, Schildkraut C (1960): Strand Separation and Specific Recombination in Deoxyribonucleic Acids: Physical Chemical Studies. Proc Natl Acad Sci U S A $\underline{46}$, 461-476 (Zitiert auf Seite 31)

du Manoir S, Speicher MR, Joos S, Schrock E, Popp S, Dohner H, Kovacs G, Robert-Nicoud M, Lichter P, Cremer T (1993): Detection of complete and partial chromosome gains and losses by comparative genomic in situ hybridization. Hum Genet 90, 590-610 (Zitiert auf Seiten 13, 14, 20, 52 und 66)

du Manoir S, Schröck E, Bentz M, Speicher MR, Joos S, Ried T, Lichter P, Cremer T (1995): Quantitative analysis of comparative genomic hybridization. Cytometry 19, 27-41 (Zitiert auf Seiten 14, 34 und 52)

Eble JN, Sauter G, Epstein JI, Sesterhenn IA: Pathology and Genetics of Tumours of the Urinary System and Male Genital Organs. IARCPress International Agency for Research on Cancer (IARC) 69008 Lyon/France 2004 (Zitiert auf Seite 7)

Ehrlich SD, Bertazzoni U, Bernardi G (1973): The specificity of pancreatic deoxyribonuclease. Eur J Biochem 므, 143-147 (Zitiert auf Seite 27)

Fearon ER, Hamilton SR, Vogelstein B (1987): Clonal analysis of human colorectal tumors. Science 238, 193-197 (Zitiert auf Seite 12)

Fearon ER, Vogelstein B (1990): A genetic model for colorectal tumorigenesis. Cell $\underline{61}, 759-767$ (Zitiert auf Seiten )

Fearon ER, Cho KR, Nigro JM, Kern SE, Simons JW, Ruppert JM, Hamilton SR, Preisinger AC, Thomas G, Kinzler KW (1990): Identification of a chromosome 18q gene that is altered in colorectal cancers. Science 247, 49-56 (Zitiert auf Seite 59)

Ficarra V, Righetti R, Pilloni S, D'amico A, Maffei N, Novella G, Zanolla L, Malossini G, Mobilio G (2002): Prognostic factors in patients with renal cell carcinoma: retrospective analysis of 675 cases. Eur Urol 41, 190-198 (Zitiert auf Seiten 6 und 7) 
Figlin RA (1999): Renal cell carcinoma: management of advanced disease. J Urol 161, 381-386 (Zitiert auf Seite 5)

Fischer CG (1999): Etiology, pathogenesis and therapy of renal cell carcinoma. Radiologe 39, 343-349 (Zitiert auf Seite 6)

Flaherty KT, Fuchs CS, Colditz GA, Stampfer MJ, Speizer FE, Willett WC, Curhan GC (2005): A prospective study of body mass index, hypertension, and smoking and the risk of renal cell carcinoma (United States). Cancer Causes Control 16, 1099-1106 (Zitiert auf Seite 5)

Foley FB, Mulvaney WP, Richardson EJ, Victor I (1952): Radical nephrectomy for neoplasms. J Urol $\underline{68}$, 39-49 (Zitiert auf Seite 6)

Foulds L (1954): The experimental study of tumor progression: a review. Cancer Res 14, 327-339 (Zitiert auf Seite 12)

Gatenby RA (1991): Population ecology issues in tumor growth. Cancer Res $\underline{51}, 2542-$ 2547 (Zitiert auf Seite 13)

Gatenby RA (1995): Models of tumor-host interaction as competing populations: implications for tumor biology and treatment. J Theor Biol $\underline{176}, 447-455$ (Zitiert auf Seite 12)

Gavrilovic IT, Posner JB (2005): Brain metastases: epidemiology and pathophysiology. J Neurooncol 75, 5-14 (Zitiert auf Seite 8)

Gayrard N, Cacheux V, Iborra F, Mourad G, Argiles A (2008): Cytogenetic studies of 24 renal epithelial tumors with von Hippel-Lindau and fragile histidine triad protein expression correlation. Arch Pathol Lab Med 132, 965-973 (Zitiert auf Seiten 110 und 111)

Glasel JA (1995): Validity of nucleic acid purities monitored by 260nm/280nm absorbance ratios. Biotechniques $\underline{18}$, 62-63 (Zitiert auf Seite 24)

Goelz SE, Hamilton SR, Vogelstein B (1985): Purification of DNA from formaldehyde fixed and paraffin embedded human tissue. Biochem Biophys Res Commun 130, 118-126 (Zitiert auf Seite 24) 
Griffin N, Gore ME, Sohaib SA (2007): Imaging in metastatic renal cell carcinoma. AJR Am J Roentgenol 189, 360-370 (Zitiert auf Seite 5)

Gronwald J, Storkel S, Holtgreve-Grez H, Hadaczek P, Brinkschmidt C, Jauch A, Lubinski J, Cremer T (1997): Comparison of DNA gains and losses in primary renal clear cell carcinomas and metastatic sites: importance of $1 \mathrm{q}$ and 3p copy number changes in metastatic events. Cancer Res $\underline{57}$, 481-487 (Zitiert auf Seiten 11, 57, 105 und 106)

Gudbjartsson T, Hardarson S, Petursdottir V, Thoroddsen A, Magnusson J, Einarsson GV (2005): Histological subtyping and nuclear grading of renal cell carcinoma and their implications for survival: a retrospective nation-wide study of 629 patients. Eur Urol 4ㅇ, 593-600 (Zitiert auf Seite 6)

Gunawan B, Huber W, Holtru, M, von Heydebreck A, Efferth T, Poustka A, Ringert RH, Jakse G, Fuzesi L (2001): Prognostic impacts of cytogenetic findings in clear cell renal cell carcinoma: gain of 5q31-qter predicts a distinct clinical phenotype with favorable prognosis. Cancer Res $\underline{61}$, 7731-7738 (Zitiert auf Seiten 10, 12, 54 und 57)

Hanahan D, Weinberg RA (2000): The hallmarks of cancer. Cell 100, 57-70 (Zitiert auf Seiten 12, 13 und 55)

Harada Y, Nonomura N, Kondo M, Nishimura K, Takahara S, Miki T, Okuyama A (1999): Clinical study of brain metastasis of renal cell carcinoma. Eur Urol 36, 230-235 (Zitiert auf Seite 9)

Heffess CS, Wenig BM, Thompson LD (2002): Metastatic renal cell carcinoma to the thyroid gland: a clinicopathologic study of 36 cases. Cancer $\underline{95}, 1869-1878$ (Zitiert auf Seite 56)

Helling RB, Goodman HM, Boyer HW (1974): Analysis of endonuclease R-EcoRI fragments of DNA from lambdoid bacteriophages and other viruses by agarose-gel electrophoresis. J Virol 14, 1235-1244 (Zitiert auf Seite 22) 
Herrington CS, Leek RD, McGee JO (1995): Correlation of numerical chromosome 11 and 17 imbalance with metastasis of primary breast cancer to lymph nodes. J Pathol 176, 353-359 (Zitiert auf Seite 62)

Hirasawa A, Saito-Ohara F, Inoue J, Aoki D, Susumu N, Yokoyama T, Nozawa S, Inazawa J, Imoto I (2003): Association of 17q21-q24 gain in ovarian clear cell adenocarcinomas with poor prognosis and identification of PPM1D and APPBP2 as likely amplification targets. Clin Cancer Res $\underline{9}, 1995-2004$ (Zitiert auf Seite 61)

Hirata H, Matsuyama H, Matsumoto H, Korenaga Y, Ohmi C, Sakano S, Yoshihiro S, Naito K (2005): Deletion mapping of 18q in conventional renal cell carcinoma. Cancer Genet Cytogenet 163, 101-105 (Zitiert auf Seite 59)

Houldsworth J, Chaganti RS (1994): Comparative genomic hybridization: an overview. Am J Pathol 145, 1253-1260 (Zitiert auf Seite 21)

Isola J, DeVries S, Chu L, Ghazvini S, Waldman F (1994): Analysis of changes in DNA sequence copy number by comparative genomic hybridization in archival paraffin-embedded tumor samples. Am J Pathol 145, 1301-1308 (Zitiert auf Seiten 24 und 52)

Izumi H, Hara T, Oga A, Matsuda K, Sato Y, Naito K, Sasaki K (2002): High telomerase activity correlates with the stabilities of genome and DNA ploidy in renal cell carcinoma. Neoplasia $\underline{4}, 103-111$ (Zitiert auf Seite 108)

James LA (1999): Comparative genomic hybridization as a tool in tumour cytogenetics. J Pathol 187, 385-395 (Zitiert auf Seite 52)

Jiang F, Desper R, Papadimitriou CH, Schaffer AA, Kallioniemi OP, Richter J, Schraml P, Sauter G, Mihatsch MJ, Moch H (2000): Construction of evolutionary tree models for renal cell carcinoma from comparative genomic hybridization data. Cancer Res $\underline{60}$, 6503-6509 (Zitiert auf Seiten 62 und 63)

Joos S, Scherthan H, Speicher MR, Schlegel J, Cremer T, Lichter P (1993): Detection of amplified DNA sequences by reverse chromosome painting using genomic tumor DNA as probe. Hum Genet $\underline{90}$, 584-589 (Zitiert auf Seite 52) 
Junker K, Schlichter A, Hindermann W, Schubert J (1999): Genetic characterization of multifocal tumor growth in renal cell carcinoma. Kidney Int 56, 1291-1294 (Zitiert auf Seite 110)

Junker K, Moravek P, Podhola M, Weirich G, Hindermann W, Janitzky V, Schubert J (2000): Genetic alterations in metastatic renal cell carcinoma detected by comparative genomic hybridization: correlation with clinical and histological data. Int J Oncol 17, 903-908 (Zitiert auf Seite 62)

Junker K, Sanger J, Schmidt A, Hindermann W, Presselt N, Helfritzsch H, Schubert J (2003): Genetic characterization of lung metastases in renal cell carcinoma. Oncol Rep 10, 1035-1038 (Zitiert auf Seiten 10, 11, 54 und 105)

Junker K, Romics I, Szendroi A, Riesz P, Moravek P, Hindermann W, Winter R, Schubert J (2004): Genetic profile of bone metastases in renal cell carcinoma. Eur Urol $\underline{45}$, 320-324 (Zitiert auf Seiten 11 und 105)

Junker K, Steiner T, Sanjmyatav J, Pilchowski R, Heinze C, Walter M, Schubert J (2009): Tumor profiling of renal cell tumors: relevance for diagnostics and therapy. Pathologe $\underline{30}, 105-110$ (Zitiert auf Seite 12)

Kallio JP, Mahlamaki EH, Helin H, Karhu R, Kellokumpu-Lehtinen P, Tammela TLJ (2004): Chromosomal gains and losses detected by comparative genomic hybridization and proliferation activity in renal cell carcinoma. Scand J Urol Nephrol 38, 225-230 (Zitiert auf Seite 110)

Kallioniemi A, Kallioniemi OP, Sudar D, Rutovitz D, Gray JW, Waldman F, Pinkel D (1992): Comparative genomic hybridization for molecular cytogenetic analysis of solid tumors. Science 258, 818-821 (Zitiert auf Seiten 13, 14, 20, 52 und 66)

Kallioniemi OP, Kallioniemi A, Piper J, Isola J, Waldman FM, Gray JW, Pinkel D (1994): Optimizing comparative genomic hybridization for analysis of DNA sequence copy number changes in solid tumors. Genes Chromosomes Cancer 10, 231-243 (Zitiert auf Seiten 14, 20, 21, 28, 37 und 52) 
Kamb A, Liu Q, Harshman K, Tavtigian S, Cordon-Cardo C, Skolnick M (1994): Rates of p16 (MTS1) mutations in primary tumors with 9p loss. Science 264, 416-417 (Zitiert auf Seite 57)

Karnofsky DA, Burchenal JH: The Clinical Evaluation of Chemotherapeutic Agents in Cancer. in: Evaluation of Chemotherapeutic Agents; hrsg. v. MacLeod CM, Columbia Univ Press New York City USA 1949 (Zitiert auf Seite 7)

Kelly RB, Cozzarelli NR, Deutscher MP, Lehman IR, Kornberg A (1970): Enzymatic synthesis of deoxyribonucleic acid. XXXII. Replication of duplex deoxyribonucleic acid by polymerase at a single strand break. J Biol Chem $\underline{245}$, 39-45 (Zitiert auf Seite 28)

King CR, Kraus MH, Aaronson SA (1985): Amplification of a novel v-erbB-related gene in a human mammary carcinoma. Science 229, 974-976 (Zitiert auf Seite 62)

Kinoshita H, Yamada H, Ogawa O, Kakehi Y, Osaka M, Nakamura E, Mishina M, Habuchi T, Takahashi R, Sugiyama T (1995): Contribution of chromosome 9p21-22 deletion to the progression of human renal cell carcinoma. Jpn J Cancer

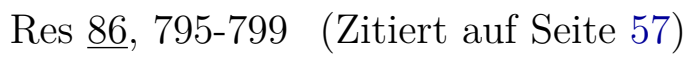

Knudson AG Jr (1971): Mutation and cancer: statistical study of retinoblastoma. Proc Natl Acad Sci U S A $\underline{68}$, 820-823 (Zitiert auf Seite 5)

Komminoth P (1992): Digoxigenin as an alternative probe labeling for in situ hybridization. Diagn Mol Pathol 1, 142-150 (Zitiert auf Seiten 20 und 28)

Korczak B, Robson IB, Lamarche C, Bernstein A, Kerbel RS (1988): Genetic tagging of tumor cells with retrovirus vectors: clonal analysis of tumor growth and metastasis in vivo. Mol Cell Biol $\underline{8}, 3143-3149$ (Zitiert auf Seite 12)

Kornberg A, Lieberman I, Simms ES (1955 a): Enzymatic synthesis and properties of 5-phosphoribosylpyrophosphate. J Biol Chem 215, 389-402 (Zitiert auf Seite 27)

Kornberg A, Lieberman I, Simms ES (1955 b): Enzymatic synthesis of purine nucleotides. J Biol Chem $\underline{215}$, 417-427 (Zitiert auf Seite 27) 
Kovacs G, Akhtar M, Beckwith BJ, Bugert P, Cooper CS, Delahunt B, Eble JN, Fleming S, Ljungberg B, Medeiros LJ (1997): The Heidelberg classification of renal cell tumours. J Pathol $\underline{183}, 131-133$ (Zitiert auf Seite 5)

Lamiell JM, Salazar FG, Hsia YE (1989): von Hippel-Lindau disease affecting 43 members of a single kindred. Medicine (Baltimore) $\underline{68}, 1-29$ (Zitiert auf Seite 4)

Landegent JE, Jansen in de Wal N, Dirks RW, Baao F, van der Ploeg M (1987): Use of whole cosmid cloned genomic sequences for chromosomal localization by non-radioactive in situ hybridization. Hum Genet $\underline{77}$, 366-370 (Zitiert auf Seiten 20 und 32)

Lichter P, Cremer T, Borden J, Manuelidis L, Ward DC (1988): Delineation of individual human chromosomes in metaphase and interphase cells by in situ suppression hybridization using recombinant DNA libraries. Hum Genet $\underline{80}$, 224234 (Zitiert auf Seite 32)

Lieberman I, Kornberg A, Simms ES (1955): Enzymatic synthesis of nucleoside diphosphates and triphosphates. J Biol Chem 215, 429-440 (Zitiert auf Seite 27)

Linehan WM, Zbar B (1987): Loss of DNA sequences on chromosome 3 in renal cell carcinoma. Urology 30, 404 (Zitiert auf Seite 57)

Ljungberg B, Hanbury DC, Kuczyk MA, Merseburger AS, Mulders PFA, Patard JJ, Sinescu IC (2007): Renal cell carcinoma guideline. Eur Urol 51, 1502-1510 (Zitiert auf Seiten 6 und 9)

Lopez-Beltran A, Scarpelli M, Montironi R, Kirkali Z (2006): 2004 WHO classification of the renal tumors of the adults. Eur Urol $\underline{49}$, 798-805 (Zitiert auf Seite 8)

Lundsteen C, Maahr J, Christensen B, Bryndorf T, Bentz M, Lichter P, Gerdes $\mathrm{T}$ (1995): Image analysis in comparative genomic hybridization. Cytometry $\underline{19}$, 42-50 (Zitiert auf Seite 34)

Mai KT, Landry DC, Robertson SJ, Commons AS, Burns BF, Thijssen A, Collins J (2001): A comparative study of metastatic renal cell carcinoma with correlation to subtype and primary tumor. Pathol Res Pract 197, 671-675 (Zitiert auf Seite 8) 
Maldazys JD, deKernion JB (1986): Prognostic factors in metastatic renal carcinoma. J Urol 136, 376-379 (Zitiert auf Seite 7)

Marmur J, Lane D (1960): Strand Separation and Specific Recombination in Deoxyribonucleic Acids: Biological Studies. Proc Natl Acad Sci U S A $\underline{46}$, 453-461 (Zitiert auf Seite 31)

MEDLINE - Medical Literature Analysis and Retrieval System Online (o. Verf.). United States National Library of Medicine. Bethesda, 2009. Verfügbar über das Internetportal PubMed: http://www.ncbi.nlm.nih.gov/pubmed/. Zugriff am 16.07.2008. (Zitiert auf Seite 38)

Mellemgaard A, Lindblad P, Schlehofer B, Bergstrom R, Mandel JS, McCredie M, McLaughlin JK, Niwa S, Odaka N, Pommer W (1995): International renal-cell cancer study. III. Role of weight, height, physical activity, and use of amphetamines. Int J Cancer $\underline{60}$, 350-354 (Zitiert auf Seite 5)

Meselson M, Stahl FW (1958): The replication of DNA. Cold Spring Harb Symp Quant Biol 23, 9-12 (Zitiert auf Seite 31)

Michor F (2005): Chromosomal instability and human cancer. Philos Trans R Soc Lond B Biol Sci 360, 631-635 (Zitiert auf Seite 12)

Mitelman F, Johansson B, Mertens F. Mitelman Database of Chromosome Aberrations in Cancer. 2009. Verfügbar unter: http://cgap.nci.nih.gov/ Chromosomes/Mitelman. Zugriff am 16.07.2008. (Zitiert auf Seite 38)

Moch H, Presti JC Jr, Sauter G, Buchholz N, Jordan P, Mihatsch MJ, Waldman FM (1996): Genetic aberrations detected by comparative genomic hybridization are associated with clinical outcome in renal cell carcinoma. Cancer Res $\underline{56}$, 27-30 (Zitiert auf Seite 57)

Moch H, Gasser T, Amin MB, Torhorst J, Sauter G, Mihatsch MJ (2000): Prognostic utility of the recently recommended histologic classification and revised TNM staging system of renal cell carcinoma: a Swiss experience with 588 tumors. Cancer 89, 604-614 (Zitiert auf Seite 6) 
Nowell PC (1976): The clonal evolution of tumor cell populations. Science 194, 23-28 (Zitiert auf Seiten 12 und 55)

Oberneder R, Wagner H, Siebels M, Stieber P, Busch M, Weiss M: Nierenzellkarzinom; MANUAL Urogenitale Tumoren. Tumorzentrum München und W. Zuckschwerdt Verlag München 2003 (Zitiert auf Seite 5)

Okamoto A, Hussain SP, Hagiwara K, Spillare EA, Rusin MR, Demetrick DJ, Serrano M, Hannon GJ, Shiseki M, Zariwala M (1995): Mutations in the p16INK4/MTS1/CDKN2, p15INK4B/MTS2, and p18 genes in primary and metastatic lung cancer. Cancer Res $\underline{55}, 1448-1451$ (Zitiert auf Seite 57)

Pardue ML, Gall JG (1969): Molecular hybridization of radioactive DNA to the DNA of cytological preparations. Proc Natl Acad Sci U S A $\underline{64}, 600-604$ (Zitiert auf Seite 31)

Parkin DM, Bray F, Ferlay J, Pisani P (2005): Global cancer statistics, 2002. CA Cancer J Clin 55, 74-108 (Zitiert auf Seite 4)

Paterson AH, Agarwal M, Lees A, Hanson J, Szafran O (1982): Brain metastases in breast cancer patients receiving adjuvant chemotherapy. Cancer $\underline{49}$, 651-654 (Zitiert auf Seite 8)

Pathak S, Strong LC, Ferrell RE, Trindade A (1982): Familial renal cell carcinoma with a 3;11 chromosome translocation limited to tumor cells. Science $\underline{217}$, 939-941 (Zitiert auf Seite 10)

Pegoraro L, Palumbo A, Erikson J, Falda M, Giovanazzo B, Emanuele BS, Rovera G, Nowell PC, Croce CM (1984): A 14;18 and an 8;14 chromosome translocation in a cell line derived from an acute B-cell leukemia. Proc Natl Acad Sci U S A $\underline{81}, 7166-7170 \quad$ (Zitiert auf Seite 60)

Pesch B, Haerting J, Ranft U, Klimpel A, Oelschlagel B, Schill W (2000): Occupational risk factors for renal cell carcinoma: agent-specific results from a case-control study in Germany. MURC Study Group. Multicenter urothelial and renal cancer study. Int J Epidemiol 29, 1014-1024 (Zitiert auf Seite 5) 
Petersen I, Hidalgo A, Petersen S, Schluns K, Schewe C, Pacyna-Gengelbach M, Goeze A, Krebber B, Knosel T, Kaufmann O (2000): Chromosomal imbalances in brain metastases of solid tumors. Brain Pathol 10, 395-401 (Zitiert auf Seite 11)

Pinkel D, Landegent J, Collins C, Fuscoe J, Segraves R, Lucas J, Gray J (1988): Fluorescence in situ hybridization with human chromosome-specific libraries: Detection of trisomy 21 and translocations of chromosome 4. Proc Natl Acad Sci U S A $\underline{85}, 9138-9142$ (Zitiert auf Seite 32)

Piper J, Rutovitz D, Sudar D, Kallioniemi A, Kallioniemi OP, Waldman FM, Gray JW, Pinkel D (1995): Computer image analysis of comparative genomic hybridization. Cytometry 19, 10-26 (Zitiert auf Seiten 34, 35 und 52)

Pomer S, Klopp M, Steiner HH, Brkovic D, Staehler G, Cabillin-Engenhart R (1997): Brain metastases in renal cell carcinoma. Results of treatment and prognosis. Urologe A $\underline{36}, 117-125$ (Zitiert auf Seiten 7, 9, 10, 14 und 63)

Receveur AO, Couturier J, Molinie V, Vieillefond A, Desangles F, Guillaud-Bataille M, Danglot G, Coullin P, Bernheim A (2005): Characterization of quantitative chromosomal abnormalities in renal cell carcinomas by interphase fourcolor fluorescence in situ hybridization. Cancer Genet Cytogenet 158, 110-118 (Zitiert auf Seite 109)

Renan MJ (1993): How many mutations are required for tumorigenesis? Implications from human cancer data. Mol Carcinog 7, 139-146 (Zitiert auf Seite 12)

Reutzel D, Mende M, Naumann S, Storkel S, Brenner W, Zabel B, Decker $\mathrm{J}$ (2001): Genomic imbalances in 61 renal cancers from the proximal tubulus detected by comparative genomic hybridization. Cytogenet Cell Genet $\underline{93}$, 221-227 (Zitiert auf Seiten 106, 107 und 108)

Rigby PW, Dieckmann M, Rhodes C, Berg P (1977): Labeling deoxyribonucleic acid to high specific activity in vitro by nick translation with DNA polymerase I. J Mol Biol 113, 237-251 (Zitiert auf Seite 27)

Rigola MA, Casadevall C, Bernues M, Caballin MR, Fuster C, Gelabert A, Egozcue J, Miro R (2002): Analysis of kidney tumors by comparative genomic hybri- 
dization and conventional cytogenetics. Cancer Genet Cytogenet 137, 49-53 (Zitiert auf Seiten 108 und 109)

Sanjmyatav J, Rubtsov N, Starke H, Schubert J, Hindermann W, Junker K (2005 a): Identification of tumor entities of renal cell carcinoma using interphase fluorescence in situ hybridization. J Urol 174, 731-735 (Zitiert auf Seiten 109 und 110)

Sanjmyatav J, Schubert J, Junker K (2005 b): Comparative study of renal cell carcinoma by CGH, multicolor-FISH and conventional cytogenic banding analysis. Oncol Rep $\underline{14}, 1183-1187$ (Zitiert auf Seite 106)

Schildkraut C (1965): Dependence of the melting temperature of DNA on salt concentration. Biopolymers $\underline{3}$, 195-208 (Zitiert auf Seite 31)

Schmid CW, Jelinek WR (1982): The Alu family of dispersed repetitive sequences. Science 216, 1065-1070 (Zitiert auf Seite 31)

Schmidt-Kittler O, Ragg T, Daskalakis A, Granzow M, Ahr A, Blankenstein TJF, Kaufmann M, Diebold J, Arnholdt Hans, Muller P (2003): From latent disseminated cells to overt metastasis: genetic analysis of systemic breast cancer progression. Proc Natl Acad Sci U S A 100, 7737-7742 (Zitiert auf Seite 56)

Schraml P, Muller D, Bednar R, Gasser T, Sauter G, Mihatsch MJ, Moch H (2000): Allelic loss at the D9S171 locus on chromosome 9p13 is associated with progression of papillary renal cell carcinoma. J Pathol $\underline{190}$, 457-461 (Zitiert auf Seite 57)

Schweizer D (1976 a): Reverse fluorescent chromosome banding with chromomycin and DAPI. Chromosoma $\underline{58}, 307-324$ (Zitiert auf Seite 20)

Schweizer D (1976 b): DAPI fluorescence of plant chromosomes prestained with actinomycin D. Exp Cell Res 102, 408-413 (Zitiert auf Seite 20)

Schweizer D, Nagl W (1976): Heterochromatin diversity in Cymbidium, and its relationship to differential DNA replication. Exp Cell Res 98, 411-423 (Zitiert auf Seite 20) 
Shaffer LG, Slovak ML, Campbell LJ: ISCN 2009 - An International System for Human Cytogenetic Nomenclature (2009) Recommendations of the International Standing Committee on Human Cytogenetic Nomenclature Published in collaboration with 'Cytogenetic and Genome Research' Plus fold-out: "The Normal Human Karyotype G- and R-bands“, hrsg. v. Shaffer LG, Slovak ML, Campbell LJ. S. Karger AG Basel/Schweiz 2009 (Zitiert auf Seite 36)

Sharp PA, Sugden B, Sambrook J (1973): Detection of two restriction endonuclease activities in Haemophilus parainfluenzae using analytical agarose-ethidium bromide electrophoresis. Biochemistry 12, 3055-3063 (Zitiert auf Seite 22)

Shuto T, Inomori S, Fujino H, Nagano H (2006): Gamma knife surgery for metastatic brain tumors from renal cell carcinoma. J Neurosurg 105, 555-560 (Zitiert auf Seiten 9 und 56)

Siemer S, Uder M, Humke U, Lindenmeier T, Moll V, Rudenauer E, Maurer J, Ziegler M (2000): Value of ultrasound in early diagnosis of renal cell carcinoma. Urologe A $\underline{39}, 149-153$ (Zitiert auf Seite 6)

Singer MF (1982): Highly repeated sequences in mammalian genomes. Int Rev Cytol 76, 67-112 (Zitiert auf Seite 31)

SKY/M-FISH \& CGH Datenbank (o. Verf.). National Cancer Institute (NCI) und National Center for Biotechnology Information (NCBI). Bethesda, 2001. Verfügbar unter: http://www.ncbi.nlm.nih.gov/sky/skyweb.cgi. Zugriff am 16.07.2008. (Zitiert auf Seite 39)

Smith MA, Freidlin B, Ries LA, Simon R (1998): Trends in reported incidence of primary malignant brain tumors in children in the United States. J Natl Cancer Inst $\underline{\text { 90, }}$ 1269-1277 (Zitiert auf Seite 8)

Speicher MR, du Manoir S, Schrock E, Holtgreve-Grez H, Schoell B, Lengauer C, Cremer T, Ried T (1993): Molecular cytogenetic analysis of formalin-fixed, paraffin-embedded solid tumors by comparative genomic hybridization after universal DNA-amplification. Hum Mol Genet $\underline{2}$, 1907-1914 (Zitiert auf Seiten 24 und 52) 
Strachan und Read: Human Molecular Genetics 2, 2. Auflage; hrsg. v. Strachan T, Read AP; John Wiley Sons, Inc., by arrangement with BIOS Scientific Publishers Ltd., Oxford/UK 1999 (Zitiert auf Seite 20)

Stumm G, Eberwein S, Rostock-Wolf S, Stein H, Pomer S, Schlegel J, Waldherr R (1996): Concomitant overexpression of the EGFR and erbB-2 genes in renal cell carcinoma $(\mathrm{RCC})$ is correlated with dedifferentiation and metastasis. Int $\mathrm{J}$ Cancer $\underline{69}, 17-22$ (Zitiert auf Seite 62)

Sükösd F, Kuroda N, Beothe T, Kaur AP, Kovacs G (2003): Deletion of chromosome 3p14.2-p25 involving the VHL and FHIT genes in conventional renal cell carcinoma. Cancer Res $\underline{63}$, 455-457 (Zitiert auf Seite 10)

Thorne HV (1963): Electrophoretic study of the interaction of radioactive poliovirus with components of cultured cells. J Bacteriol $\underline{85}, 1247-1255$ (Zitiert auf Seite 22)

Thorne HV (1966): Electrophoretic separation of polyoma virus DNA from host cell DNA. Virology 29, 234-239 (Zitiert auf Seite 22)

Wagle DG, Scal DR (1970): Renal cell carcinoma-a review of 256 cases. J Surg Oncol $\underline{2}, 23-32$ (Zitiert auf Seite 5)

Weiss MM, Hermsen MA, Meijer GA, van Grieken NC, Baak JP, Kuipers EJ, van Diest PJ (1999): Comparative genomic hybridisation. Mol Pathol 므, 243-251 (Zitiert auf Seite 14)

Wente MN, Kleeff J, Esposito I, Hartel M, Muller MW, Frohlich BE, Buchler MW, Friess H (2005): Renal cancer cell metastasis into the pancreas: a single-center experience and overview of the literature. Pancreas $\underline{30}$, 218-222 (Zitiert auf Seite 56)

Wetmur JG (1975): Acceleration of DNA renaturation rates. Biopolymers 14, 2517 2524 (Zitiert auf Seite 31)

Wetmur JG, Davidson N (1968): Kinetics of renaturation of DNA. J Mol Biol 31, 349370 (Zitiert auf Seite 31) 
Wilfinger WW, Mackey K, Chomczynski P (1997): Effect of pH and ionic strength on the spectrophotometric assessment of nucleic acid purity. Biotechniques 22 , 474476, 478-481 (Zitiert auf Seite 24)

Wronski, M and Arbit, E and Russo, P and Galicich, J H (1996): Surgical resection of brain metastases from renal cell carcinoma in 50 patients. Urology $\underline{47}, 187-193$ (Zitiert auf Seite 14)

Yoshimoto T, Matsuura K, Karnan S, Tagawa H, Nakada C, Tanigawa M, Tsukamoto Y, Uchida T, Kashima K, Akizuki S (2007): High-resolution analysis of DNA copy number alterations and gene expression in renal clear cell carcinoma. J Pathol 213, 392-401 (Zitiert auf Seite 109)

Zbar B, Brauch H, Talmadge C, Linehan M (1987): Loss of alleles of loci on the short arm of chromosome 3 in renal cell carcinoma. Nature $\underline{327}, 721-724$ (Zitiert auf Seite 57) 


\section{Abbildungsverzeichnis}

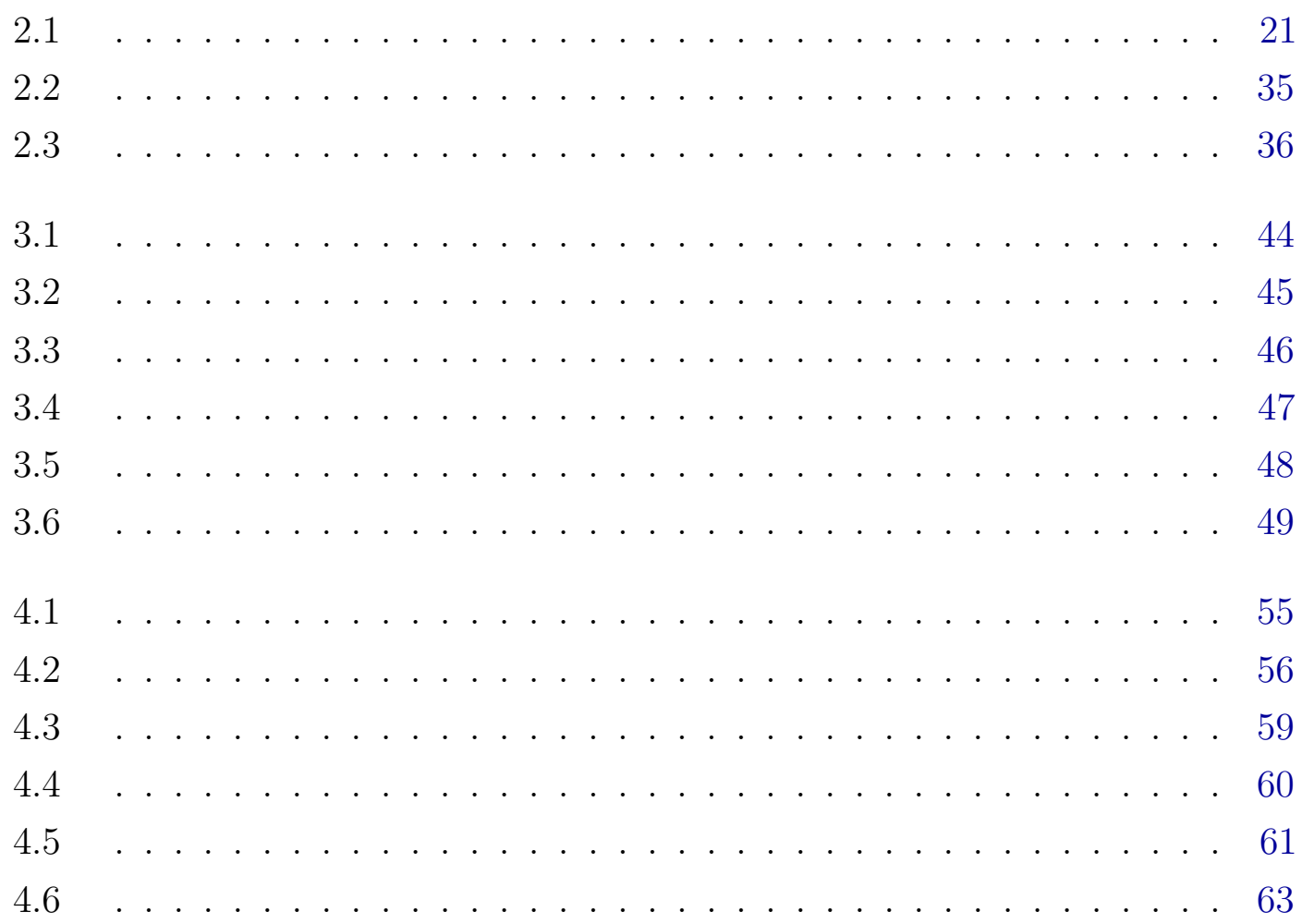




\section{Tabellenverzeichnis}

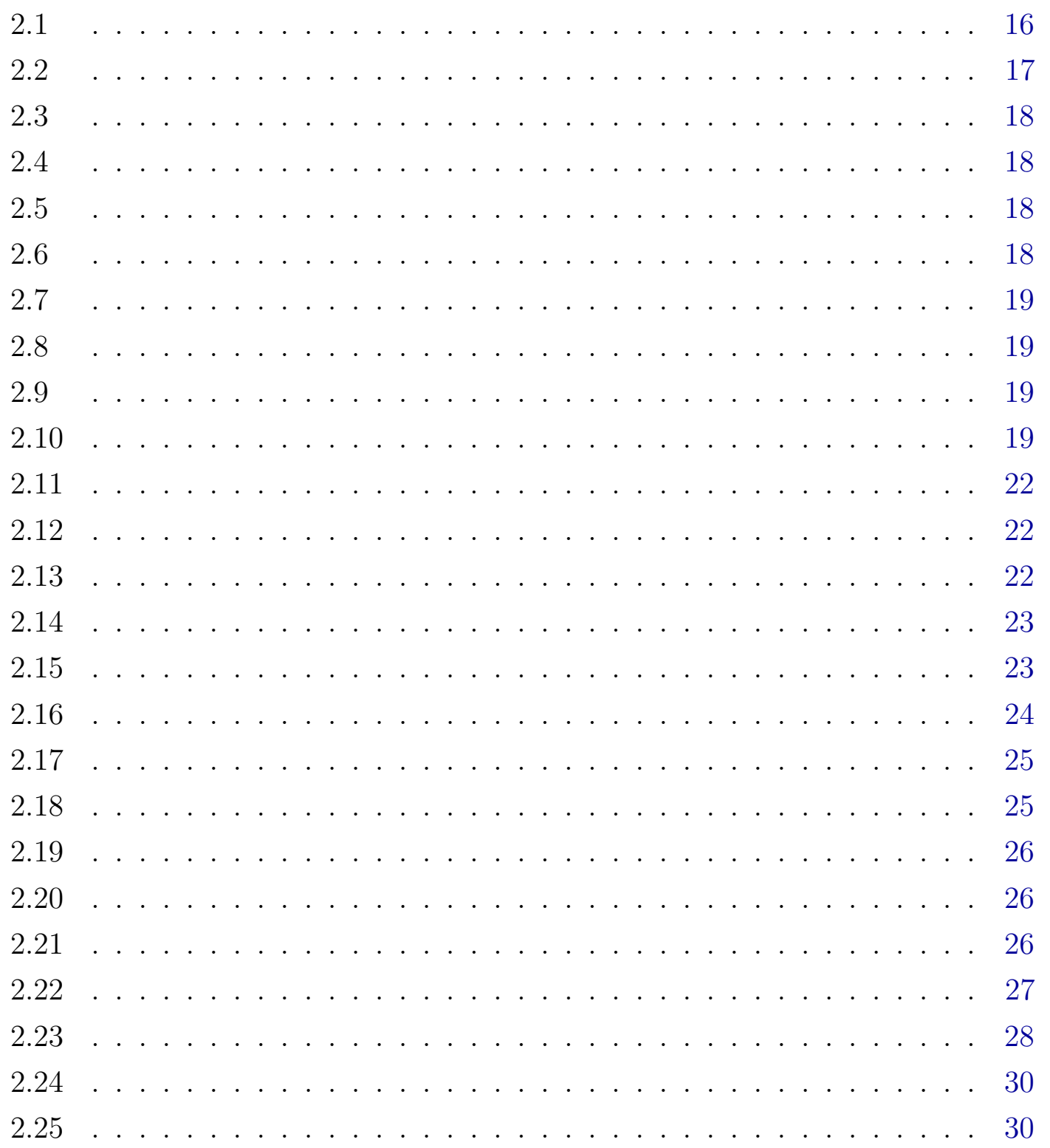




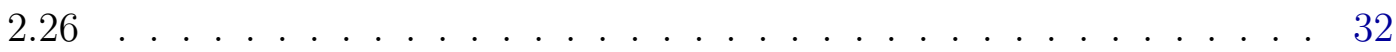

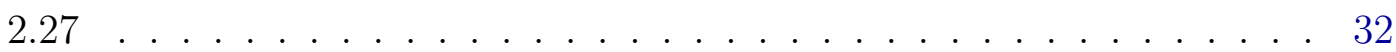

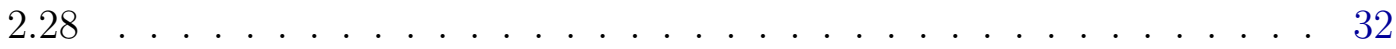

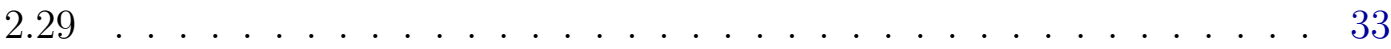

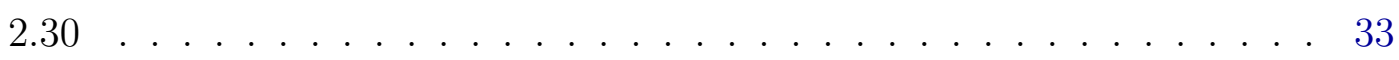

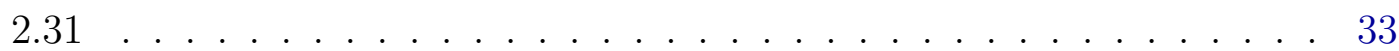

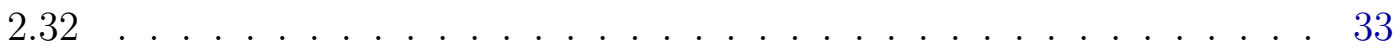

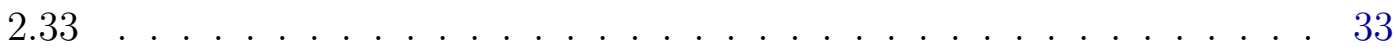

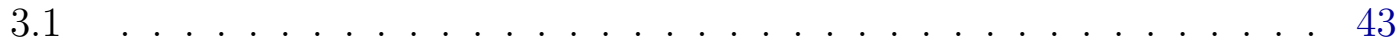

A.1 . . . . . . . . . . . . . . . . . . 89

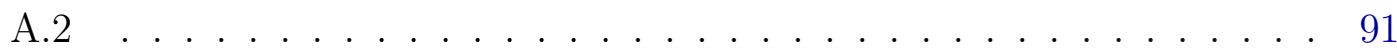

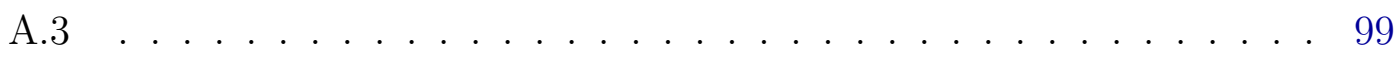

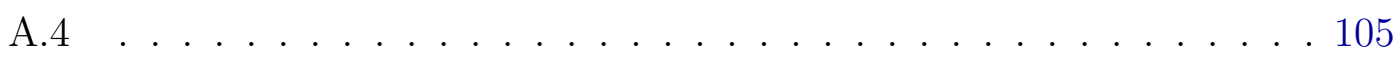


A Anhang 


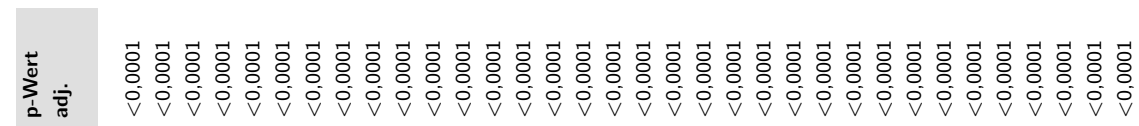

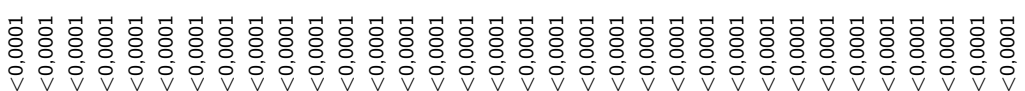

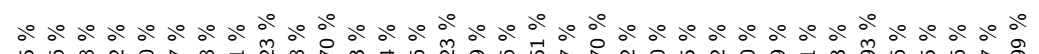

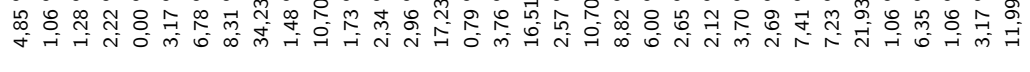

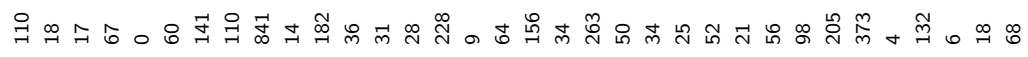

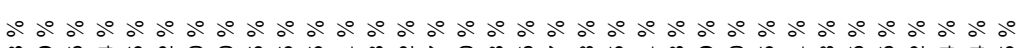

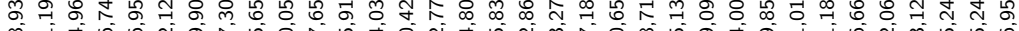
œ

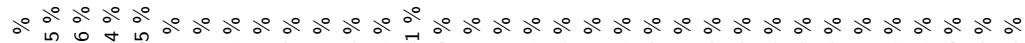

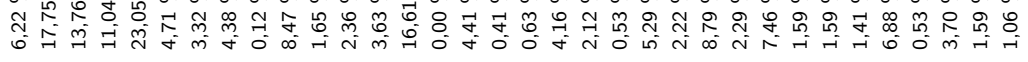

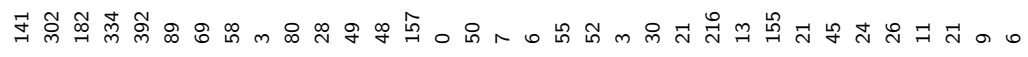

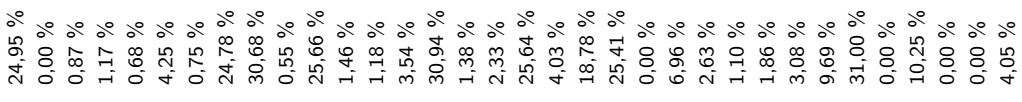

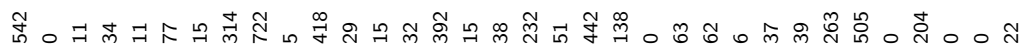

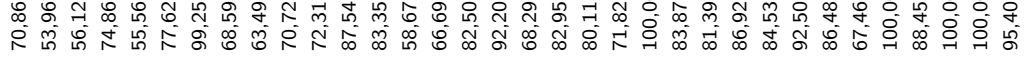

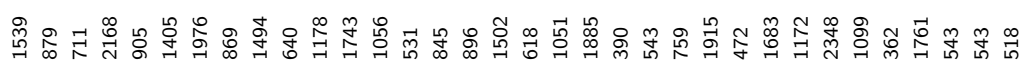

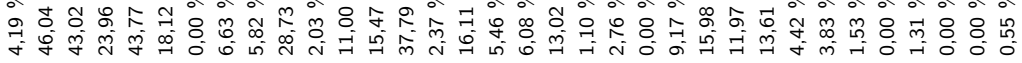




\begin{tabular}{|c|c|}
\hline 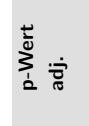 & 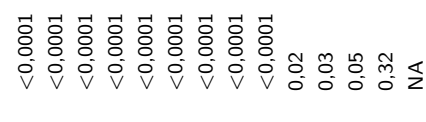 \\
\hline$\stackrel{3}{3}$ & 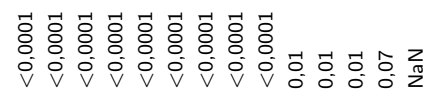 \\
\hline$\therefore$ & 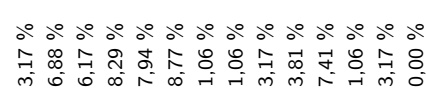 \\
\hline 跑 & 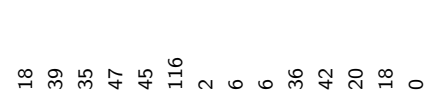 \\
\hline ॰ & 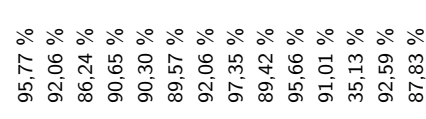 \\
\hline$\underline{\underline{\underline{\omega}}}$ & 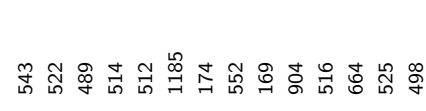 \\
\hline & 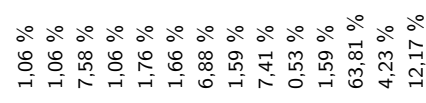 \\
\hline 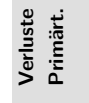 & 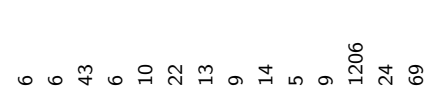 \\
\hline 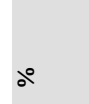 & 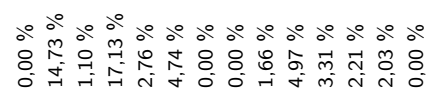 \\
\hline 竧离 & 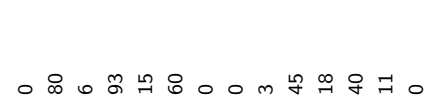 \\
\hline & 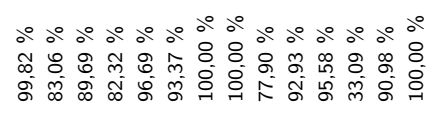 \\
\hline 䓂育 & 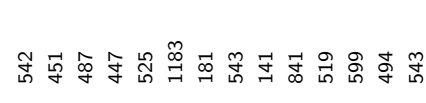 \\
\hline$\circ$ & 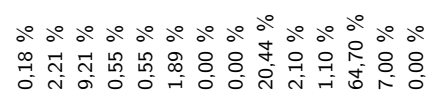 \\
\hline$\frac{\underline{\underline{\underline{z}}}}{\bar{n}}$ & 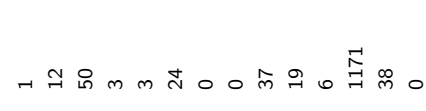 \\
\hline ह & 行 \\
\hline
\end{tabular}




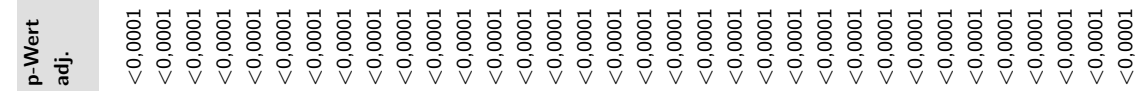

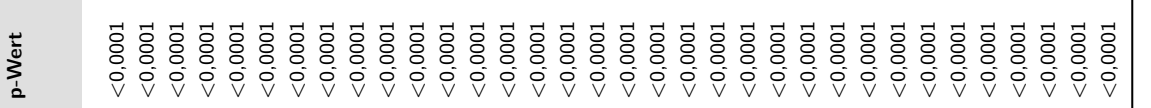

$c$

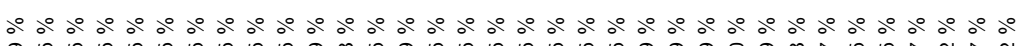

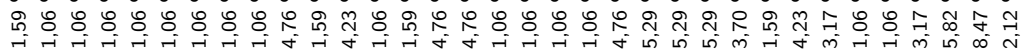

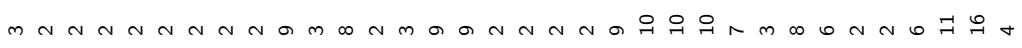

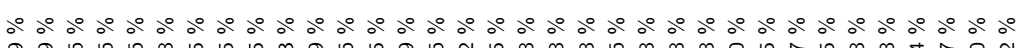

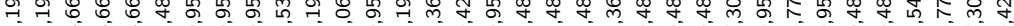

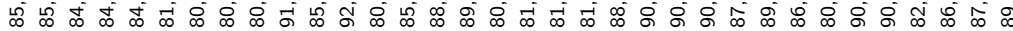

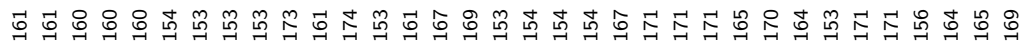

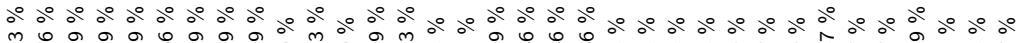

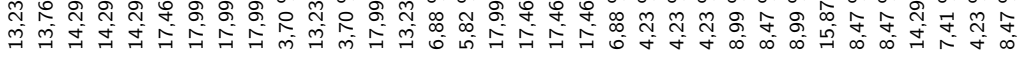

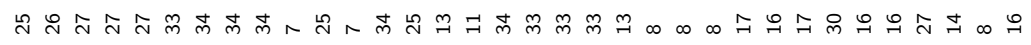

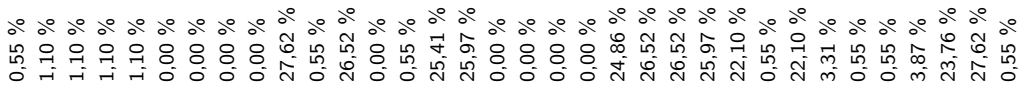

Hn hN

வீ

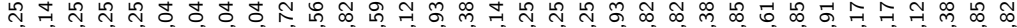

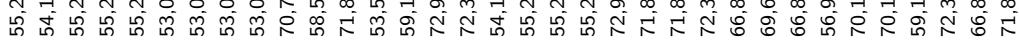

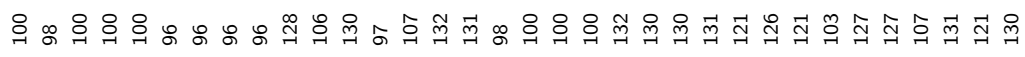

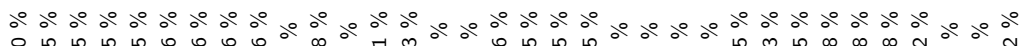

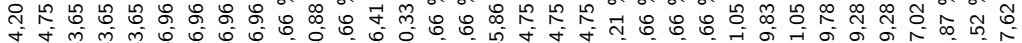

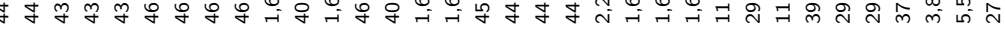




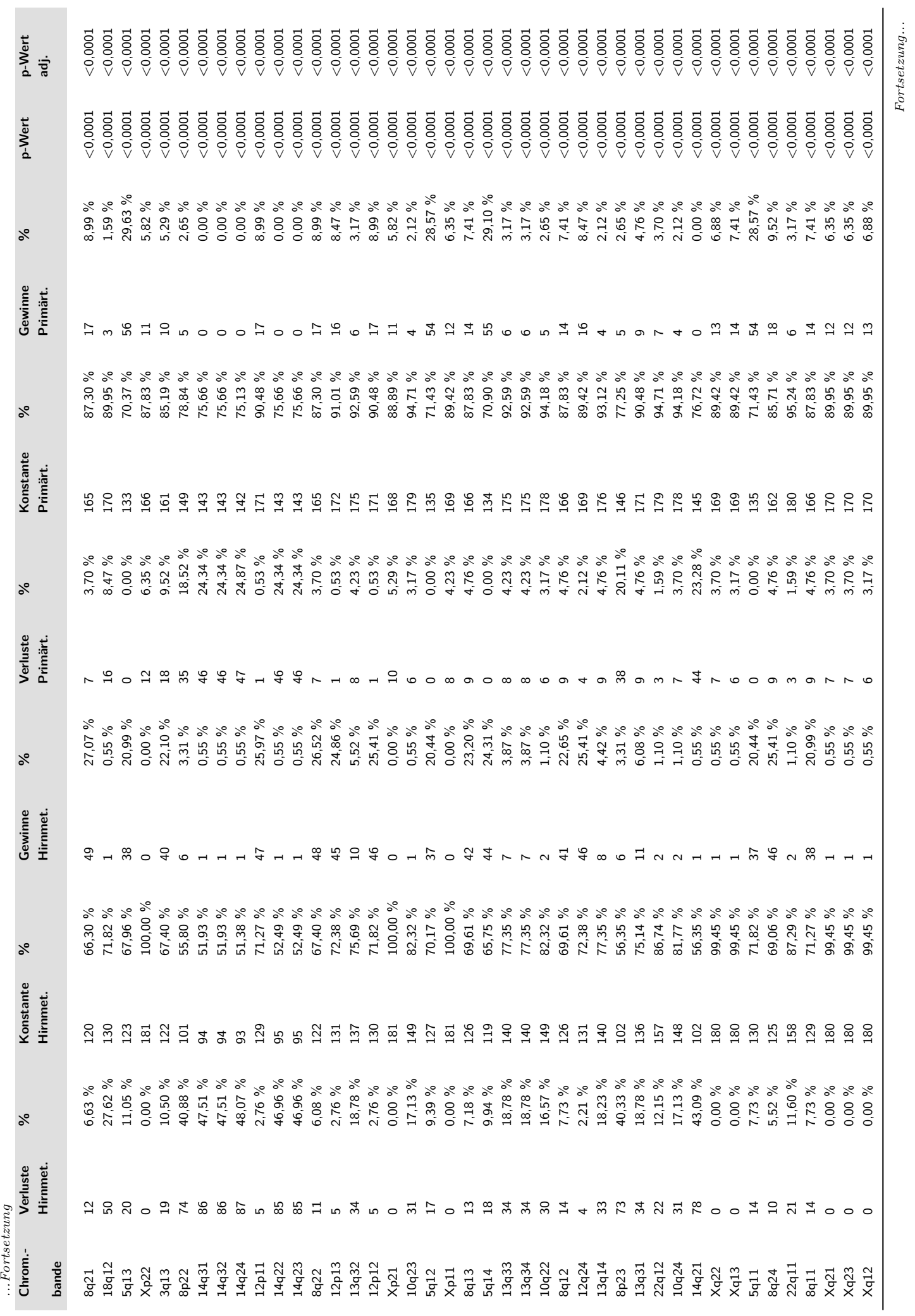




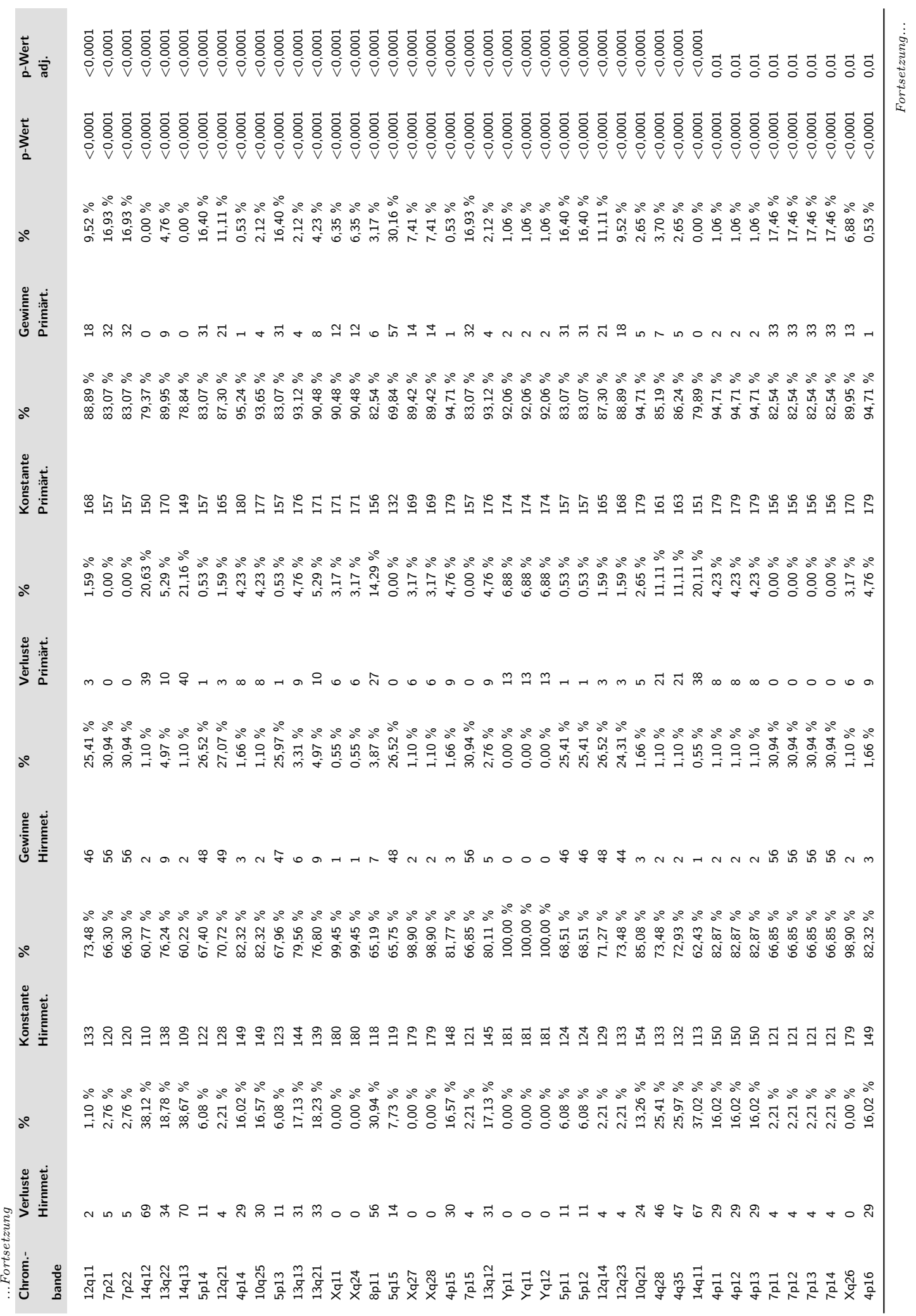




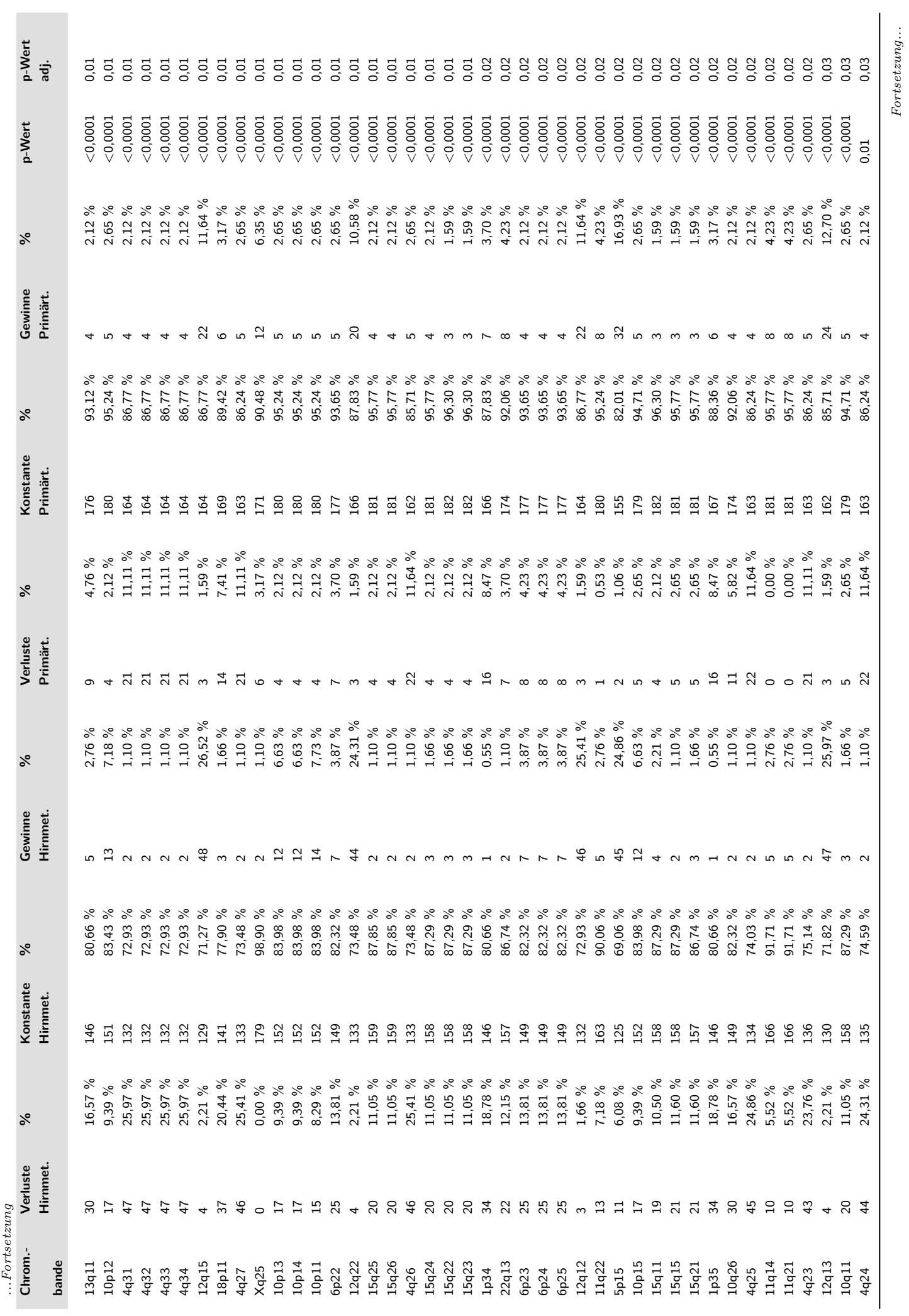




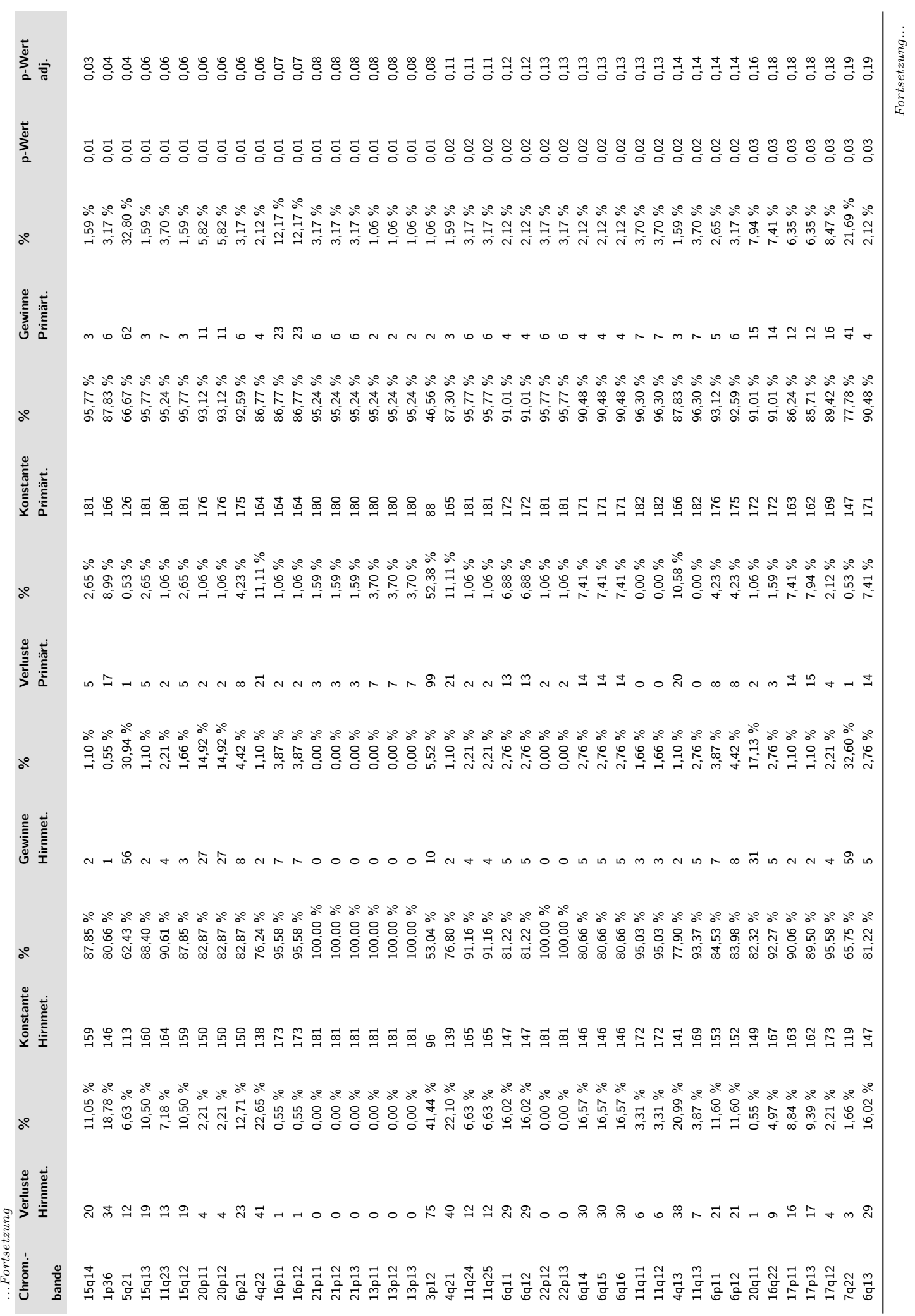




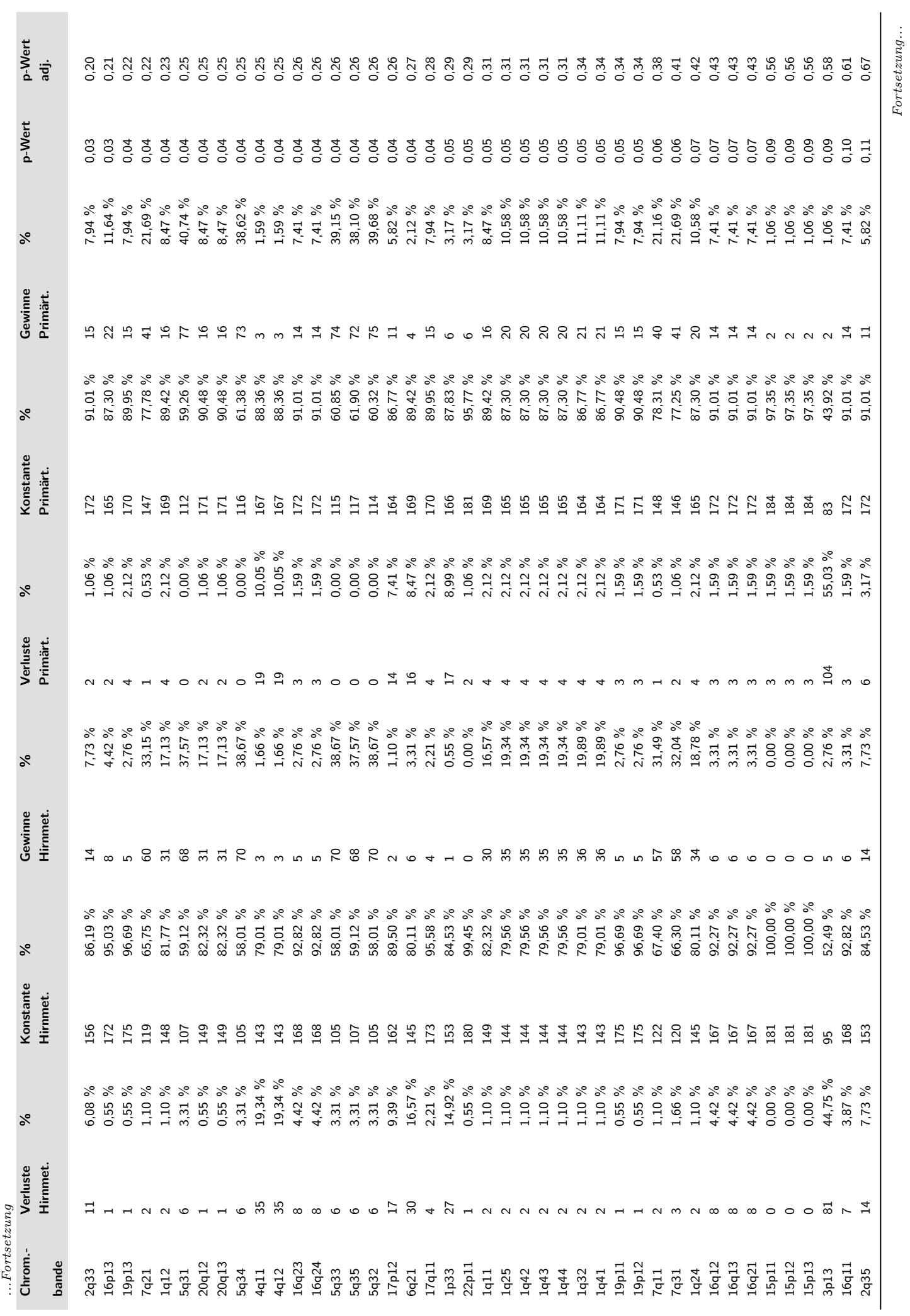




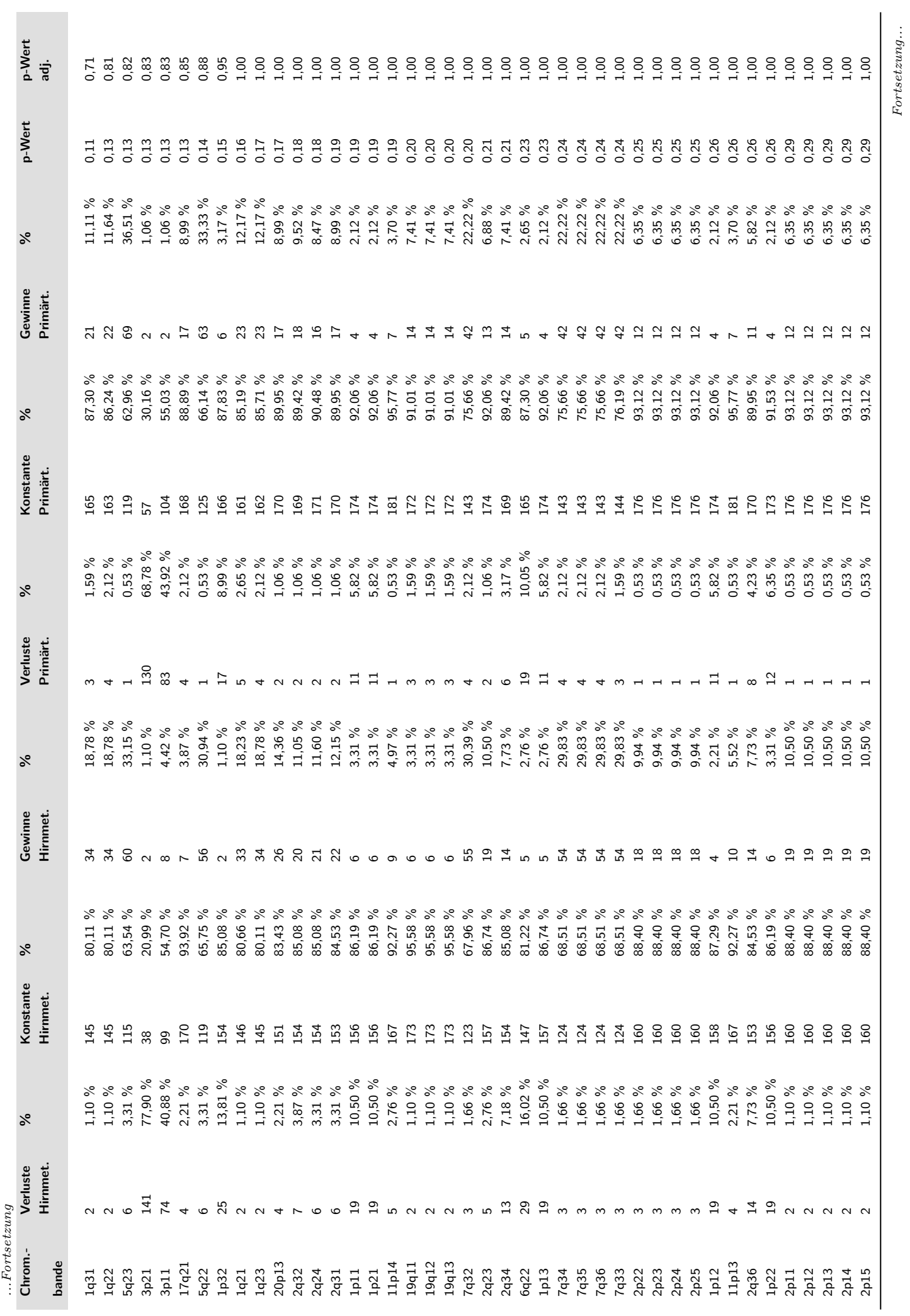




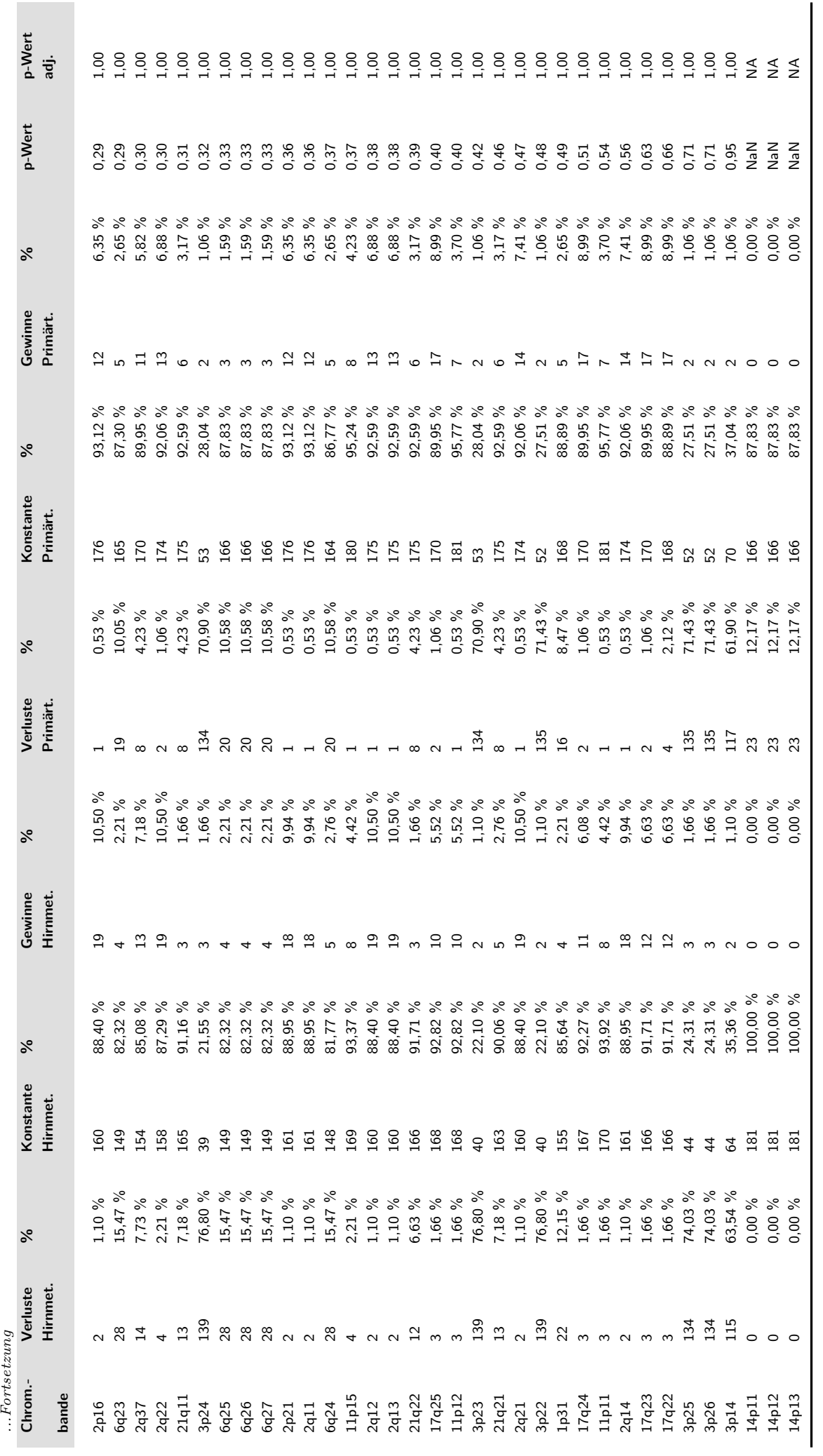




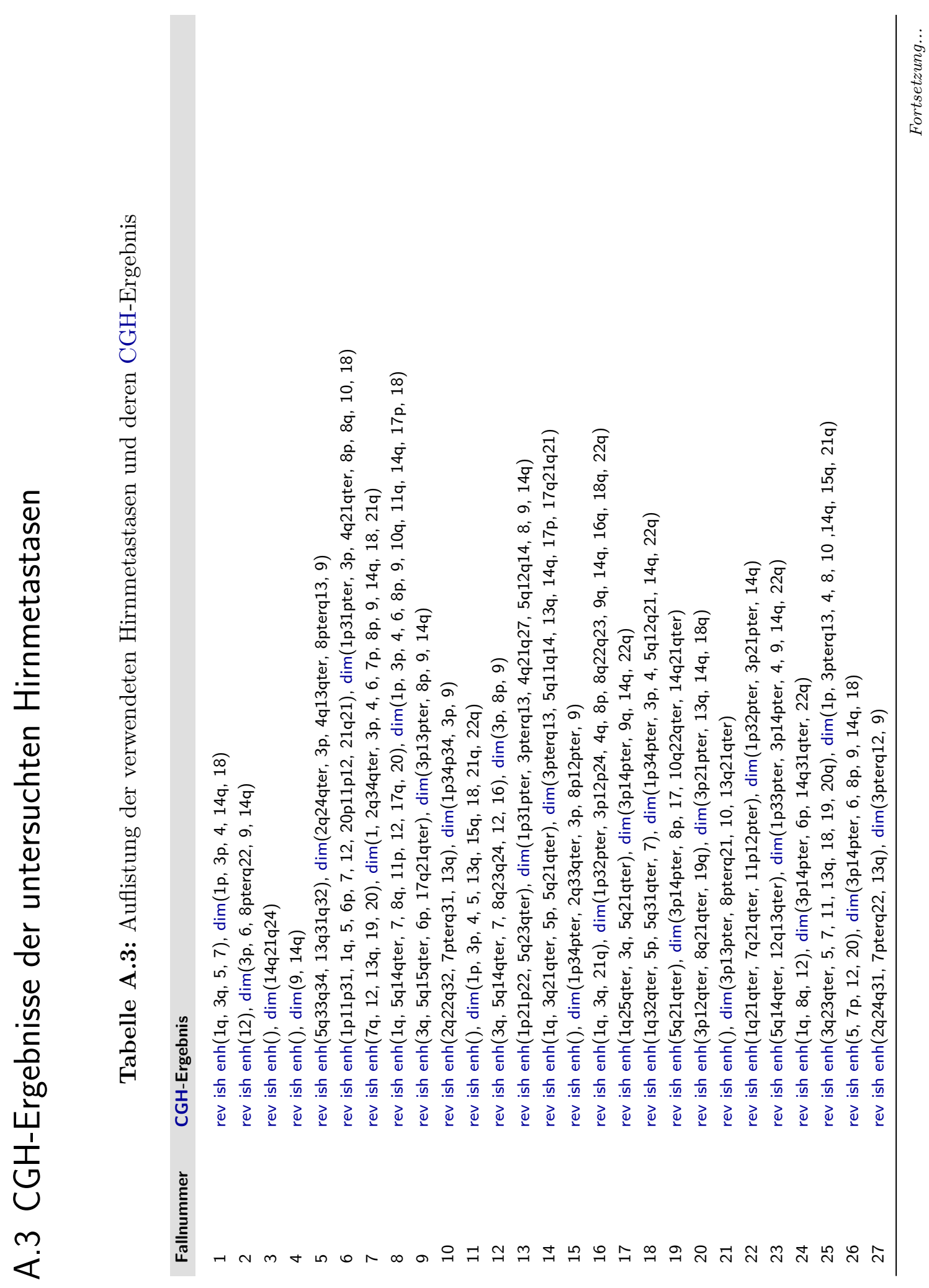




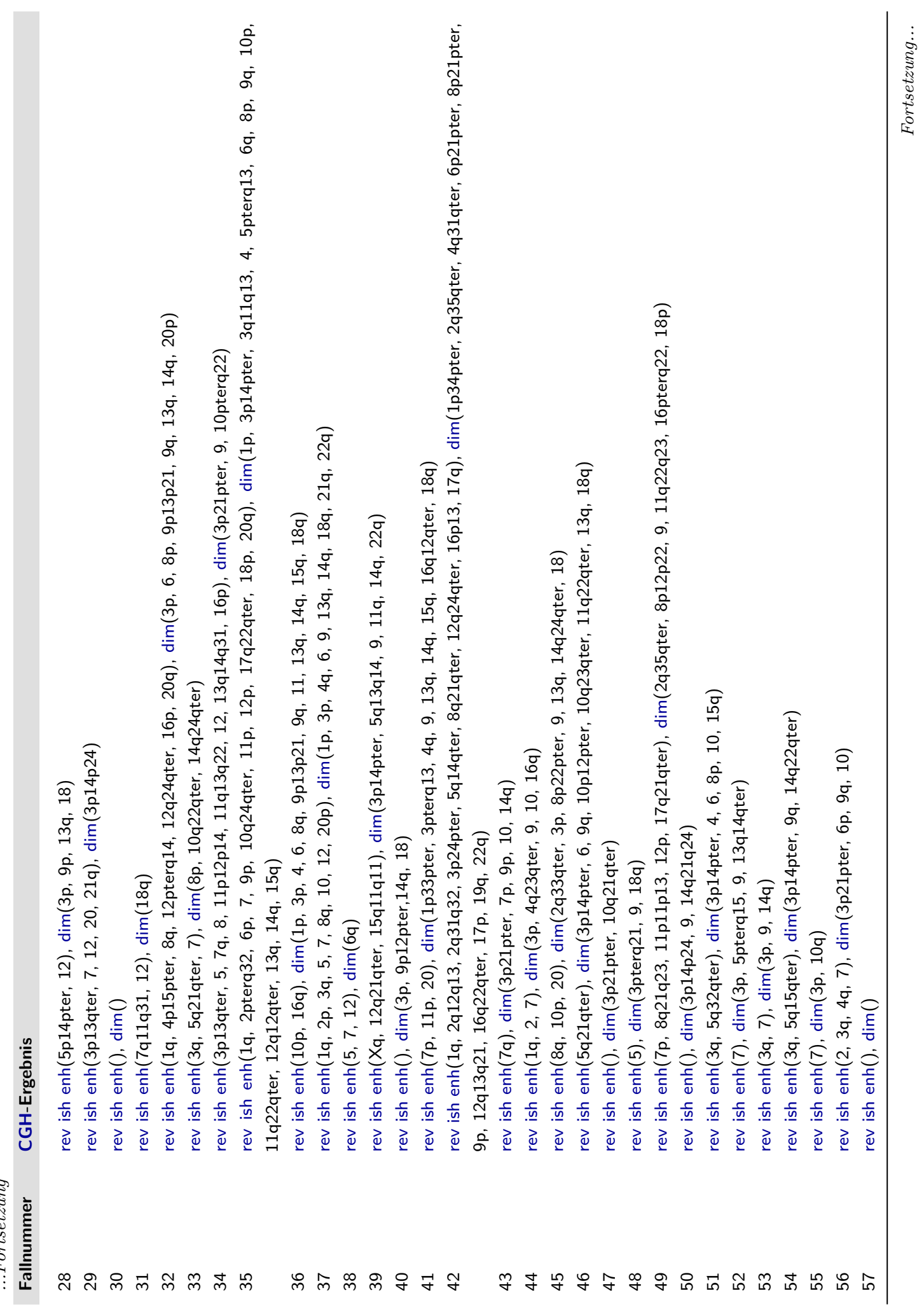




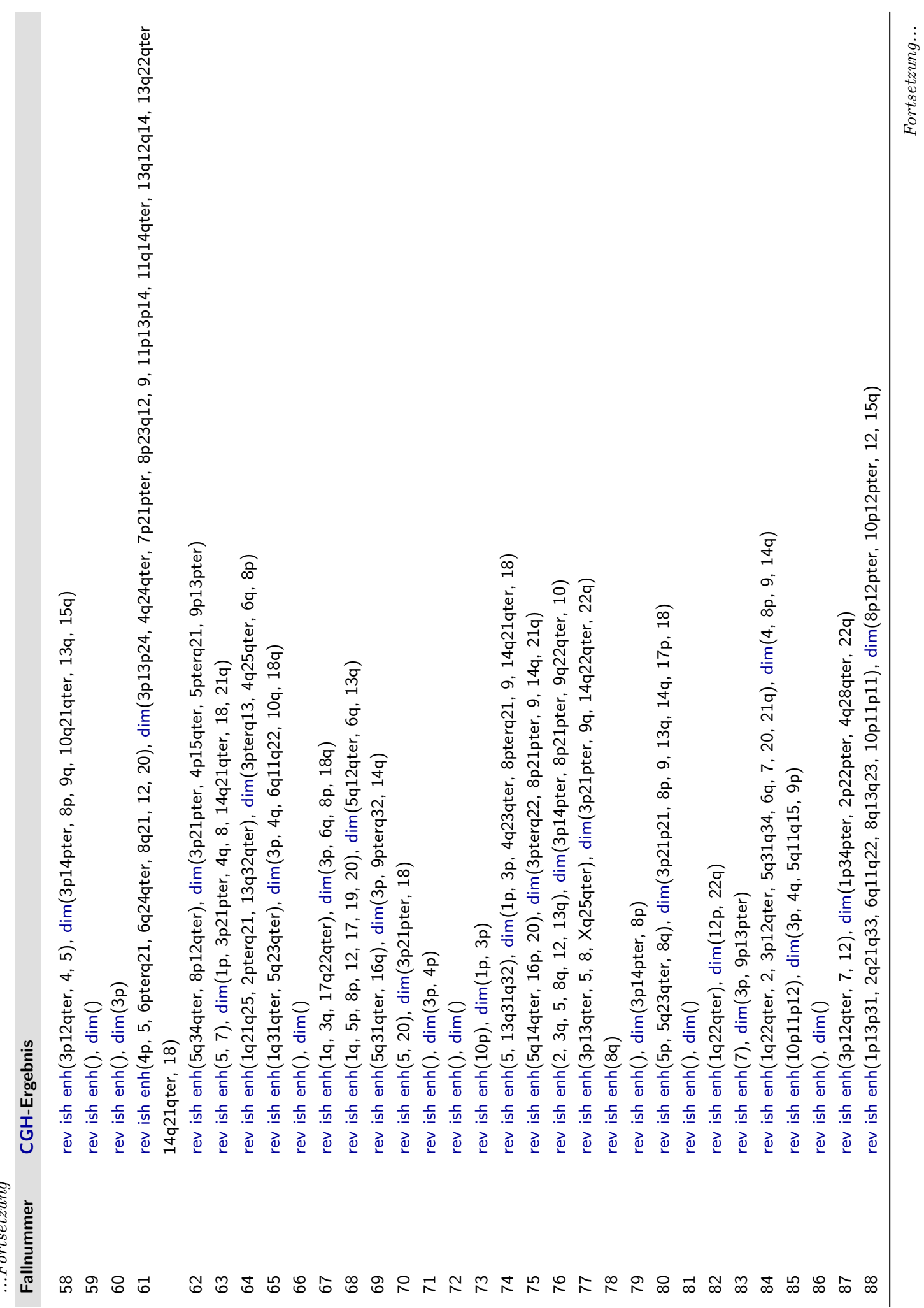




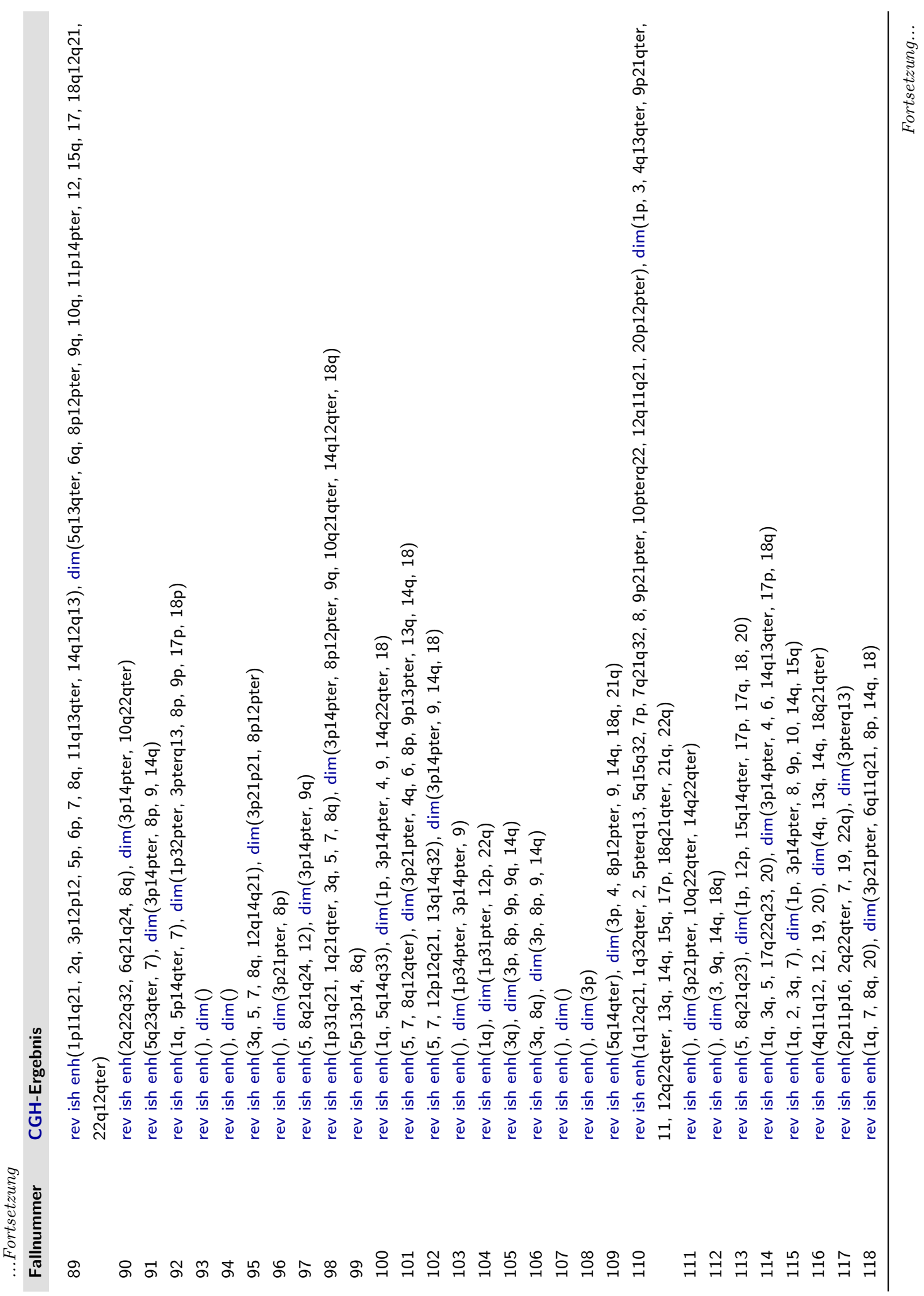




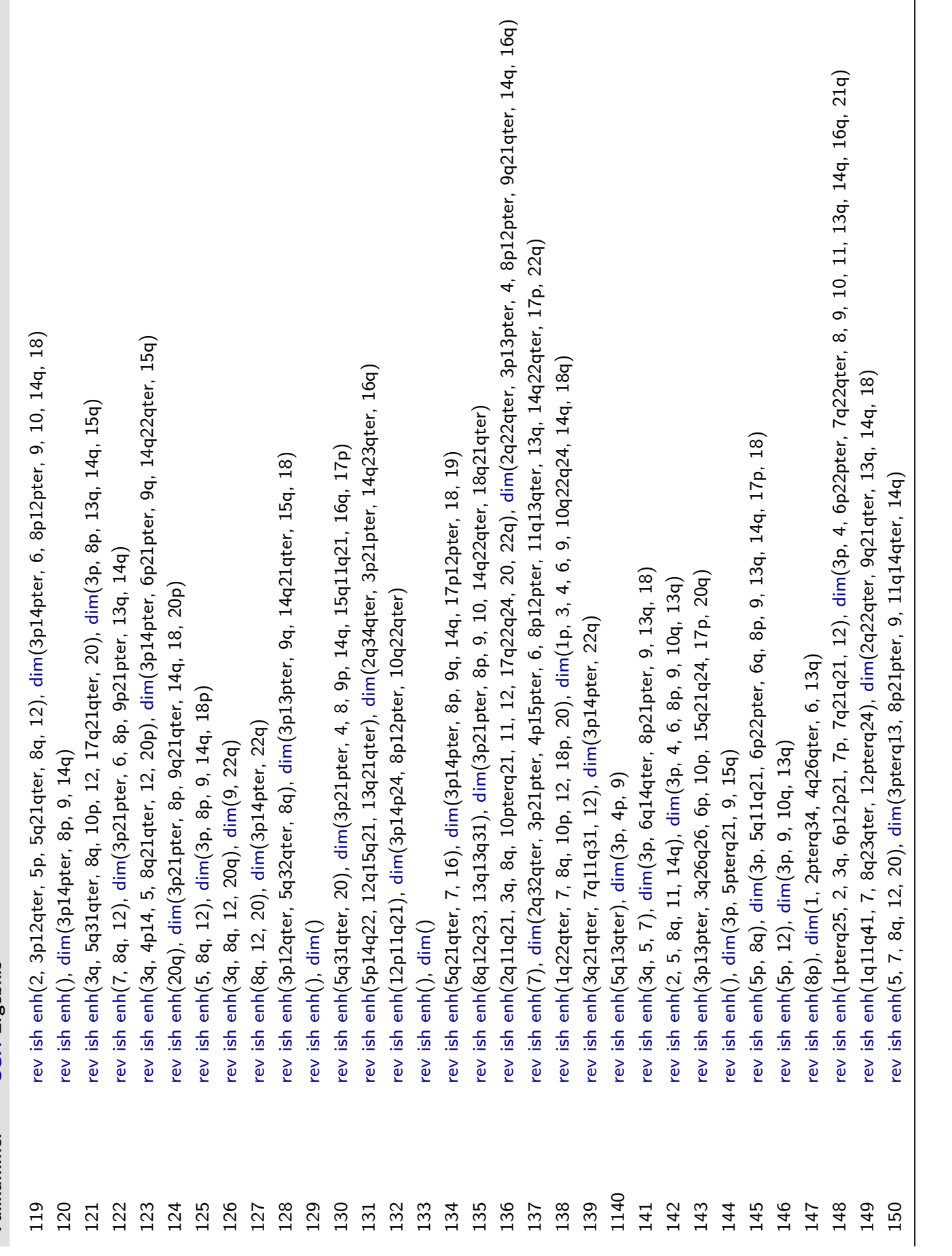




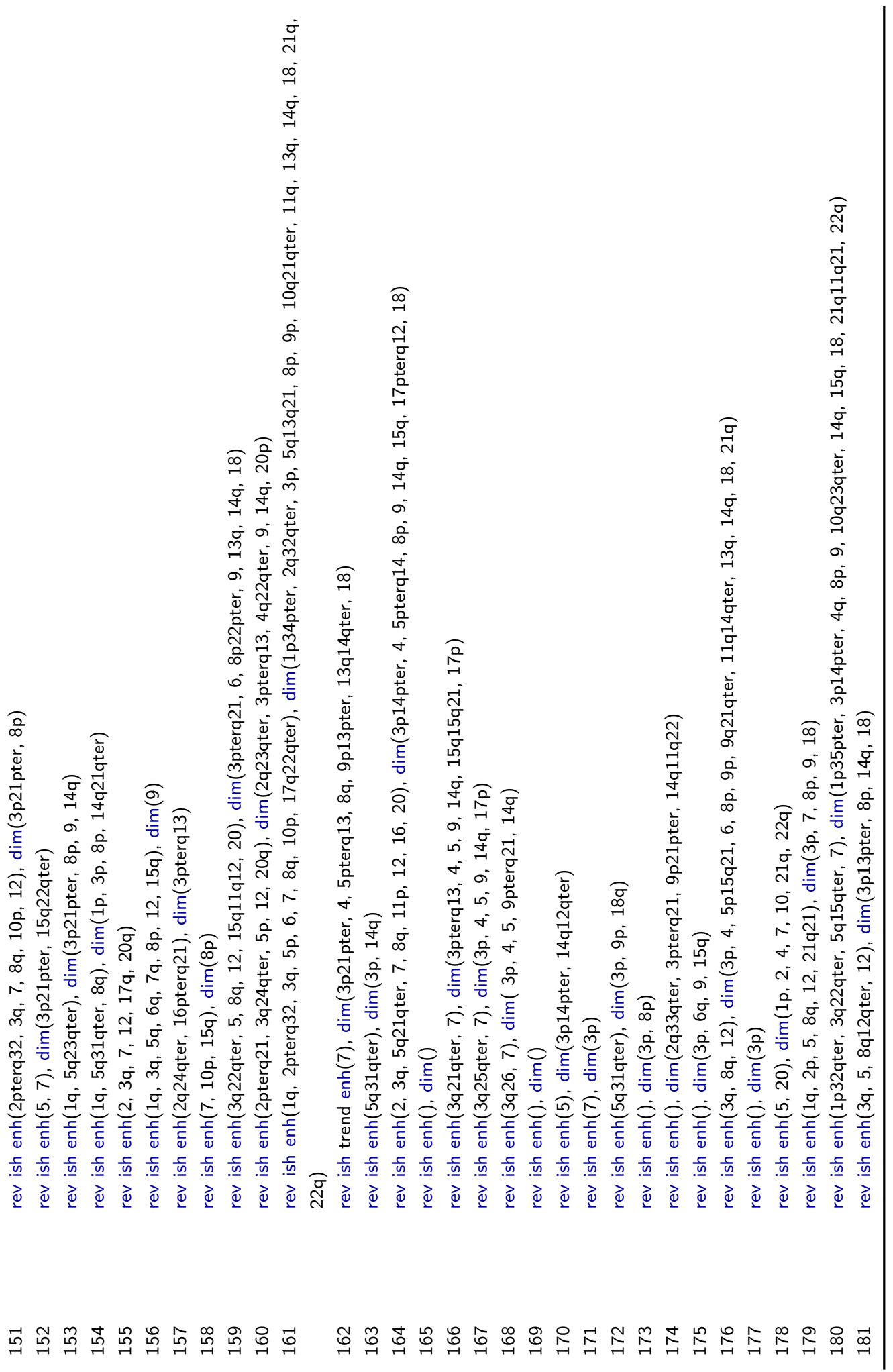




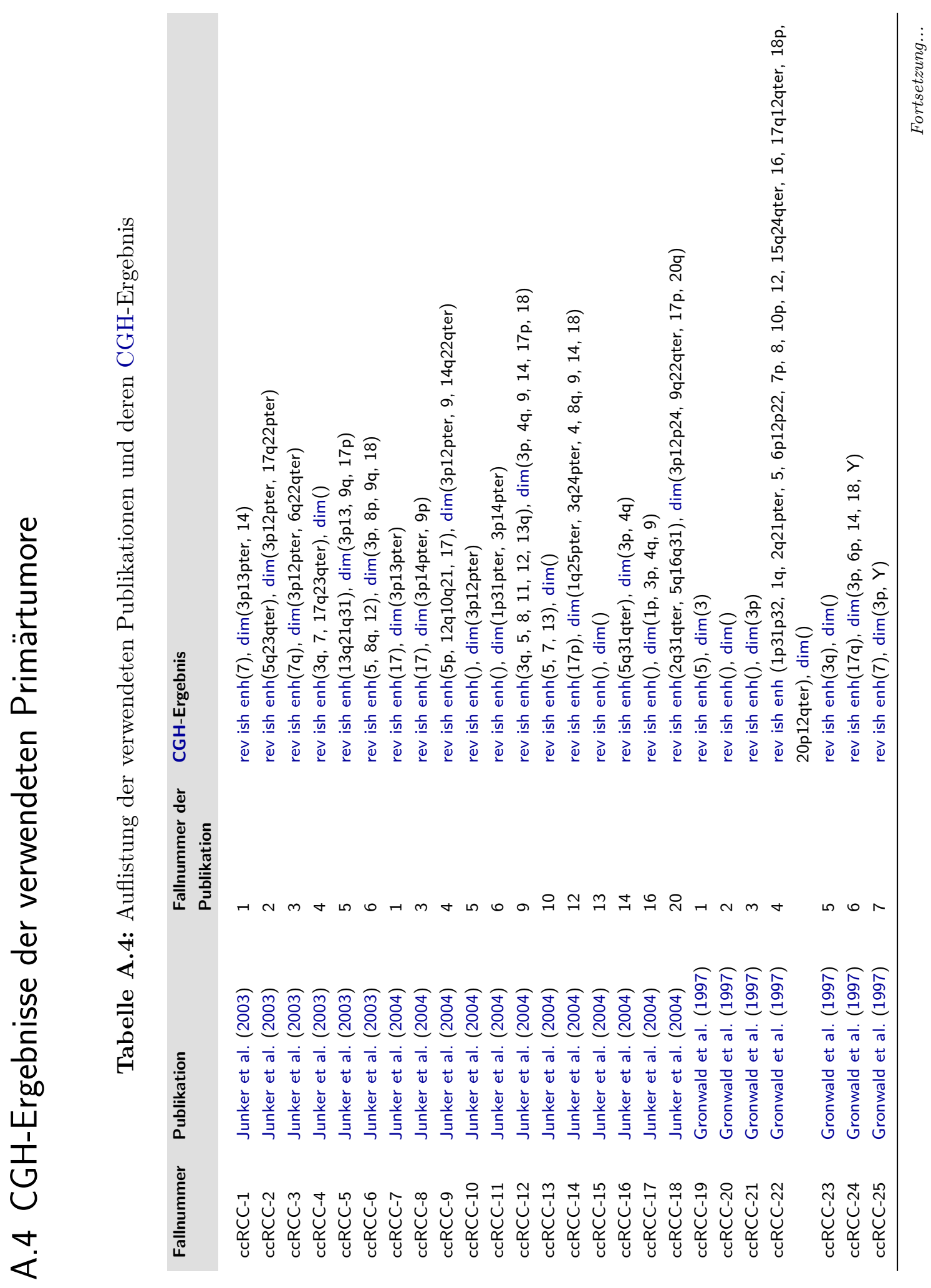




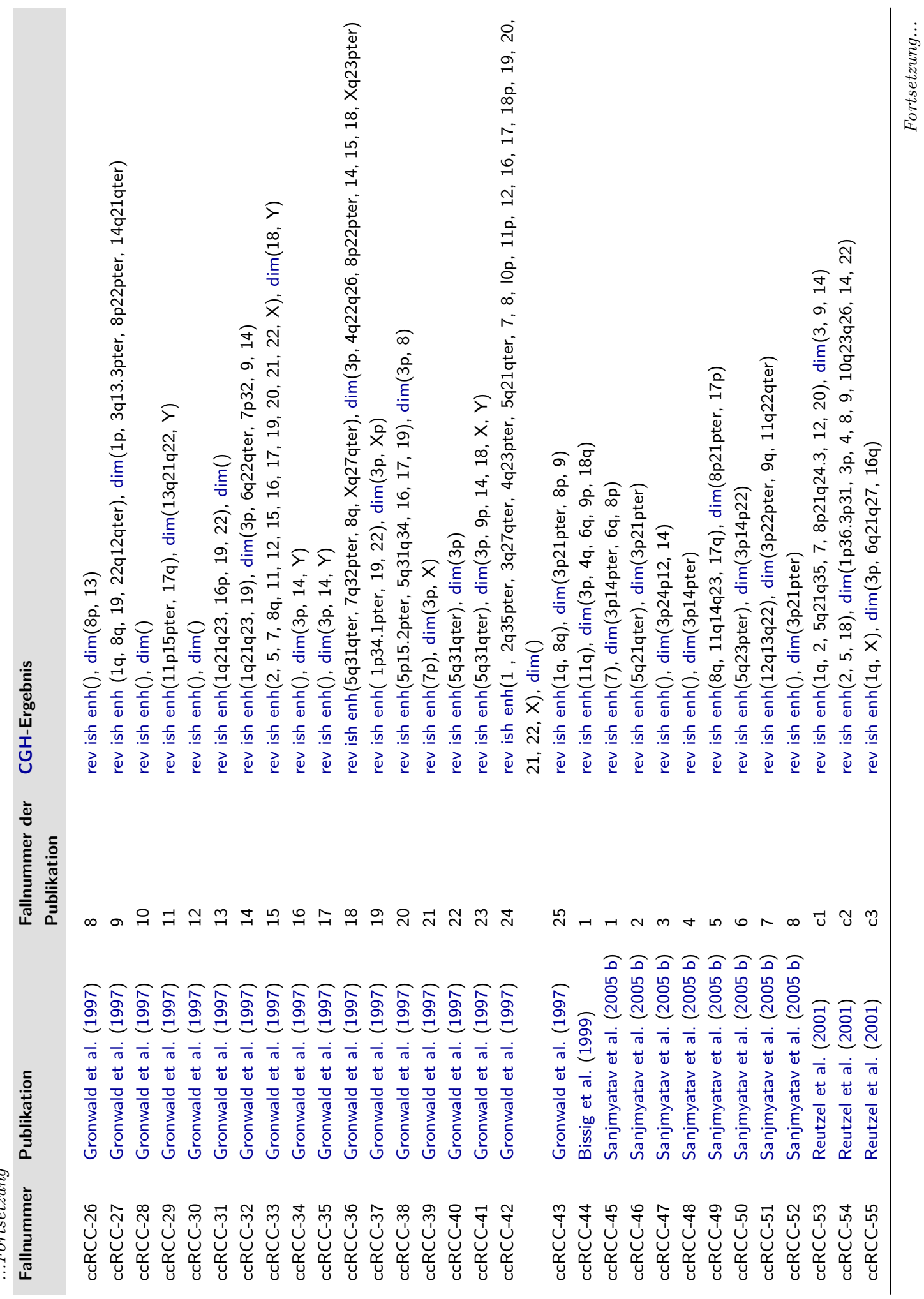




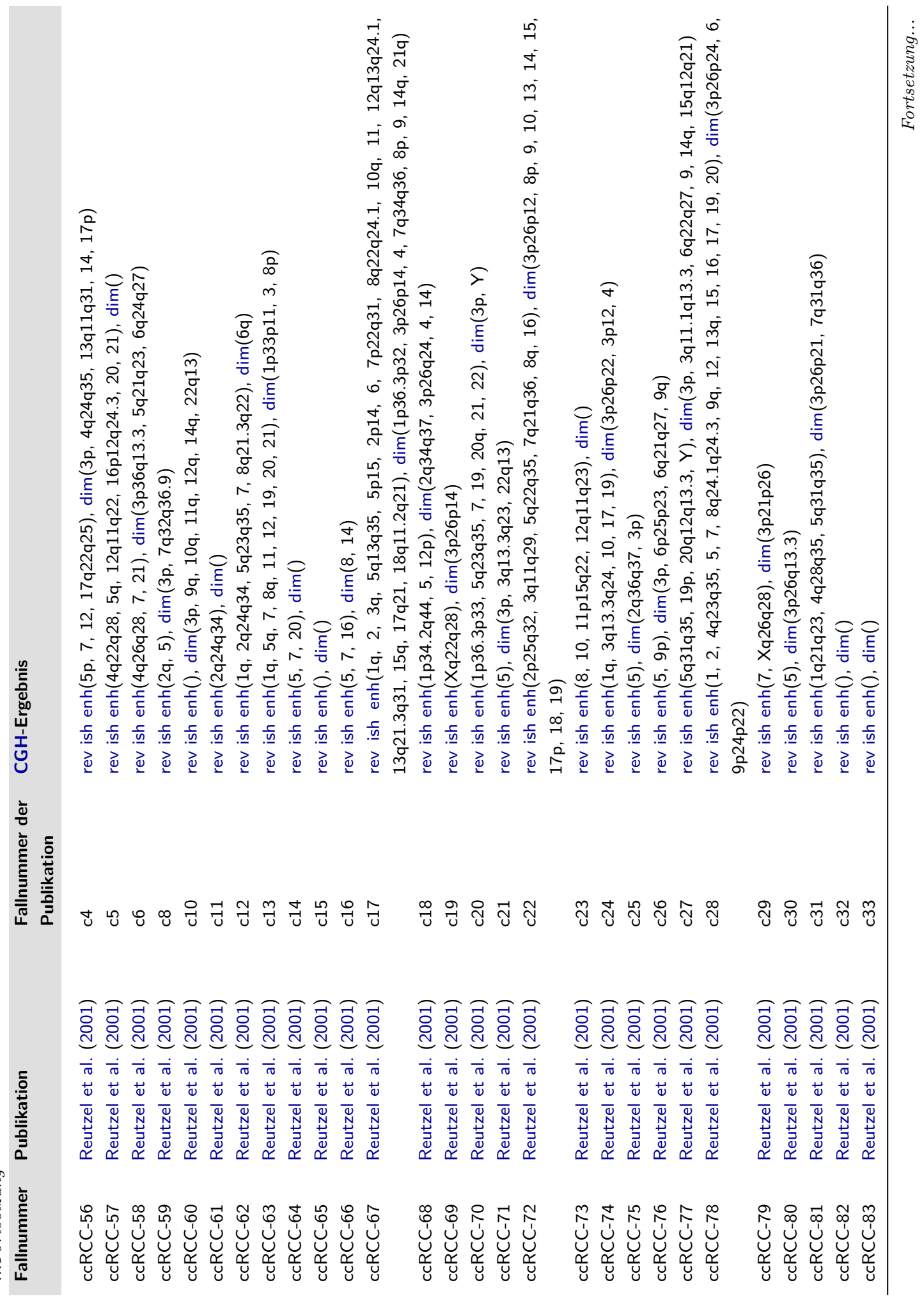




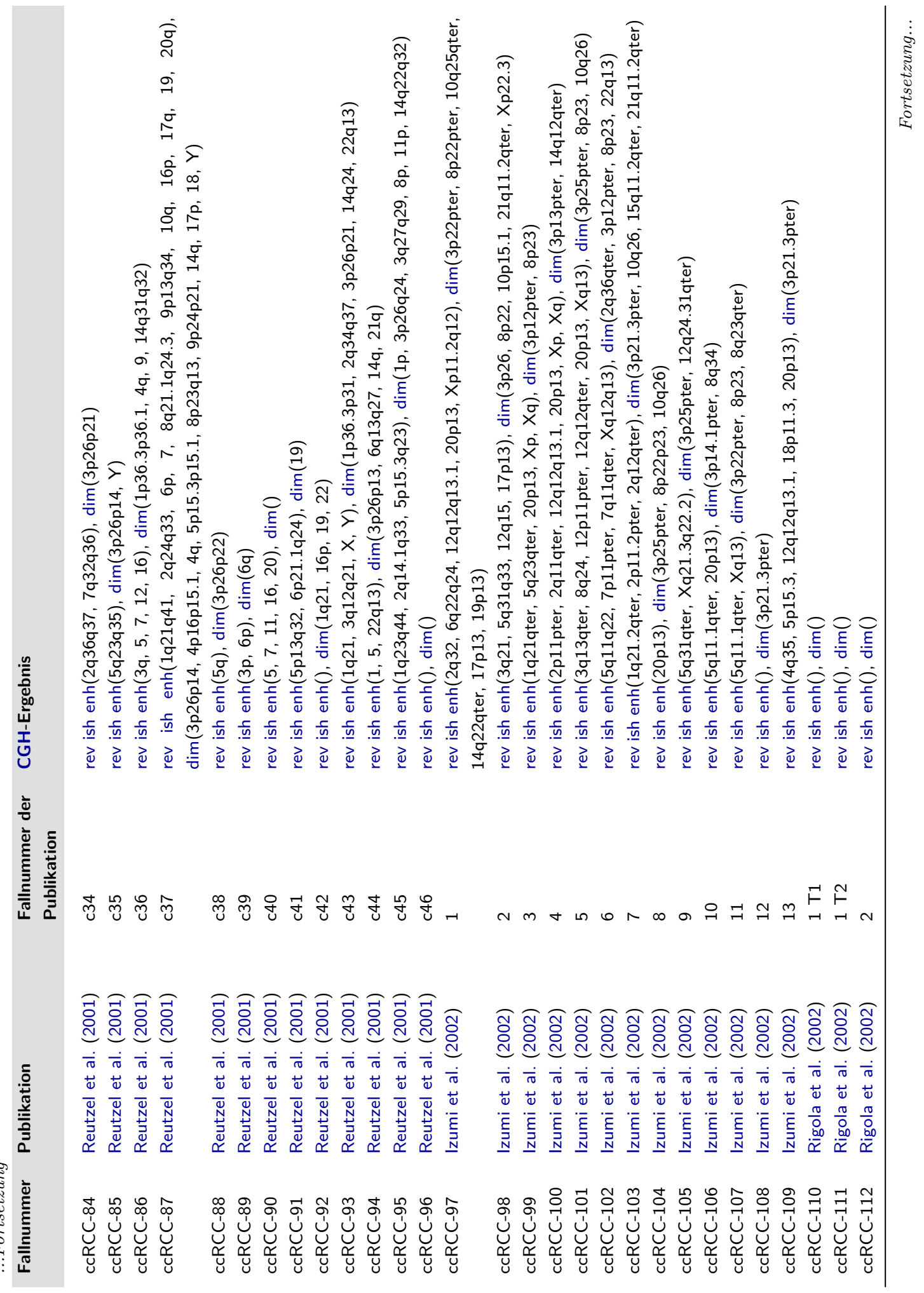




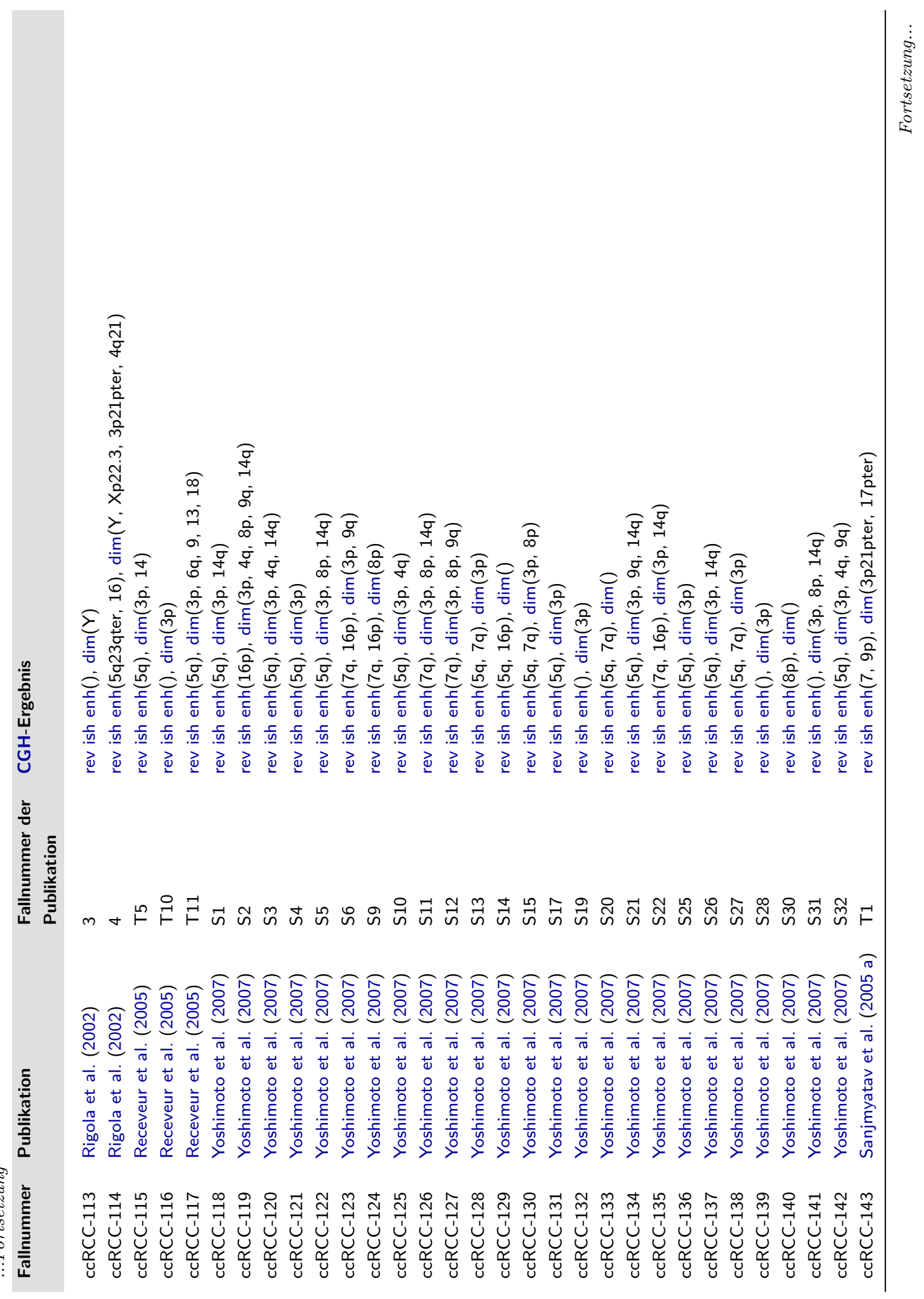




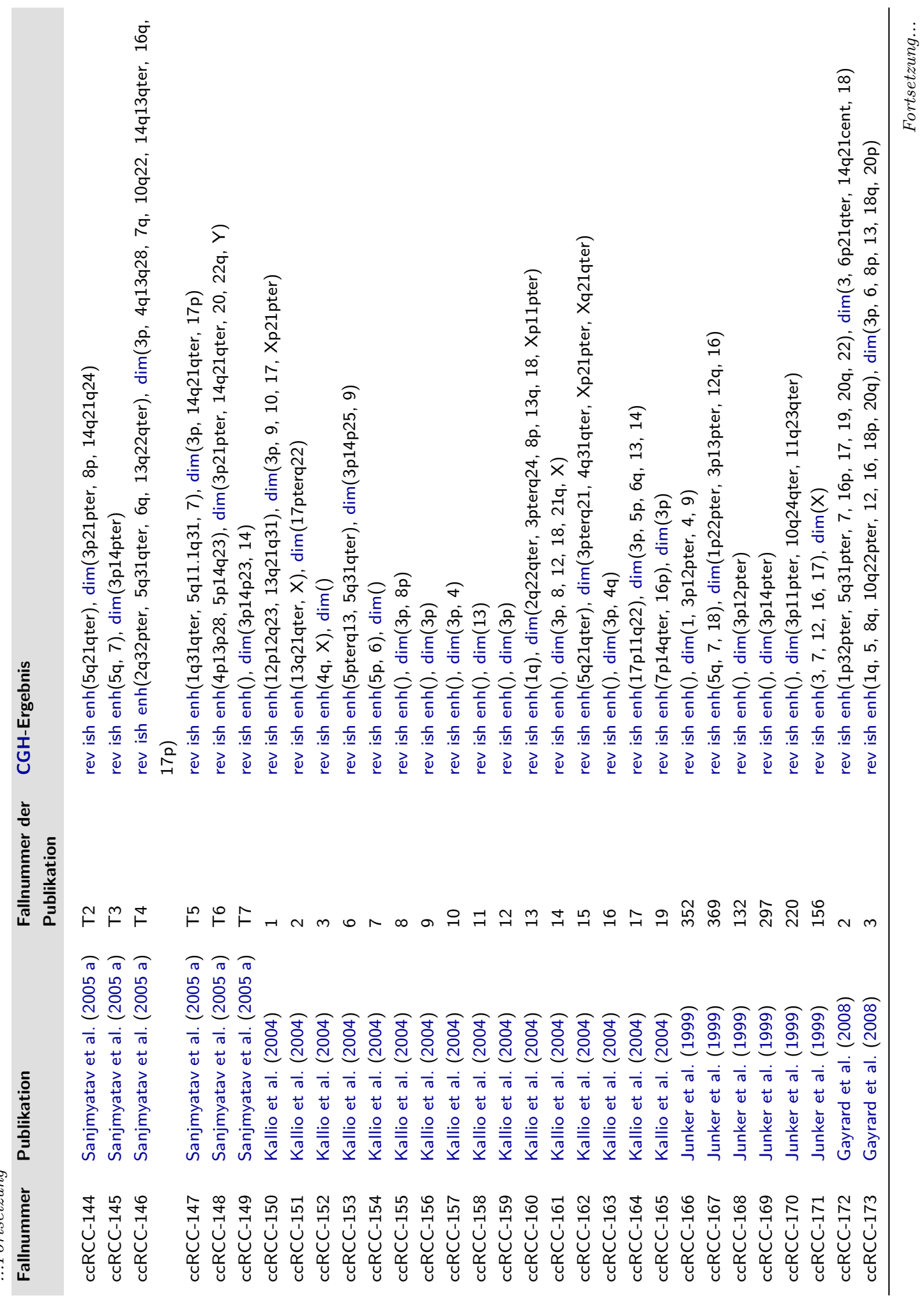




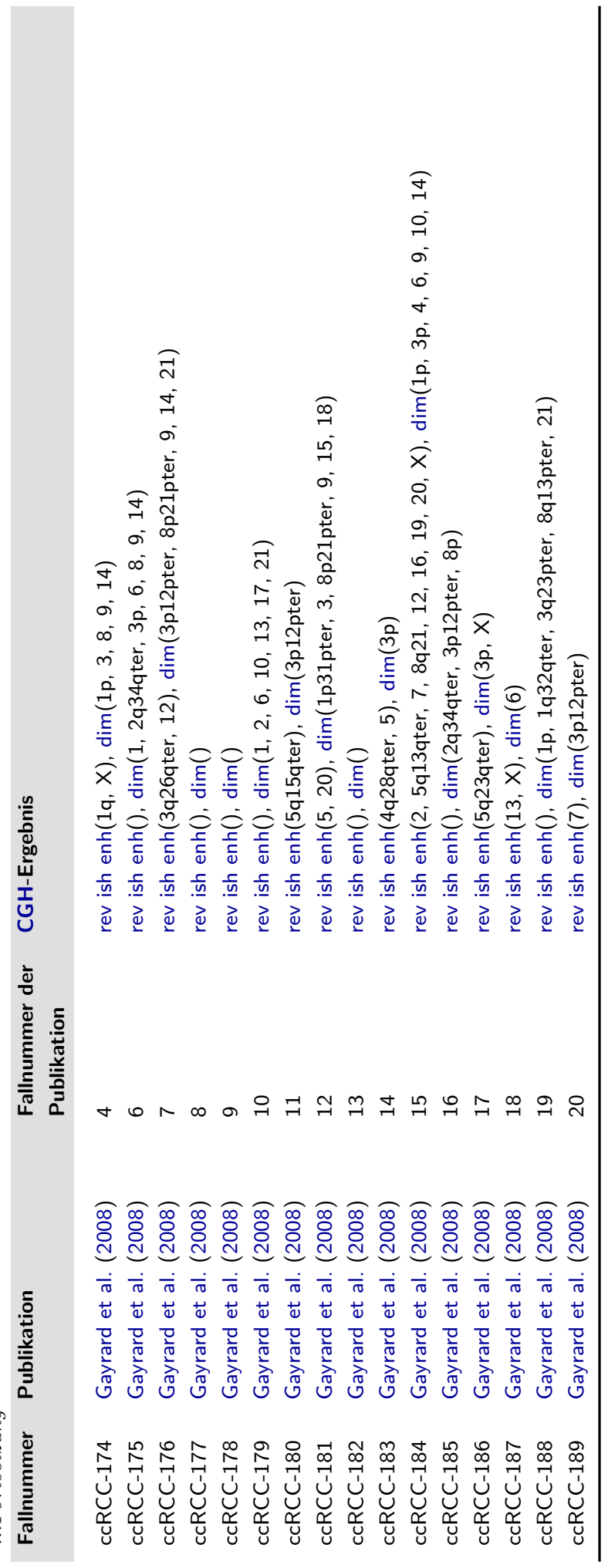




\section{Publikationen}

Aus den Ergebnissen dieser Dissertation sind folgende wissenschaftliche Publikationen hervorgegangen:

Vortrag

Im Rahmen der 60. Jahrestagung der Deutschen Gesellschaft für Neurochirurgie (DGNC); Münster, 24. - 27. Mai 2009:

Zytogenetische Vorhersage des Auftretens von Hirnmetastasen bei Nierenzellkarzinomen

Cytogenetic factors predicting the development of early brain metastases in renal cell carcinoma

Gutenberg A, Nischwitz MD, Enders C, Brück W, Füzesi L, Rohde V

Poster

Im Rahmen der 93. Jahrestagung der Deutschen Gesellschaft für Pathologie e.V. gemeinsam mit der 13. Dreiländertagung für Zytologie (DGZ, ÖGZ, SGZ); Freiburg, 4. 7. Juni 2009:

Prognostische Bedeutung von chromosomalen Veränderungen in Hirnmetastasen klarzelliger Nierenzellkarzinome

Nischwitz MD, Gutenberg A, Gerdes JS, Enders C, Rohde V, Brück W, Gunawan B, Füzesi L 


\section{Danksagung}

Ich danke Herrn Prof. Dr. L. Füzesi für die Vergabe dieses Themas, für seine ständige Diskussionsbereitschaft, die fachliche Betreuung sowie sein großes persönliches Engagement bei der Realisierung meiner Dissertation. Einen besseren Einstieg in die Welt der Forschung hätte ich nicht erhalten können.

Ich danke Herrn PD Dr. B. Gunawan und Herrn Dr. H. J. Schulten für ihre uneingeschränkte Unterstützung bei der Durchführung der Untersuchungen sowie der Gewinnung und Auswertung der Ergebnisse.

Besonderer Dank gilt Frau C. Enders, Frau J. Wolf-Salgo, Frau I. Dückmann und Frau N. Kunkel für ihre Unterstützung während der experimentellen Arbeit im Labor. Das Zustandekommen meiner Dissertation wäre ohne ihre fachliche Kompetenz und Unterstützung unmöglich gewesen.

Großer Dank gilt außerdem Frau K. Hannemann.

Ich danke Herrn Dr. K. Jung aus der Abteilung Medizinische Statistik der GeorgAugust-Universität Göttingen für die statistische Auswertung.

Ein großer Dank gilt Frau Dr. A. Gutenberg aus der Abteilung Neurochirurgie der Georg-August-Universität Göttingen, ohne deren Hilfe das untersuchte Kollektiv niemals diese Größe erreicht hätte.

Abschließend danke ich meinen Freunden und Mitdoktoranden J. S. Gerdes und G. C. Klipp für die inspirierenden und kritischen Diskussionen sowie die gegenseitige Unterstützung. 